Portland State University

PDXScholar

$4-15-2021$

\title{
Connecting Environment and Phenotype: Deciphering Mechanisms of Diapause Entry and Exit in the Annual Killifish Austrofundulus limnaeus
}

Erin Monica Davis

Portland State University

Follow this and additional works at: https://pdxscholar.library.pdx.edu/open_access_etds

Part of the Animal Sciences Commons, and the Biology Commons Let us know how access to this document benefits you.

Recommended Citation

Davis, Erin Monica, "Connecting Environment and Phenotype: Deciphering Mechanisms of Diapause Entry and Exit in the Annual Killifish Austrofundulus limnaeus" (2021). Dissertations and Theses. Paper 5680. https://doi.org/10.15760/etd.7552

This Thesis is brought to you for free and open access. It has been accepted for inclusion in Dissertations and Theses by an authorized administrator of PDXScholar. Please contact us if we can make this document more accessible: pdxscholar@pdx.edu. 
Connecting Environment and Phenotype:

Deciphering Mechanisms of Diapause Entry and Exit in the Annual Killifish Austrofundulus limnaeus

\author{
by \\ Erin Monica Davis
}

A thesis submitted in partial fulfillment of the requirements for the degree of

Master of Science

in

Biology

Thesis Committee:

Jason Podrabsky, Chair

Deborah Duffield

Annie Lindgren

Portland State University

2021 
(C)2021 Erin Monica Davis 


\begin{abstract}
Embryonic development is complex, dynamic, and dependent on environmental factors. Mechanisms of sensing and integrating environmental stimuli are diverse, and understanding these mechanisms in extant species can elucidate how complex phenotypes emerge from genomic information expressed in an environmental context. In Austrofundulus limnaeus, an annual killifish with alternative developmental trajectories, light and temperature are vital factors that determine if an embryo will enter a state of diapause. We hypothesize that embryos of $A$. limnaeus use the vitamin $\mathrm{D}_{3}$ signaling pathway as a vehicle to incorporate these ecological signals into their developmental programing. Here we provide evidence of this pathway's importance in regulating both entrance into and exit from diapause. We use a pharmacological approach to explore this pathway and closely related hormone receptors on the regulation of diapause. Exposure of $A$. limnaeus embryos to metabolites found in similar invertebrate signaling pathways, as well as parallel studies performed on Danio rerio zebrafish embryos support a role for vitamin $\mathrm{D}_{3}$ signaling in the control of developmental progression. Further, we highlight key potential targets for the vitamin $\mathrm{D}_{3}$ pathway that may elicit exit from diapause through regulation of DNA methylation.
\end{abstract}




\section{DEDICATION}

To my parents, Michael K and Monica A Davis.

Thank you for providing me every opportunity within your means and pushing me towards the ones that were seemingly out of grasp. 


\section{ACKNOWLEDGEMENTS}

I am indebted to many people that supported this work and time of my life. First, thank you to my advisor, Jason Podrabsky, for having supported and nurtured this project and my growth as a scientist, writer, and mentor. Your expertise was invaluable through this entire process for which I will always be grateful. Thank you to my committee, Deborah Duffield and Annie Lindgren, who helped foster these ideas through their own scientific knowledge and mentorship.

Thank you to Amie Romney for discovering the connection to vitamin $\mathrm{D}$ in her own dissertation work, allowing this project to exist. Much appreciation is extended towards Meranda Corona, who assisted in many of these experiments; this work would not have been possible without you. Your genuine spirit and love of science has always been and will continue to be an inspiration. Appreciation for my many fellow graduate students both in the Podrabsky lab and within the Biology Department at large: Amy Seufert, Lillian Raley, Brie Tripp, Andrew Clements, Scott Kiel, Daniel Zajic, and Andrew Ashford. Your friendships have made my time at Portland State memorable and life changing to say the least.

Lastly, thank you to my friends and family. To Ali, for encouraging me at my worst and celebrating me at my best. Thank you for always believing the good in me and helping me see it when I could not. I am eternally grateful to know you. To Katie, Tori and Kasannah, for supporting this process of growth and adaptation and always being willing to listen. To Adam, for teaching me how to look at life differently and being a source of clarity and laughter when I need it most. To Quinn, for being my best girl. To 
my parents and grandparents, for encouraging this and every endeavor. Your love has been such a source of comfort, and I miss you every day. 
TABLE OF CONTENTS

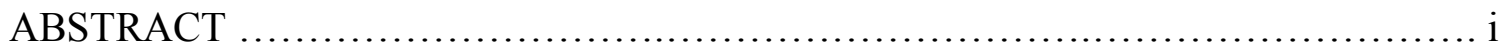

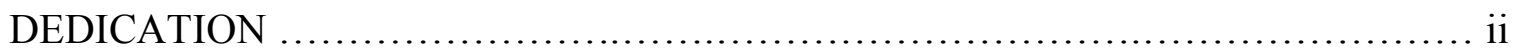

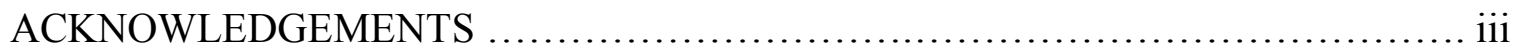

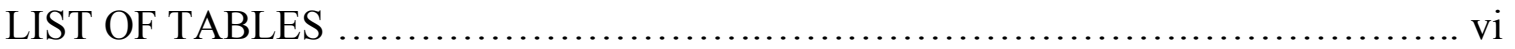

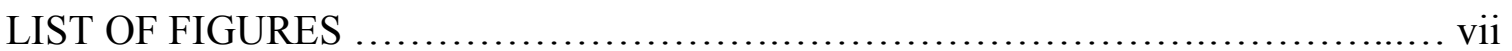

CHAPTER 1: Developmental environment impacts phenotype $\ldots \ldots \ldots \ldots \ldots \ldots \ldots \ldots \ldots 1$

CHAPTER 2: Vitamin $\mathrm{D}_{3}$ signaling regulates phenotypic trajectory in early

Austrofundulus limnaeus development........................... 17

CHAPTER 3: Reigniting the furnace: The role of vitamin $\mathrm{D}_{3}$ signaling, heat shock protein activity, and DNA methylation in the exit from diapause in an annual killifish .................................. 41

CHAPTER 4: Hormone cell signaling to regulate embryonic life history $\ldots \ldots \ldots \ldots \ldots . . . .76$

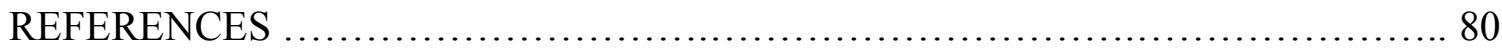




\section{LIST OF TABLES}

Table 2.1. Percent survival of Austrofundulus limnaeus embryos treated with

Dafadine A.................................................................... 28

Table 2.2. Comparison of developmental features between Austrofundulus

limnaeus embryos in diapause II and Danio rerio embryos treated with 5 - 35

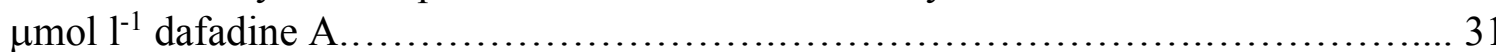

Table 2.3. Percent survival of Austrofundulus limnaeus embryos treated to $\Delta 4 \&$ $\Delta 7$-dafachronic acids at $25^{\circ} \mathrm{C}$

Table 2.4. Nuclear hormone receptor agonists and antagonists exposed to Austrofundulus limnaeus embryos had no effect on development observed.

Table 2.5. mTOR inhibitors exposed to Austrofundulus limnaeus embryos had no apparent effect on development. 


\section{LIST OF FIGURES}

Figure 1.1. Vitamin $D_{3}$ signaling pathway. ........................................ 4

Figure 1.2. Life cycle of Austrofundulus limnaeus. ................................. 7

Figure 1.3. Entrance into diapause II in embryos of Austrofundulus limnaeus is temperature dependent. ........................................................... 8

Figure 1.4. Temperature and light influence the developmental trajectory of Austrofundulus limnaeus embryos. ............................................... 9

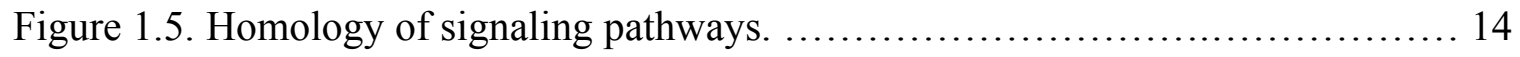

Figure 2.1. The effect of dafadine A on the developmental trajectory of

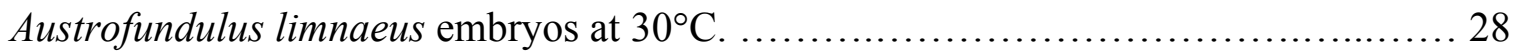

Figure 2.2. Effect of dafadine A on the development of Danio rerio embryos at $28.5^{\circ} \mathrm{C}$.

Figure 2.3. Effect of dafachronic acids on Austrofundulus limnaeus embryo development at $25^{\circ} \mathrm{C}$.

Figure 3.1. Effect of vitamin $\mathrm{D}_{3}$ metabolites on exit from diapause and active development in Austrofundulus limnaeus embryos at $25^{\circ} \mathrm{C}$. 53

Figure 3.2. The effect of increasing durations of exposure to $10 \mathrm{nmol} \mathrm{l}^{-1}$ and $100 \mathrm{nmol} \mathrm{l}^{-1} 1,25(\mathrm{OH})_{2} \mathrm{VitD}_{3}$ on exit from diapause II and subsequent embryonic development at $25^{\circ} \mathrm{C}$.

Figure 3.3. Effect of continuous incubation in 7-dehydrocholesterol and dafadine A on exit from diapause in Austrofundulus limnaeus embryos at $25^{\circ} \mathrm{C}$.

Figure 3.4. The effect of heat shock protein inhibition on exit from diapause II in embryos of Austrofundulus limnaeus.

Figure 3.5. Summary of differentially methylated regions (DMRs) in diapause II embryos treated with $10 \mathrm{nmol} \mathrm{l}^{-1} 1,25(\mathrm{OH})_{2} \mathrm{VitD}_{3}$.

Figure 3.6. The top 51 hypo- and hypermethylated DMRs.

61

Figure 3.7. Gene ontology analysis of differentially methylated regions in response to $1,25(\mathrm{OH})_{2} \mathrm{VitD}_{3}$ that were associated with any annotated genic elements in the genome of Austrofundulus limnaeus. 63 
Figure 3.8. Enriched Gene Ontology terms for DMRs that overlapped with annotated promoter regions in the Austrofundulus limnaeus genome. .................. 65 


\section{CHAPTER 1:}

\section{Developmental environment impacts phenotype}

Integration of environmental information into the developmental program

An organism's life history is profoundly affected by its developmental environment which can determine the outcome of embryogenesis and adult traits (Androwski et al., 2017; Badyaev, 2005; Cossins et al., 2006; Dufty et al., 2002; Furness et al., 2015a). During development, an organism establishes necessary mechanisms which buffer against stress and allow for adaptive responses - such as developmental trajectory determination, cellular and organismal stress responses, shifts in metabolism, and allocation of endogenous resources - in response to key environmental variables (Jonsson and Jonsson, 2019). It is essential that embryos utilize mechanisms to sense their environment early in development where these effects can be most impactful. The detection and integration of these signals can lead to transcription of target genes promoting survival under the present or future conditions. For example, in vertebrates, environmental temperature can differentially impact muscle fiber density in developing embryos of the Atlantic cod Gadus morhua, the Senegal sole Solea senegalensis and the zebrafish Danio rerio (Bizuayehu et al., 2015; Campos et al., 2013; Johnston et al., 2009).

Deciphering how epigenetic mechanisms can alter developmental outcomes is an essential part of understanding embryonic development in context of a dynamic environment where stress can have both detrimental and positive effects on individual organisms, populations, and perhaps entire species. Diapause in annual killifishes is not 
an obligatory phase of development, but can be induced by environmental conditions experienced during early development (Furness et al., 2015b; Podrabsky et al., 2010; Romney et al., 2018). Studying environmentally provoked phenotypic plasticity in an organism that naturally experiences environmental extremes during development offers a unique situation to explore these important epigenetic facets of embryology. This thesis focuses on the embryos of the annual killifish, Austrofundulus limnaeus, and their means of sensing and reacting to environmental cues through the synthesis and action of vitamin $\mathrm{D}_{3}$ which regulates their plastic ability to enter a state of diapause to endure in a variable and often extreme environment (Podrabsky et al., 2017; Podrabsky et al., 2016a; Wourms, 1972c).

\section{Biochemistry and action of vitamin $D_{3}$ signaling}

Vitamin $\mathrm{D}_{3}$ was discovered in the 1920 s as a means of treating children with rickets, a disease causing severe bone malformations (Bikle, 2011). As a result of these studies, research expanded and found that vitamin $\mathrm{D}_{3}$ is necessary for numerous biological functions such as calcium homeostasis and metabolism (Bikle, 2014). Subsequently, it has been shown that vitamin $\mathrm{D}_{3}$ is involved in supporting the immune response, growth of various cancers, and development of type 1 diabetes mellitus, among others (Bikle, 2014). Thus far, research on vitamin $\mathrm{D}_{3}$ signaling has been largely humancentric, with a slow growing body of knowledge on the effects in other non-mammalian vertebrates including the endocrine, paracrine, and molecular functions in fish, amphibians and chicks (Craig et al., 2008; Holick, 2003; Li et al., 1997; Lock et al., 2010; Sunde et al., 1978). In addition, comparatively little work has explored the role of 
vitamin $\mathrm{D}_{3}$ signaling during embryonic development (Craig et al., 2008; Han et al., 2019; Sunde et al., 1978). The pathway's identification across a diversity of phyla has led to studies using a variety of model and non-model species, including various plant species, nematodes, crustaceans, mice, Xenopus laevis, teleost fishes, and birds (chickens) to further understand impacts of vitamin $\mathrm{D}_{3}$ on biological function (Boland et al., 2003; Connelly et al., 2015; Goltzman et al., 2018; Li et al., 1997; Lock et al., 2007; Mark et al., 2016; Messing et al., 2013; Sunde et al., 1978).

Vitamin D refers to a group of secosteroid molecules found across eukaryotes. There are two separate molecules, $\mathrm{D}_{2}$ and $\mathrm{D}_{3}$ that are commonly referred to as vitamin $\mathrm{D}$. Vitamin $\mathrm{D}_{2}$ (ergocalciferol) is made by fungi and yeast while $\mathrm{D}_{3}$ is produced in animals and plants (Bikle, 2014). Both molecules form through exposure of lipid membranes to UVB light. In humans and other vertebrate organisms, research shows that vitamin $\mathrm{D}_{2}$, which must be obtained through dietary intake, is not as effective as vitamin $\mathrm{D}_{3}$ at increasing the active form of vitamin $\mathrm{D}_{3}$ in the blood stream (Bikle, 2014). Therefore, the effects of vitamin $\mathrm{D}_{3}$ are of higher relevance to vertebrate physiology, especially under conditions where dietary intake is not possible, such as during embryonic development.

Vitamin $\mathrm{D}_{3}$ synthesis requires multiple steps. First, the cholesterol ring structure of 7-dehydrocholesterol (7-DHC, provitamin $\mathrm{D}_{3}$ ) is broken and pre-vitamin $\mathrm{D}_{3}$ forms. In humans, this step is thought to be primarily induced by exposure to UV light in the skin. If temperatures are also elevated, this compound isomerizes into vitamin $\mathrm{D}_{3}$ (cholecalciferol). Vitamin $\mathrm{D}_{3}$ is then acted upon by two different $\mathrm{P} 450$ hydroxylase enzymes that convert it into the most potent form of vitamin $D_{3}, 1 \alpha, 25$ dihydroxyvitamin $\mathrm{D}_{3}\left(1,25(\mathrm{OH})_{2} \mathrm{Vit}_{3}\right.$, calcitriol) which can then bind to the vitamin $\mathrm{D}$ receptor (VDR), a 
nuclear hormone receptor (NR) and transcription factor that can directly alter patterns of gene expression and thus elicit changes in biological function (Fig. 1.1).

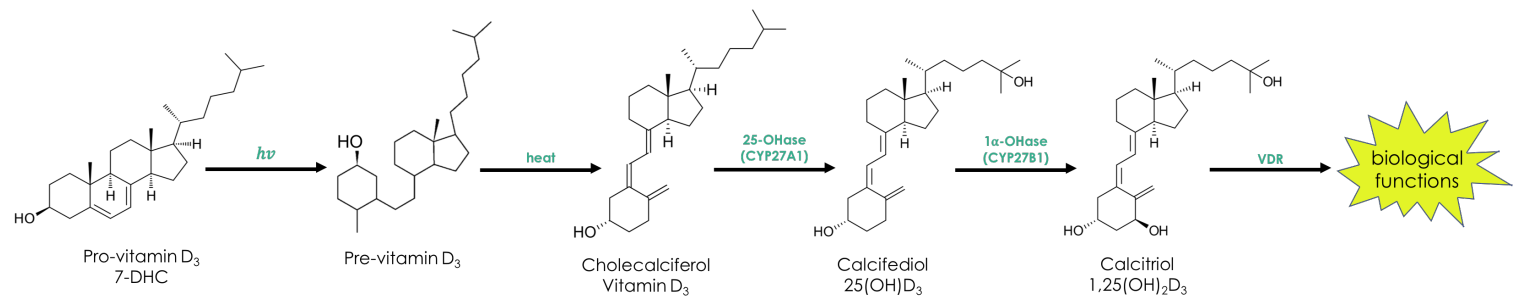

Figure 1.1. Vitamin $\mathbf{D}_{3}$ signaling pathway. 7-dehydrocholesterol (7-DHC) is converted through light (hv) and heat reactions to vitamin $\mathrm{D}_{3}$. A series of enzymatic hydroxylation steps then transform the molecular into calcitriol that binds to the vitamin $\mathrm{D}$ receptor (VDR), a nuclear hormone receptor and transcription factor that elicits biological function.

Entrance into diapause in A. limnaeus embryos is controlled in part through epigenetic and environmental mechanisms such as maternal provisioning during oogenesis as well as the incubation temperature experienced by the developing embryo (Podrabsky et al., 2010; Romney and Podrabsky, 2017). While specific mechanisms that regulate maternal influences on development are not yet known in this system, incubation temperature has been shown to induce direct development through activation of vitamin $\mathrm{D}_{3}$ synthesis and signaling (Romney et al., 2018). The ability to alter developmental trajectory by manipulating incubation temperature provides a powerful model for studying integration of environmental signals into vertebrate development.

Austrofundulus limnaeus as an experimental model

Annual killifishes inhabit temporary pools in regions with pronounced dry and rainy seasons (Furness et al., 2015b). Survival through periods when the ponds are dry is due entirely to drought-tolerant embryos encased in the soil. There are three specific 
developmental checkpoints at which diapause can occur in A. limnaeus. Diapause I is associated with early development before an embryonic axis forms (Wourms, 1972b). Diapause II occurs midway through development after somitogenesis but before organogenesis. This period of arrest exhibits the highest tolerance to environmental stress, especially against dehydration, and thus is thought to be of utmost importance to surviving the dry season (Podrabsky et al., 2016a; Podrabsky et al., 2007; Wourms, 1972c). Diapause III occurs in the pre-hatching stage embryo and is described as a final checkpoint late in development to ensure hatching coincides with conditions consistent with larval survival (Wourms, 1972a). A single individual can enter at all three points of arrest, a subset, or none depending on a combination of environmental conditions and maternal influence (Furness, 2015; Furness et al., 2015a; Furness et al., 2015b).

Developmental timing of these annual killifish embryos thus depends on which trajectory they follow (diapause vs escape) in addition to which subset of checkpoints the individual embryo experiences. It is important to note that the divergence in trajectories occurs after diapause I and before diapause II during the critical window (Fig. 1.3); therefore, an escape trajectory embryo may experience diapause I or III and still be considered an escape trajectory embryo. This partially explains the variation in developmental timing for embryos and highlights the importance as to why developmental stages defined by presence or absence of specific morphological features is a more accurate way to describe developmental time rather than simply stating dpf.

Due to the intense and variable environmental conditions experienced by annual killifishes (Cyprinidontiformes, Aplocheiloidei), these species have evolved a complex life history that includes arrest of embryonic development in diapause on several 
presumably independent occasions (Furness, 2015; Furness et al., 2015a). Austrofundulus limnaeus, a laboratory model for annual killifishes, inhabits ephemeral ponds of the Maracaibo Basin in Venezuela (Podrabsky et al., 1998). The adult fish persist and reproduce during the wet, rainy season; however, once the dry season begins, the ponds dry up and only the embryos deposited in the sediment remain to perpetuate the population (Fig. 1.2). The continuation of this species therefore relies on the embryos' ability to enter a state of suspended development termed diapause (Podrabsky et al., 2016b; Podrabsky et al., 2010). Through entrance into diapause, embryos can survive for extended periods of time encased in the surrounding substrate without oxygen, water, or nutrition except what was prepackaged by the mother during oogenesis (Podrabsky et al., 2010). While the dry season is anticipated each year, the highly variable and unpredictable nature of their habitat has likely led to the ability to produce alternative developmental trajectories in this species which may maximize the probability of at least some fraction of the embryos surviving under a wide variety of conditions, including long or prevailing rainy conditions (i.e. diapause vs escape trajectories; Fig. 1.2). 


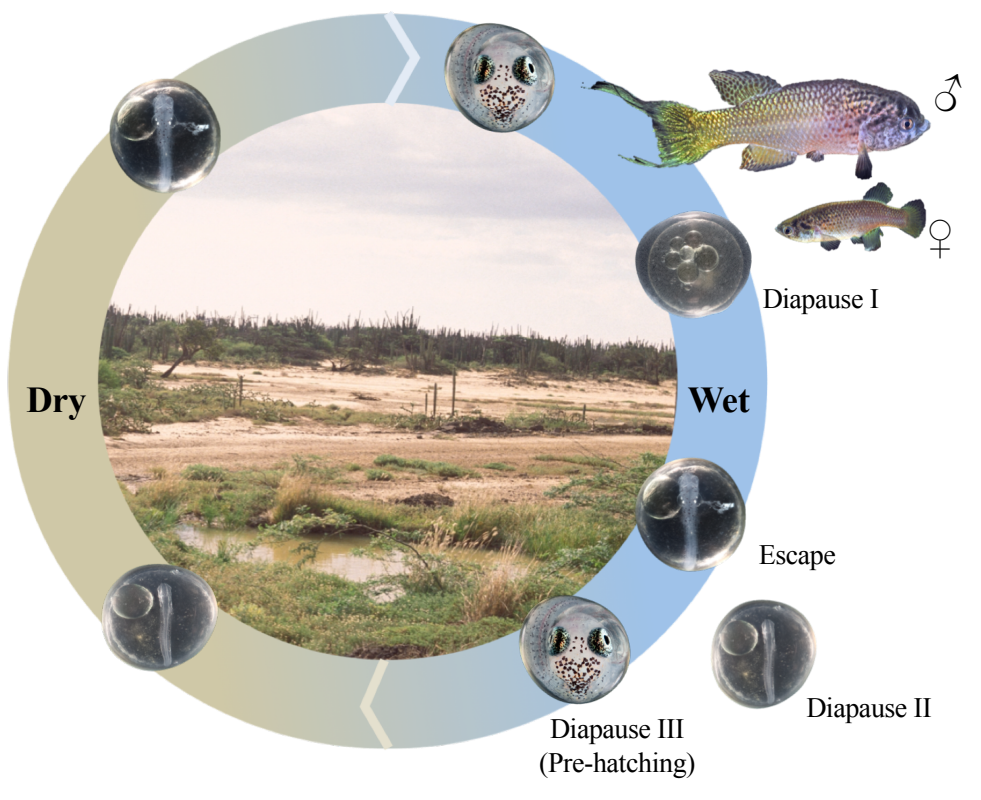

Figure 1.2. Life cycle of Austrofundulus limnaeus. Image of the Maracaibo basin in Venezuela, the native habitat of $A$. limnaeus. Arrows surrounding the image indicate the changing environment experienced by embryos from the wet to dry season. Embryos are deposited into sediment where they will either follow the escape or diapause trajectories. Escape embryos forego diapause and continue developing to the pre-hatching stage, hatch, and survive as long as the environment is favorable. Otherwise, embryos enter diapause and wait out the dry season until environmental signals indicate the wet season is approaching and the embryo can then break diapause to continue developing.

Importantly, incubation conditions experienced by the embryo impact developmental trajectory, with even short exposures to high temperatures $\left(30-33^{\circ} \mathrm{C}\right)$ and full spectrum light causing embryos to develop directly, while incubation at lower temperatures $\left(20-25^{\circ} \mathrm{C}\right)$ in the dark leads to entrance into diapause (Fig. 1.3 \& 1.4; Podrabsky et al., 2016b). Metabolic and developmental dormancy has been studied in depth using invertebrate models such as C. elegans, various insects, and crustaceans (Bradford and Roff, 1993; Hand et al., 2016; Podrabsky and Hand, 2015; Qiu et al., 2007). While these organisms provide valuable insight into diapause as a mechanism of surviving environmental stressors, $A$. limnaeus offers a rare opportunity to study diapause 
in a free-living vertebrate system. The exploration of the molecular mechanisms that regulate diapause in A. limnaeus increases the potential to identify highly conserved pathways of metabolic dormancy across animals and theoretically all forms of eukaryotic life.

To date no studies have examined the mechanisms that regulate entrance into and exit from diapause in wild annual killifishes. Elevated temperatures that are within normal field conditions are sufficient to promote an accelerated exit from diapause, and thus temperature is likely relevant in nature (Podrabsky et al., 1998). It is uncertain how pertinent UV light exposure is in promoting active development - through activating the vitamin $\mathrm{D}_{3}$ pathway or some other mechanism - since the embryos are encased in the dense sediment (Podrabsky et al., 1998). However, Furness et al. hypothesize that light and heat likely signify pond drying and thus are relevant cues for annual killifish embryos to infer changing environmental conditions (Furness et al., 2015a). Further information on the ecology typical in A. limnaeus' environment is necessary to note whether light is able to penetrate the soil to reach the embryos resulting in an initiation of the vitamin $\mathrm{D}_{3}$ pathway.

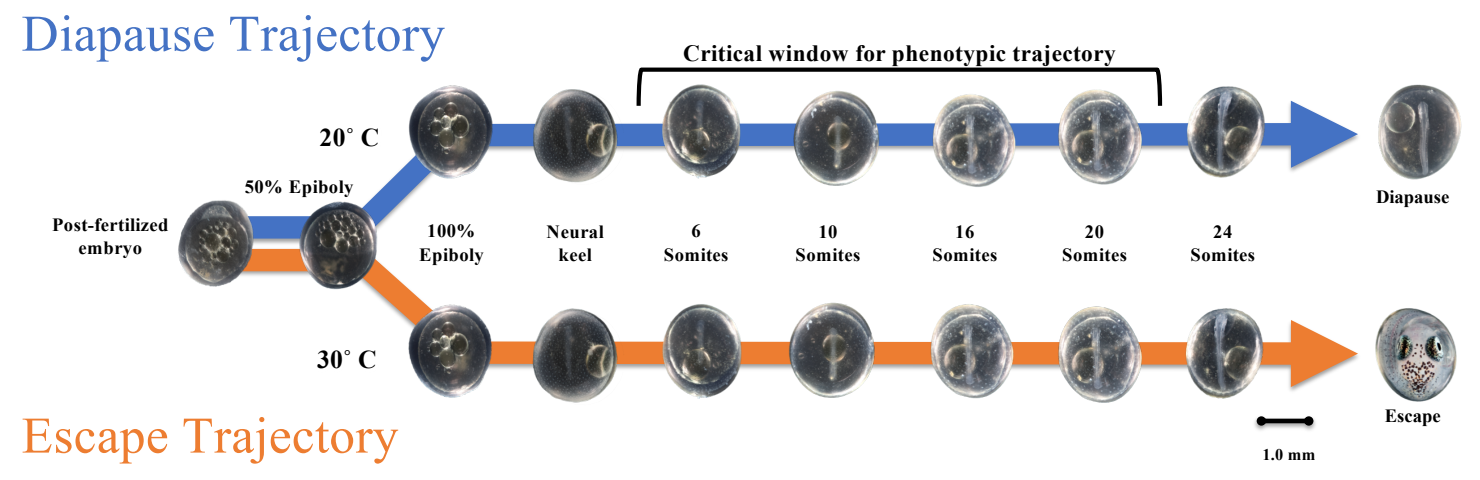


Figure 1.3. Entrance into diapause II in embryos of Austrofundulus limnaeus is temperature dependent. Embryos enter diapause II when exposed to $20-25^{\circ} \mathrm{C}$ whereas $30^{\circ} \mathrm{C}$ incubation produces continually developing embryos that "escape" diapause. The period of time when temperature has irreversible effects on developmental trajectory, or the "critical window," is when embryos possess $6-20$ pairs of somites (Podrabsky et al., 2010).

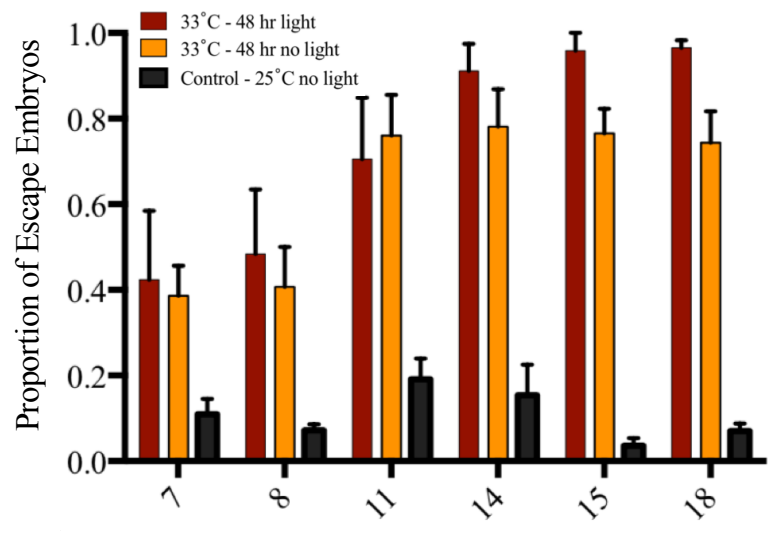

Days post-fertilization (DPF)

Figure 1.4. Temperature and light influence the developmental trajectory of Austrofundulus limnaeus embryos. Control embryos that were incubated at $25^{\circ} \mathrm{C}$ with no light show a low baseline proportion of escape trajectory embryos. Meanwhile, $33^{\circ} \mathrm{C}$ incubation in darkness or with full-spectrum light for only $48 \mathrm{~h}$, drastically increased this proportion of escape trajectory embryos during the temperature-sensitive window of development (Romney et al., 2018).

Recently, vitamin $\mathrm{D}_{3}$ signaling has been found to regulate entrance into diapause under laboratory conditions in embryos of A. limnaeus (Romney et al., 2018). This study showed that exposure to picomolar levels of $1,25(\mathrm{OH})_{2} \mathrm{VitD}_{3}$ could drive embryos to develop along the escape trajectory even under conditions $\left(20-25^{\circ} \mathrm{C}\right.$ in the dark) that should support embryos entering diapause (Fig. 1.3). Thus, based on the similarity of phenotypes between escape trajectory embryos and those developing in the presence of $1,25(\mathrm{OH})_{2} \mathrm{VitD}_{3}$, what is known about the effects of light and elevated temperatures on developmental trajectory, and the canonical pathway for synthesis of vitamin $\mathrm{D}_{3}$, I 
hypothesize that vitamin $\mathrm{D}_{3}$ synthesis can act to integrate environmental cues into the developmental program of embryos and regulate developmental progression in annual killifishes.

\section{Evolution of diapause}

Embryonic diapause is a strategy used to survive variable environments by putting development on hold at specific checkpoints while maintaining low levels of metabolic activity (Chennault and Podrabsky, 2010; Hand and Podrabsky, 2000; Podrabsky et al., 2016a; Podrabsky and Hand, 1999). However, many killifish species, specifically nonannual species, do not experience diapause since their environment does not necessitate such an alternative life history. This suggests that the direct development seen in these nonannual killifish and the escape trajectory embryos of annual killifish may be ancestral and that the evolution of diapause is potentially a derived trait (Furness, 2015). Many species of annual killifishes, such as A. limnaeus, produce embryos that can experience diapause for varying lengths of time based on conditions of their current developmental environment. This natural divergence between annual and nonannual killifish creates a unique opportunity to explore evolution of phenotypic plasticity in closely related species (Furness, 2015; Furness et al., 2015a; Furness et al., 2015b).

Phenotypic plasticity is a common theme in developmental biology that can take different forms. Some species experience immediate adjustments in which an adaptive response occurs early in development that is vital in the moment but may result in less advantageous traits later on in life. Certain species of amphibians can sense a predator and forcibly hatch early to escape being eaten. While surviving the predator was vital in 
that moment, a tradeoff results in being less developed and potentially less prepared for life in the pond (Kaplan, 1987; Warkentin, 1995). Alternatively, other species are able to forecast future environmental change through maternal influence, environmental cues, or likely a combination of both (Burgess and Marshall, 2011; Donaldson-Matasci et al., 2013; Feil and Fraga, 2012; Furness et al., 2015b; Zhou et al., 2017). Entrance into diapause for A. limnaeus is a prime example of this type of plasticity (Podrabsky et al., 2010; Romney and Podrabsky, 2017). Therefore, understanding the molecular mechanisms of how environmental signals are interpreted and then integrated into the developmental program may provide insights into how vertebrate embryos sense and respond to their environment.

\section{Ecology and examples of exiting diapause}

Developmental delays are a common strategy of various plants, insects, crustaceans, and vertebrates to wait out adverse environmental conditions (Denlinger, 2013). In most species, specific environmental cues are required to "break" diapause and support the continuation of active development. For example, abiotic factors are able to induce exit from dormancy associated with diapause in Artemia such as an increase in photoperiod, temperature or oxygen (Martinez-Lamparero et al., 1996; Robbins et al., 2010). There is also evidence of lengthening photoperiods and increased temperatures ending diapause in the moth Sesamia nonagrioides (Fantinou et al., 1998). Plant species likely also respond to abiotic factors to exit dormancy after a winter period or drought (Browse and Xin, 2001; Fujikawa et al., 1997). Interestingly, a 2010 study looking at RNA expression during growth cycles of Populus trees suggested that the exit of seasonal 
dormancy may be connected to the circadian clock system (Ibáñez et al., 2010). Experiments on various insects, Riptortus pedestris (bean beetle) and Culex pipiens (mosquito), also suggest regulation of circadian rhythms as an important aspect of entrance into diapause and perhaps exit from diapause as well (Hand et al., 2016).

Adequate nutrition is the most well-known environmental stimulus utilized by Caenorhabditis elegans (nematode) to exit from dauer dormancy (a diapause-like state). This recognition of ample resources can occur through either an increase in food source or a decreasing population density (Macrae, 2005). The mechanisms involved in sensing and responding to these environmental cues are not fully understood, but researchers suggest $\mathrm{NAD}^{+}$as a nutrition constituent may promote the exit of dauer (Mylenko et al., 2016). This study further postulates that an increase in redox cofactors and serotonin play an important role in reactivation of development. While commonality is shared amongst the environmental stimuli used by these different species to kickstart development again, the mechanisms by which they integrate these signals are not well described and are actively being explored.

The cues that regulate entrance into and exit from dormancy are often distinct and it is not clear if similar molecular mechanisms are involved (Hand et al., 2016; Renfree and Fenelon, 2017). Exit from diapause II in A. limnaeus appears to be regulated by similar environmental variables that regulate the decision to enter diapause II or develop directly. In both cases, exposure to light and increased temperatures have been shown to promote active development (Meller et al., 2012; Romney et al., 2018). This major life history shift is likely to rely on integration of environmental changes typical during the transition from dry to wet seasons in which active development is supported. I 
hypothesize that exit from diapause II can be promoted through synthesis of vitamin $\mathrm{D}_{3}$ and activation of the vitamin D receptor (VDR) in a manner similar to that observed in early embryos that do not enter diapause II in response to increased temperatures (Ch. 3).

\section{Endocrine signaling and regulation of developmental dormancy}

Exploring the action of life history-specific metabolites will allow for a better understanding of life history evolution, and the mechanisms that integrate environmental information into developmental programs (Kollitz et al., 2014). Vitamin $\mathrm{D}_{3}$ signaling is highly conserved across all eukaryotes (Bikle, 2011) and is potentially an important unexplored mechanism for integration of environmental information into developmental programs across a diversity of species. The role of vitamin $\mathrm{D}_{3}$ signaling is hypothesized in this thesis to be a mechanism that regulates developmental progression and integrates environmental cues into major life history decisions. Congruently, sequence similarity and ligand cross-activation suggest that the VDR signaling in A. limnaeus may be developmentally homologous to DAF-12 signaling in C. elegans and ecdysone signaling in Drosophila, both of which regulate metabolic dormancy (Fig 1.5; Antebi et al., 2000; Monteiro et al., 2015; Romney et al., 2018).

As mentioned previously, 7-DHC is a precursor molecule for vitamin $\mathrm{D}_{3}$ and is involved in the cholesterol biosynthetic pathway (Bikle, 2017; Jackson et al., 1997). Interestingly, 7-DHC is the precursor molecule for the synthesis of dafachronic acids and ecdysone compounds (Antebi et al., 2000; Jackson et al., 1997; Monteiro et al., 2015). These pathways are also integral in regulating development and reproduction in addition to impacting dormancy (Kumar et al., 2002; Mahanti et al., 2014; Monteiro et al., 2015; 
Motola et al., 2006). It is therefore a reasonable hypothesis that vitamin $\mathrm{D}_{3}$ signaling may share these functional roles in A. limnaeus embryo development.

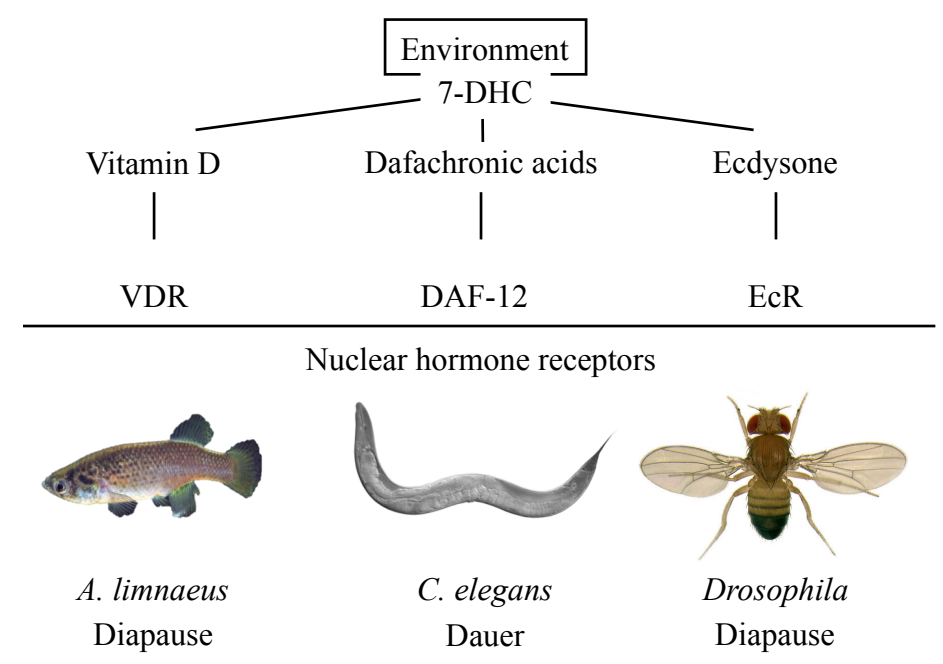

Figure 1.5. Homology of signaling pathways. In a variety of organisms, 7dehydrocholesterol (7-DHC) is the precursor for downstream metabolites that bind to specific nuclear hormone receptors. Entrance into and exit from metabolic dormancy via these unique signaling pathways is known in three evolutionarily distinct lineages across a wide range of animal life.

As stated previously, exposure to picomolar concentrations of vitamin $\mathrm{D}_{3}$ metabolites impacts developmental trajectory for A. limnaeus embryos (Romney et al., 2018). This signaling pathway utilizes the vitamin D receptor (VDR), a nuclear hormone receptor (NR) which regulates gene expression by acting as a transcription factor. Not only does the hormonally active form of vitamin $\mathrm{D}_{3}, 1,25(\mathrm{OH})_{2} \mathrm{VitD}_{3}$, bind to the ligand binding domain of VDR, there is evidence that VDR has affinity for other ligands (Kollitz et al., 2014; Norman, 2006). Alternative mechanisms of pathway initiation have been hypothesized including VDR's affinity for a variety of ligands in addition to $1,25(\mathrm{OH})_{2} \mathrm{VitD}_{3}$, which could allow for cross-talk or transactivation of VDR by other molecular pathways due to similarity in structure, chemical affinity, or biological 
function (Bikle, 2011; Kollitz et al., 2016; Krasowski et al., 2011a; Reschly et al., 2007; Romney and Podrabsky, 2017; Schuster, 2011; Slominski et al., 2017).

The VDR is part of NR subfamily 1 and is thought to be closely related to other NRs such as the pregnane $\mathrm{X}$ receptor (PXR), liver $\mathrm{X}$ receptor (LXR), and the farnesoid $\mathrm{X}$ receptor (FXR; Thomson et al., 2009). These receptors overlap in processes like cholesterol homeostasis as well as metabolism and are thought to share ligands for pathway activation and subsequent transcriptional regulation (Krasowski et al., 2011b). The alternative methods of vitamin $\mathrm{D}_{3}$ pathway activation, in addition to closely related hormone receptors' ability to impact trajectory determination must be explored to conclude if the vitamin $\mathrm{D}_{3}$ signaling pathway is unique in promoting the phenotypic plasticity associated with diapause in A. limnaeus. I hypothesize that the vitamin $\mathrm{D}_{3}$ signaling pathway and closely related NRs share in the ability to elicit the adaptive response seen in A. limnaeus (Ch. 2).

\section{Thesis framework}

The naturally occurring alternative phenotypes of A. limnaeus offer a unique opportunity to explore how phenotypic plasticity is induced from the developmental environment. I used incubation temperature to control developmental phenotype and perturbed the expected outcome with various pharmacological agents. This was done early in embryo development to determine which molecular pathways were relevant for regulating entrance into diapause. Additional experiments were conducted to explore what pathways may play a role in causing an embryo to break diapause. Further, modern 
epigenetic tools were employed to gain insight as to what other genes may be relevant in the breakage of diapause in this species.

This thesis is broken into two data chapters, focusing on entrance and exit from diapause II as described above. In Chapter 2, early stage embryos were exposed to various agonists and antagonists of the vitamin $\mathrm{D}_{3}$ pathway and other closely related pathways to explore molecular control for the entrance into diapause. Similar tests were performed on Danio rerio zebrafish embryos to explore if the results found with $A$. limnaeus embryos extend to a teleost that does not naturally experience diapause. In Chapter 3, A. limnaeus embryos in diapause were exposed to a different suite of agonists and antagonists to test what conditions may promote the exit of an embryo from diapause. Additionally, reduced representation bisulfite sequencing was utilized to identify differentially methylated regions of the genome in response to exit from diapause induced by treatment with $1,25(\mathrm{OH})_{2} \mathrm{VitD}_{3}$. These datasets identify a series of genes that may have a critical role in the breaking of diapause in A. limnaeus which will require future attention. Chapter 4 explores the context of epigenetic control on phenotype and attempts to connect what was learned in this thesis to the broader literature on regulation of developmental dormancy. Together, this thesis expands knowledge of the molecular mechanisms that regulate diapause in an annual killifish and suggests a mechanism for the integration of environmental information into the developmental programs of teleost fish embryos. 


\title{
CHAPTER 2:
}

\section{Vitamin $D_{3}$ signaling regulates developmental progression in annual and non-}

\section{annual fishes}

Some data in this chapter has been previously published:

Amie L. T. Romney, Erin M Davis, Meranda M Corona, Josiah T Wagner, and Jason E Podrabsky (2018). Temperature-dependent vitamin D signaling regulates developmental trajectory associated with diapause in an annual killifish. PNAS, 115 (50), 6. https://doi.org/10.1073/pnas.1804590115

\begin{abstract}
Nuclear hormone receptors (NRs) are highly conserved across animal species and are known to be powerful regulators of gene expression. The vitamin D receptor (VDR) is a NR best known for regulating blood calcium homeostasis in humans. In the annual killifish Austrofundulus limnaeus, the vitamin $\mathrm{D}_{3}$ signaling pathway has recently been shown to impact developmental phenotype early in development by promoting alternative developmental trajectories. Through pharmacological exposures, we additionally show a key role of vitamin $\mathrm{D}_{3}$ signaling in promoting developmental arrest in embryos of the zebrafish Danio rerio; a species that normally does not enter developmental dormancy. Here, we confirm that blocking synthesis of vitamin $\mathrm{D}_{3}$ results in a strikingly similar state of developmental arrest in both of these distantly related species. Further, when embryos of $A$. limnaeus are exposed to dafachronic acids they develop continuously despite being incubated in conditions that should induce diapause. Dafachronic acids are signaling molecules that target NRs used by $C$. elegans to promote active development and prevent
\end{abstract}


developmental arrest in the dauer larval stage. Together, these data suggest a similarity of signaling mechanisms that control developmental arrest in animals. 


\section{Introduction}

Nuclear hormone receptors (NR) are ligand-activated transcription factors that have the ability to regulate a large variety of genes and thus are often involved in determining complex cellular and organismal phenotypes. These proteins contain a ligand-binding-domain (LBD) which binds to hormones or other small molecules and a DNA-binding-domain (DBD) which binds to certain genomic sequences allowing for targeting of specific suites of genes (Aranda and Pascual, 2001). NRs and their function are strongly conserved across animals as has been shown through structural and genomic investigations (Escriva et al., 2004). Interestingly, the ligands for these receptors vary greatly in structure and include various hydrophobic molecules such as steroid hormones, fatty acids, retinoic acids, and thyroid hormones amongst others (Escriva et al., 2004). In this Chapter, the role of the vitamin D receptor (VDR) in the regulation of vertebrate development and metabolic dormancy is explored.

The VDR belongs to a large subfamily of NRs (subfamily 1) that includes among others the liver $\mathrm{x}$ receptor (LXR), farnesoid $\mathrm{x}$ receptors (FXR), DAF-12, and the ecdysone receptor (EcR; (Thomson et al., 2009). While all of these receptors are involved in vastly different signaling pathways, their ligands are all cholesterol derivatives $1,25(\mathrm{OH})_{2} \mathrm{VitD}_{3}(\mathrm{VDR})$, oxysterols (LXR), bile acids (FXR), dafachronic acids (DAF12) and ecdysone (EcR; Thomson et al., 2009). These pathways have all shown connection to metabolism, development, and reproduction suggesting a functional convergence of cholesterol derivative ligands (Antebi, 2015).

Interestingly, VDR, DAF-12, and EcR all have ligands that, more specifically, are produced from 7-dehydrocholesterol (7-DHC) and are associated with regulation of 
developmental arrest (Antebi et al., 2000; Arbeitman and Hogness, 2000; Romney et al., 2018). In A. limnaeus, 7-DHC is converted to $1,25(\mathrm{OH})_{2} \mathrm{VitD}_{3}$ which binds to the VDR to promote active development and prevent entrance into diapause (Romney et al., 2018). In Drosophila, 7-DHC is converted into ecdysone which binds to the EcR and prevents entry into pupal diapause (Milner et al., 1986; Rinehart et al., 2001). Similarly, $C$. elegans converts 7-DHC into dafachronic acids which target DAF-12 amongst other proteins (Motola et al., 2006). DAF-12 is well known to regulate dauer dormancy, a diapause-like state (Antebi et al., 2000).

Vitamin $\mathrm{D}_{3}$ signaling is conserved in vertebrates and plays many key roles in regulating gene expression across all life stages (Lock et al., 2010; Pludowski et al., 2013; Pols et al., 1990; Yoshizawa et al., 1997). In A. limnaeus embryos, this pathway determines the developmental trajectory of embryos, a process that creates two distinct developmental phenotypes. In the presence of exogenous vitamin $\mathrm{D}_{3}$ metabolites at temperatures that should promote diapause $\left(20-25^{\circ} \mathrm{C}\right)$, embryos bypass this metabolic dormancy and instead develop continuously (Romney et al., 2018). Absence of hydroxylated forms of vitamin $\mathrm{D}_{3}$ leads to entrance into diapause at these temperatures. It is critical to note that embryos on these two trajectories differ morphologically, physiologically, and biochemically (Fig 1.3; Chennault and Podrabsky, 2010; Duerr and Podrabsky, 2010; Podrabsky et al., 2010). Entrance into diapause is not simply an arrest of development wherein the embryo pauses for a time and then continues developing as an escape trajectory embryo. Rather, a diapausing embryo follows a different developmental trajectory identifiable using the facets listed above that have been previously published. Together these data illustrate a key role for vitamin $\mathrm{D}_{3}$ signaling in 
normal development of annual killifishes, and suggest that the key to vertebrate embryonic dormancy lies in control of vitamin $\mathrm{D}_{3}$ signaling during early development.

The use of a closely related family of NRs and ligands derived from 7-DHC to regulate dormancy across a wide variety of animals suggests a commonality of these pathways for regulating critical life history decisions in response to harsh or highly seasonal environments. In this Chapter, we explore the role of vitamin $\mathrm{D}_{3}$ signaling in embryos of the zebrafish Danio rerio, a teleost that does not experience developmental arrest as part of its normal developmental program. Zebrafish are a common choice for addressing questions of embryology, in addition to use in other fields of study, for their quick development and transparent body allowing for quick and easy experimentation. This species' embryonic developmental stages have been thoroughly described allowing us to make highly specific morphological comparisons to A. limnaeus embryos using features of development common to both species (Kimmel et al., 1995; Podrabsky et al., 2017). Further, we test the potential for cross-species activation of the vitamin D receptor in A. limnaeus with nematode-specific ligands, namely dafachronic acids. In total, this work suggests a possible mechanistic theme of regulating developmental progression in early development by closely related subfamily 1 nuclear receptors.

\section{Methods}

\section{Animal care and embryo collection}

Adult annual killifish Austrofundulus limnaeus were housed in Portland State University's Aquatic Vertebrate facility according to previously established protocols (Podrabsky, 1999) and under the approval of the Institutional Animal Care and Use 
Committee (IACUC protocols \#33 and \#64). Fish were descendants of a wild-caught sampling collected near Quisiro, Venezuela in 1995 (Podrabsky et al., 1998). Fish were kept in 10-liter tanks with 21 tanks sharing a common sump and filtration system. Water was changed twice daily. 42 mating pairs were spawned twice weekly and embryos were collected immediately after spawning. Embryos were incubated in embryo medium that mimics the natural pond environment (Podrabsky, 1999; Podrabsky et al., 1998) with the addition of $0.0001 \%$ methylene blue at $25^{\circ} \mathrm{C}$ in darkness. At 4 days post-fertilization (dpf) embryos were bleached to prevent microbial infections and transferred to $A$. limnaeus embryo medium $\left(590 \mathrm{mg} \mathrm{l}^{-1} \mathrm{NaCl}, 11.0 \mathrm{mg} \mathrm{l}^{-1} \mathrm{KCl}, 436.7 \mathrm{mg} \mathrm{l}^{-1} \mathrm{MgCl}_{2} \cdot 6 \mathrm{H}_{2} \mathrm{O}\right.$, $0.313 \mathrm{mg} \mathrm{l}^{-1} \mathrm{MgSO}_{4} \cdot 7 \mathrm{H}_{2} \mathrm{O}, 116.0 \mathrm{mg} \mathrm{l}^{-1} \mathrm{CaCl}_{2} \cdot 2 \mathrm{H}_{2} \mathrm{O}, 10 \mathrm{mg} \mathrm{l}^{-1}$ gentamicin sulfate in ultrapure $\mathrm{H}_{2} \mathrm{O}$ ) at $25^{\circ} \mathrm{C}$ in darkness until needed for experimentation (Podrabsky, 1999). This timing varied based on the specific experiment being performed and details on age of embryos at experimentation (dpf) is described in the Results section for each test. Embryo medium was changed daily.

Embryos of the Tübingen (TU) strain of zebrafish, Danio rerio, were obtained from Dr. Kim Brown's laboratory (IACUC protocol \#58). Embryos were incubated in $D$. rerio embryo medium $\left(15 \mathrm{mM} \mathrm{CaCl}_{2} \cdot 2 \mathrm{H}_{2} \mathrm{O}, 250 \mathrm{mM} \mathrm{NaCl}, 10 \mathrm{mM} \mathrm{KCl}\right.$, and $15 \mathrm{mM}$ $\mathrm{MgSO}_{4}$ in ultrapure $\mathrm{H}_{2} \mathrm{O}$ ) in the dark at $28.5^{\circ} \mathrm{C}$ (Westerfield, 1995).

Characterization of A. limnaeus and D. rerio embryos

Stages of A. limnaeus embryo development - termed Wourms' Stages (WS) have been previously defined (Podrabsky et al., 2017) and were utilized to describe developmental progression of embryos in pharmacological exposures (detailed in 
subsequent section). In a laboratory setting, embryo trajectory can be manipulated using temperature as was mentioned in Chapter 1. Escape trajectory embryos (incubated at $30^{\circ} \mathrm{C}$ ) will be fully formed and hatch at approximately $32 \mathrm{dpf}$ while diapause trajectory embryos (incubated at $20-25^{\circ} \mathrm{C}$ ) are competent to hatch about 24 days post-diapause II (dpd) after taking roughly another 24 days to reach diapause II and an additional, variable amount of time in diapause II and III.

Contrasting to A. limnaeus embryos, D. rerio embryos do not experience diapause and typically develop and hatch within $3 \mathrm{dpf}$. Their development can be broken down into several broad periods - namely the Zygote, Cleavage, Blastula, Gastrula, Segmentation, Pharyngula, and Hatching periods - with several specific stages falling into each. Each stages' morphological features have been described in detail (Kimmel et al., 1995) and these details were used to characterize zebrafish embryo development during exposures.

Due to the high level of specificity given for both $A$. limnaeus and $D$. rerio staging, comparisons of developmental timing are able to be made despite the vast differences in speed of development and consideration of diapause. Once in experimental conditions, care was taken to manipulate and view all embryos only under minimal yellow light (580 $\mathrm{nm}$ bandpass filter) using a Leica inverted microscope at 40X magnification (model DMIRB, Wetzlar, Germany). Representative images of embryos were taken using Leica DFC450C camera and Leica V4.3 software.

\section{Pharmacological exposures}


A variety of pharmacological compounds that inhibit or activate nuclear hormone receptors (NR), the synthesis of ligands for NRs, or potential downstream targets of NR signaling pathways were used to explore the role of these molecular pathways in the entrance of embryos of $A$. limnaeus into diapause. Inhibition of vitamin $\mathrm{D}_{3}$ synthesis was achieved using dafadine A (Sigma Aldrich, St. Louis, Missouri; Luciani et al., 2011) and ketoconazole (Sigma-Aldrich; Sonino, 1987). Activation of the vitamin D receptor (VDR) was achieved using vitamin $\mathrm{D}_{3}$ (Sigma-Aldrich; Valdivielso, 2009) and $1,25(\mathrm{OH})_{2} \mathrm{VitD}_{3}$ (Selleck Chemicals, Houston, TX, or Cayman Chemicals, Ann Arbor, MI; Norman, 2006). $\Delta 4$ - and $\Delta 7$-dafachronic acids (Cayman Chemicals) were also tested for their ability to activate the VDR (Motola et al., 2006; Thomson et al., 2009). Based on results from exposures on $A$. limnaeus embryos, dafadine $\mathrm{A}$ and $1,25(\mathrm{OH})_{2} \mathrm{VitD}_{3}$ were also tested on embryos of $D$. rerio to test for similar developmental phenotypes in a fish that does not naturally enter embryonic diapause.

To confirm the vitamin $\mathrm{D}_{3}$ pathway acted uniquely through the VDR, NRs closely related to VDR were also tested (Krasowski et al., 2011b; Thomson et al., 2009). In addition, inhibition of the mTOR pathway was explored using pharmacological inhibition. The compound GW3965 (Tocris, Bristol, UK; Krasowski et al., 2011b) was used to activate the liver X receptor, while GW4064 (Tocris; Krasowski et al., 2011b) was used to activate the farnesoid X receptor. Lithocholic acid, 5-pregnen-3ß-ol-20-one (Sigma-Aldrich; Krasowski et al., 2011b) and rifampicin (Tocris; Krasowski et al., $2011 b$ ) were used to activate the pregnane-X receptor. The protein mTOR, known to impact cell growth and mammalian metabolism, was inhibited by rapamycin (Biotang, 
Lexington, MA; Saxton and Sabatini, 2017) and Torin1 (Selleck Chemicals; Thoreen et al., 2020).

Embryos of A. limnaeus were exposed to these compounds starting prior to completion of epiboly at 1 or $2 \mathrm{dpf}$ as well as at the dispersed cell phase which occurs at the completion of epiboly at $4 \mathrm{dpf}$ (Podrabsky et al., 2017). Embryos were separated into individual wells of a 96 -well plate $(n=12-24$ per treatment). A total volume of $120 \mu 1$ of experimental media was added to each well. Embryos were monitored until $28-31$ dpf when final developmental trajectory determinations could be made (Podrabsky et al., 2017). D. rerio embryos were exposed starting at the 1,000 -cell stage, housed in 24 -well plates with a total volume of $1.5 \mathrm{ml}$ experimental media per well $(\mathrm{n}=10-15$ per treatment). D. rerio development was tracked until $3-5 \mathrm{dpf}$ (Kimmel et al., 1995). DMSO and $100 \% \mathrm{EtOH}$ were used as solvents to deliver chemicals to embryos; percentages of which did not exceed $1 \%$ total volume of experimental media. Media was changed every 1-3 days.

To begin exposures, media was removed completely from the 1, 2, or $4 \mathrm{dpf}$ embryos, then rinsed once with fresh media, and then media containing the pharmacological compounds was introduced. Embryos were incubated at $25^{\circ} \mathrm{C}$ and $30^{\circ} \mathrm{C}$. For $A$. limnaeus a temperature of $25^{\circ} \mathrm{C}$ typically induces diapause II while $30^{\circ} \mathrm{C}$ leads to direct development in embryos that "escape” diapause II (Podrabsky et al., 2010). Embryos of D. rerio were incubated at their optimal temperature for development of $28.5^{\circ} \mathrm{C}$ (Westerfield, 1995). Embryos were monitored (every 1-3 d) until developmental phenotype determinations could be made - entering diapause II or escaping diapause II 
for A. limnaeus (28 - $31 \mathrm{dpf})$ and general phenotypic characterizations for D. rerio (3 - 5 dpf).

\section{Heart rate}

Since a greatly reduced or absent heart rate is a feature of $A$. limnaeus diapause embryos (Podrabsky et al., 2017), heart rates of individual D. rerio embryos were monitored and recorded. These data were used to indicate if experimental conditions caused a deviation from the active cellular metabolism of normal zebrafish embryonic development and used to compare observations of $D$. rerio experiments to facets of diapause in A. limnaeus. Heart rates were recorded during the 3 days of exposure to experimental media in addition to those in recovery experiments where experimental media was removed and normal D. rerio media was introduced to see if experimental conditions could be reversed. Temperature was controlled at $28.5^{\circ} \mathrm{C}$ (optimal developmental temperature(Kimmel et al., 1995) while heart rates were collected using a Heat Exchanger (HEC-400, 20/20 Technology, Inc., Wilmington, NC) and Bionomic Controller (BC-100, 20/20 Technology, Inc.) attachment inserted on the Leica inverted microscope. Embryos were put into position where heart beat was visible at $40 \mathrm{X}$ magnification. Contractions were then counted using a hand-held tally counter for 30 seconds. This number was recorded and later multiplied by 2 to obtain beats per minute (beats $\left.\min ^{-1}\right)$.

Statistical analysis and graphical representation of data 
Graphical representation of the data and statistical analyses were performed using GraphPad Prism 8 software (V8.4.2, San Diego, CA). Embryo heart rates when treated with dafadine A were compared to controls and analyses were performed using Tukey's multiple comparisons test with alpha set to 0.05 also using GraphPad Prism 8 software.

\section{Results}

Dafadine A exposures: Austrofundulus limnaeus

Embryos at $4 \mathrm{dpf}$ were exposed to $20 \mu \mathrm{mol}^{-1}$ and $25 \mu \mathrm{mol} \mathrm{l}^{-1}$ concentrations of dafadine $\mathrm{A}$ in an attempt to block the escape trajectory and induce diapause II at $30^{\circ} \mathrm{C}$. Dafadine A is an inhibitor of the cytochrome P450 enzyme CYP27A1 - the vertebrate enzyme that synthesizes 25 -hydroxyvitamin $\mathrm{D}_{3}$, the precursor molecule for active $1,25(\mathrm{OH})_{2} \mathrm{VitD}_{3}$ (Bikle, 2014; Luciani et al., 2011). Exposure to dafadine A inhibits development at diapause II even under conditions that should favor escape embryos (Fig.2.1A). Control embryos and those treated with $100 \mathrm{pmol}^{-1} 1,25(\mathrm{OH})_{2} \mathrm{VitD}_{3}$ developed along the escape trajectory at $30^{\circ} \mathrm{C}$ (Fig. $2.1 \mathrm{~A} ; \mathrm{n}=20,18$ ). Exposure to 20 $\mu \mathrm{mol} \mathrm{l}^{-1}$ and $25 \mu \mathrm{mol} 1^{-1}$ dafadine A resulted in $29.41 \%$ and $25.00 \%$ escape trajectory embryos, respectively, while the rest entered diapause II (Fig. 2.1B; $\mathrm{n}=17,12$ ). Addition of $100 \mathrm{pmol} \mathrm{l}^{-1} 1,25(\mathrm{OH})_{2} \mathrm{VitD}_{3}$ to embryos already exposed to $20 \mu \mathrm{mol} \mathrm{l}^{-1}$ and $25 \mu \mathrm{mol}$ $1^{-1}$ dafadine A was sufficient to rescue the escape phenotype in embryos, effectively reversing the inhibitor's impact (Fig. 2.1A \& B; $n=16,5$ ). Survival of embryos was generally high in all treatments except for those exposed to the highest levels of dafadine A and $1,25(\mathrm{OH})_{2} \mathrm{VitD}_{3}$ (Table 2.1). 

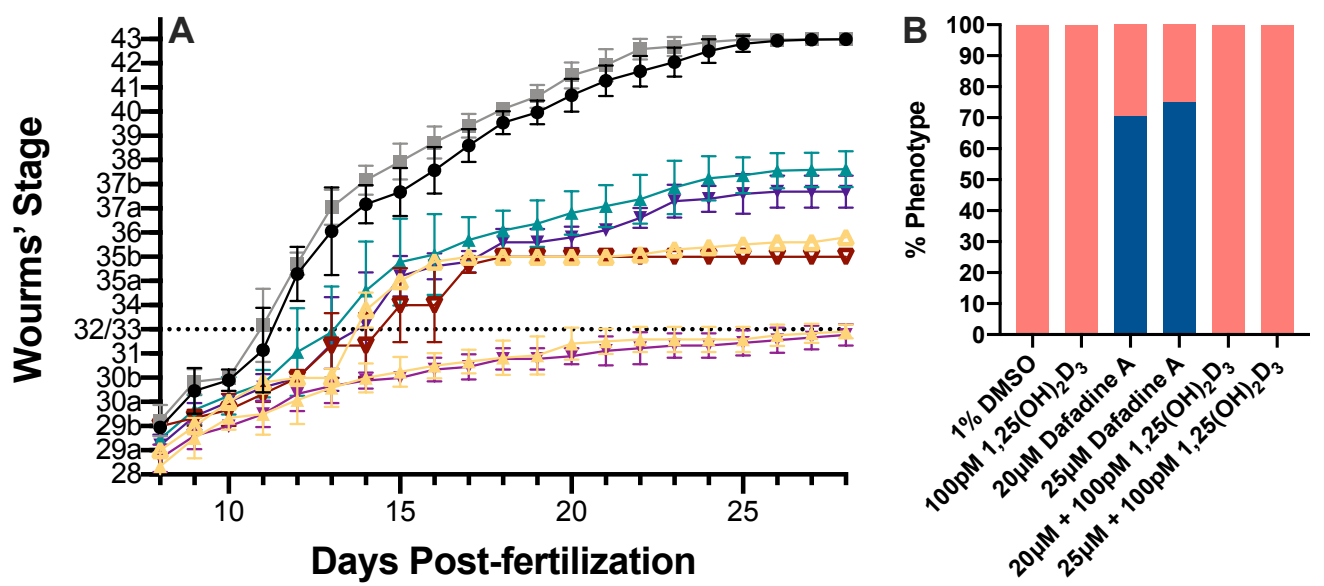

$\begin{array}{lllll}\text { - } \quad 1 \% \mathrm{DMSO} & \mathrm{A} & 20 \mu \mathrm{M} \text { (Diapause) } & \Delta & 20 \mu \mathrm{M} \text { (Escape) } \\ \text { - } 100 \mathrm{pM} 1,25(\mathrm{OH})_{2} \mathrm{D}_{3} & \boldsymbol{\nabla} & 25 \mu \mathrm{M} \text { (Diapause) } & \boldsymbol{\nabla} & 25 \mu \mathrm{M} \text { (Escape) }\end{array}$

$20 \mu \mathrm{M}+100 \mathrm{pM} 1,25(\mathrm{OH})_{2} \mathrm{D}_{3}$
$25 \mu \mathrm{M}+100 \mathrm{pM} 1,25(\mathrm{OH})_{2} \mathrm{D}_{3}$

Escape
Diapause

Figure 2.1. The effect of dafadine $A$ on the developmental trajectory of Austrofundulus limnaeus embryos at $30^{\circ} \mathbf{C}$. (A) Control embryos develop as escape embryos, while $70.59 \%$ and $75 \%$ of embryos treated with 20 and $25 \mu \mathrm{mol}^{-1}$ dafadine A arrest development in a state that appears very similar to diapause II, respectively. Inhibition of development at diapause II can be fully rescued by addition of $100 \mathrm{pmol} \mathrm{l}^{-1}$ $1,25(\mathrm{OH})_{2} \mathrm{VitD}_{3}$. Symbols are means $\pm \mathrm{SD}(\mathrm{n}=5-20$ per treatment). (B) Percent of diapause and escape embryos for each treatment as of $28 \mathrm{dpf}$ ( $\mathrm{n}=5-20$ per treatment; (Romney et al., 2018).

\section{Table 2.1. Percent survival of Austrofundulus limnaeus embryos treated with} dafadine A. Each treatment began with 20 embryos, and number of alive embryos indicates those that survived until $28 \mathrm{dpf}$ when final developmental trajectory determinations were made. Percent phenotype reported in Fig. 2.1B is based on these final $\mathrm{n}$ values.

\begin{tabular}{|l|c|c|}
\hline \multicolumn{1}{|c|}{ Treatment } & Alive & Survival \\
\hline $1 \% \mathrm{DMSO}^{-1}$ & 20 & $100.00 \%$ \\
\hline $100 \mathrm{pmol} \mathrm{l}^{-1} 1,25(\mathrm{OH})_{2} \mathrm{VitD}_{3}$ & 18 & $90.00 \%$ \\
\hline $20 \mu \mathrm{mol} \mathrm{l}^{-1}$ Dafadine A & 17 & $85.00 \%$ \\
\hline $25 \mu \mathrm{mol} \mathrm{l}^{-1}$ Dafadine A & 12 & $60.00 \%$ \\
\hline $20 \mu \mathrm{mol} \mathrm{l}^{-1}$ Dafadine A $+100 \mathrm{pmol} \mathrm{l}^{-1} 1,25(\mathrm{OH})_{2} \mathrm{VitD}_{3}$ & 16 & $80.00 \%$ \\
\hline $25 \mu \mathrm{mol} \mathrm{l}^{-1}$ Dafadine A $+100 \mathrm{pmol} \mathrm{l}^{-1} 1,25(\mathrm{OH})_{2} \mathrm{VitD}_{3}$ & 5 & $25.00 \%$ \\
\hline
\end{tabular}

Dafadine A exposures: Danio rerio 
D. rerio embryos were exposed to dafadine A beginning at the 1,000-cell stage. At 3dpf when embryos should be fully developed, controls and $5 \mu$ mol $1^{-1}$ dafadine A treated embryos reached or were near the Pec-fin stage (Fig. 2.2A). Interestingly, the 20 and $30 \mu \mathrm{mol}^{-1}$ dafadine A treated embryos stalled near the Prim-5/7 stage by $3 \mathrm{dpf}$ which is phenotypically similar to diapause II A. limnaeus embryos (Fig. 2.2A \& B; Table 2.2). Upon removal of $20 \mu \mathrm{mol}^{-1}$ dafadine A at $48 \mathrm{~h}$ of exposure, embryos were continually monitored for $72 \mathrm{~h}$ of recovery, at which point $100 \%$ had fully developed (Fig. 2.2A \& B). $30 \mu \mathrm{mol} \mathrm{l}^{-1}$ dafadine treated embryos (48h exposure) were also continually monitored for $72 \mathrm{~h}$ and reached the Long Pec stage of development (Fig. 2.2A). All treatments were $\mathrm{n}=3$ of 20 embryos each. Exposures combining dafadine A and $1,25(\mathrm{OH})_{2} \mathrm{VitD}_{3}$ were also performed but resulted in abnormal development and death ( $\mathrm{n}=15$ per treatment). Embryos stalled in development and died around the prim-5 to prim-7 stage for those treated with $20 \mu \mathrm{mol}^{-1}$ dafadine $\mathrm{A}$ and 100 or $500 \mathrm{pmol} \mathrm{l}^{-1} 11,25(\mathrm{OH})_{2} \mathrm{VitD}_{3}$. Those exposed to $30 \mu \mathrm{mol} \mathrm{l}^{-1}$ dafadine A and 100 or $500 \mathrm{pmol} \mathrm{l}^{-1} 1,25(\mathrm{OH})_{2} \mathrm{VitD}_{3}$ stalled development and died at approximately 20 -somite to prim- 5 stages. The prim- 5 stage begins once somite development is completed and embryos form $30-34$ pairs of somites; this may prove to be a critical stage in normal teleost development.

Dafadine A had a pronounced negative effect on embryonic heart rate. Compared to controls at the prim-5/7 stage, $20 \mu \mathrm{mol} \mathrm{l}^{-1}$ dafadine A reduced heart rate to $21.5 \pm 7.47$ beats $\min ^{-1}$ (mean \pm SD), while $30 \mu \mathrm{mol}^{-1}$ led to a complete cessation of cardiac activity ( $\mathrm{n}=10$, and 11, respectively; $\mathrm{p}<0.0001$; Fig. $2.2 \mathrm{C}$ ). Comparatively, control embryos at this stage had a heart rate of $98.8 \pm 11.7$ beats $\mathrm{min}^{-1}$. Once at the Long Pec stage of 
development, the heart rate of control embryos was $159.9 \pm 11.56$ beats $\min ^{-1}(\mathrm{n}=12) .72 \mathrm{~h}$ recovered $20 \mu \mathrm{mol} \mathrm{l}^{-1}$ dafadine A was $137.6 \pm 15.9$ beats $\min ^{-1}(\mathrm{n}=9)$, and $72 \mathrm{~h}$ recovered $30 \mu$ mol $1^{-1}$ dafadine A was $129.5 \pm 55.17$ beats $\min ^{-1}(n=6)$. Both treatments were statistically different than controls at this stage ( $\mathrm{p}=0.0326$ and 0.0084 , respectively; Fig. $2.2 \mathrm{C})$.

A

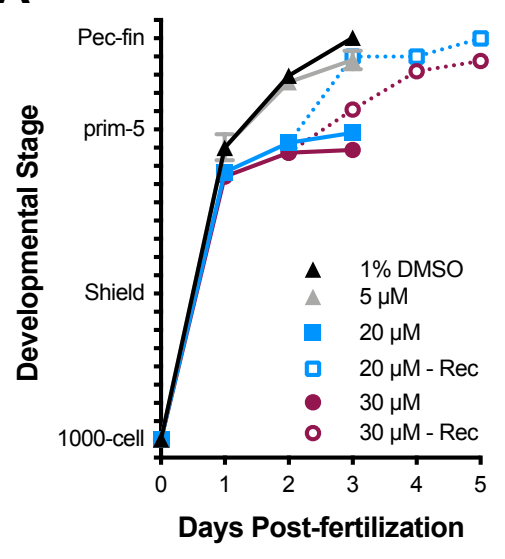

C

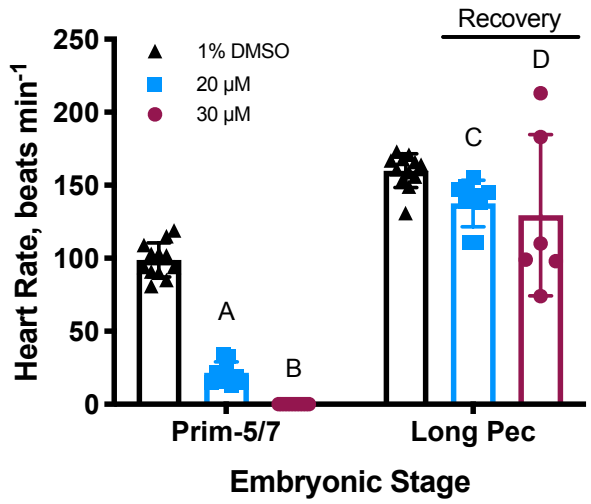

B
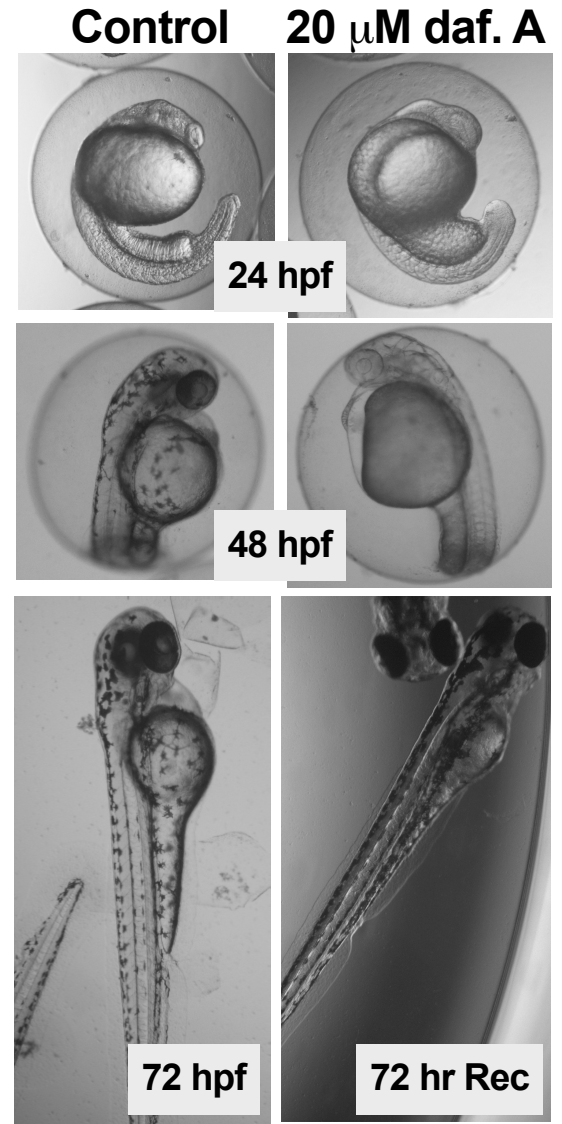

Figure 2.2. Effect of dafadine A on the development of Danio rerio embryos at $28.5^{\circ}$ C. (A) Embryos given 20 or $30 \mu \mathrm{mol} \mathrm{l}^{-1}$ dafadine A developed to approximately the prim-5/7 stage by $3 \mathrm{dpf}$. Experimental media was then removed for a proportion of embryos at $48 \mathrm{~h}$ which were allowed to recover in normal embryo media. Removal of inhibitor promoted further development until $5 \mathrm{dpf}$. Symbols are means $\pm \mathrm{SD}(\mathrm{n}=3$ groups of 20 embryos for $48 \mathrm{~h}$ exposures and 9-12 embryos for recovery groups). (B) Images of Control embryos and those treated with dafadine A. Development is arrested in the presence of dafadine A, but removal of the inhibitor allows for recovery after $72 \mathrm{~h}(\mathrm{C})$ Individual embryo (symbols) and mean ( $\pm \mathrm{SD}$ ) heart rates for controls, 20 and $30 \mu \mathrm{mol} \mathrm{l} \mathrm{l}^{-1}$ 
dafadine A treatment groups at two different stages of development ( $\mathrm{n}=6-12$ per treatment). Removal of dafadine $\mathrm{A}$ increases heart rate to levels similar to controls (A,B $\mathrm{p}<0.0001 ; \mathrm{C}=0.0326$; $\mathrm{D} \mathrm{p}=0.0084$; Romney et al., 2018).

Table 2.2. Comparison of developmental features between Austrofundulus limnaeus embryos in diapause II and Danio rerio embryos treated with $5-35 \mu \mathrm{mol} \mathrm{l}^{-1}$

dafadine A. Phenotypes present in a diapause II A. limnaeus embryo are listed at the top, with presence $(+)$ or absence (-) of each phenotype for each treatment group underneath. D. rerio embryos given $25-35 \mu \mathrm{mol} 1^{-1}$ dafadine A share each marker of a diapausing embryo. Lower concentrations produce a mixed set of results as some embryos in a treatment group developed features while others did not $(n=15$ per treatment; Romney et al., 2018).

\begin{tabular}{|c|c|c|c|c|c|c|c|c|c|c|c|}
\hline & 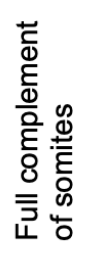 & 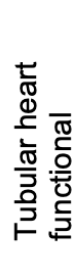 & 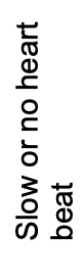 & 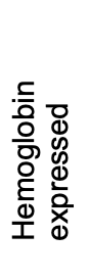 & 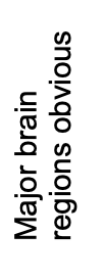 & 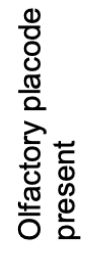 & 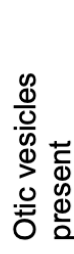 & 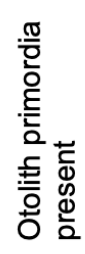 & 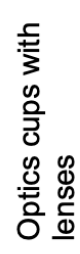 & 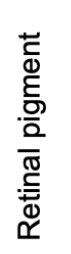 & \begin{tabular}{l} 
d \\
\multirow{2}{*}{} \\
0 \\
$\frac{0}{0}$ \\
$\frac{\pi}{0}$ \\
$\sum$
\end{tabular} \\
\hline $\begin{array}{l}\text { A. limnaeus } \\
\text { diapause }\end{array}$ & + & + & + & - & + & + & + & - & + & - & - \\
\hline zebrafish $35 \mu \mathrm{M}$ & + & + & + & - & + & + & + & - & + & - & - \\
\hline zebrafish $30 \mu \mathrm{M}$ & + & + & + & - & + & + & + & - & + & - & - \\
\hline zebrafish $25 \mu \mathrm{M}$ & + & + & + & - & + & + & + & - & + & - & - \\
\hline zebrafish $20 \mu \mathrm{M}$ & + & + & + & $+/-$ & + & + & + & - & + & $+/-$ & $+/-$ \\
\hline zebrafish $10 \mu \mathrm{M}$ & + & + & - & $+/-$ & + & + & + & + & + & $+/-$ & $+1-$ \\
\hline zebrafish $5 \mu \mathrm{M}$ & + & + & - & $+/-$ & + & + & + & + & + & $+/-$ & + \\
\hline
\end{tabular}

Dafachronic acid exposures

Dafachronic acids ( $\Delta 4$ - and $\Delta 7$ - dafachronic acids) promote active development in the nematode Caenorhabditis elegans through activation of DAF-12, the ortholog of the vertebrate vitamin D receptor (Becker, 2014). Exposure of $A$. limnaeus embryos to $\Delta 4$ dafachronic acid $\left(25-75 \mu \mathrm{mol}^{-1}\right)$ led to an increasing proportion of escape embryos as concentration increased even under conditions that should favor entry into diapause II $\left(25^{\circ} \mathrm{C}\right.$; Fig. 2.3B). Rates of development for each treatment were similar once embryo groups were split into those that followed the diapause trajectory stalling around Wourms' stage (WS) 32/33 and those that followed the escape trajectory surpassed 
diapause II and reached mid-organogenesis by the time the experiment ended (Fig. 2.3A;

Table 2.3).
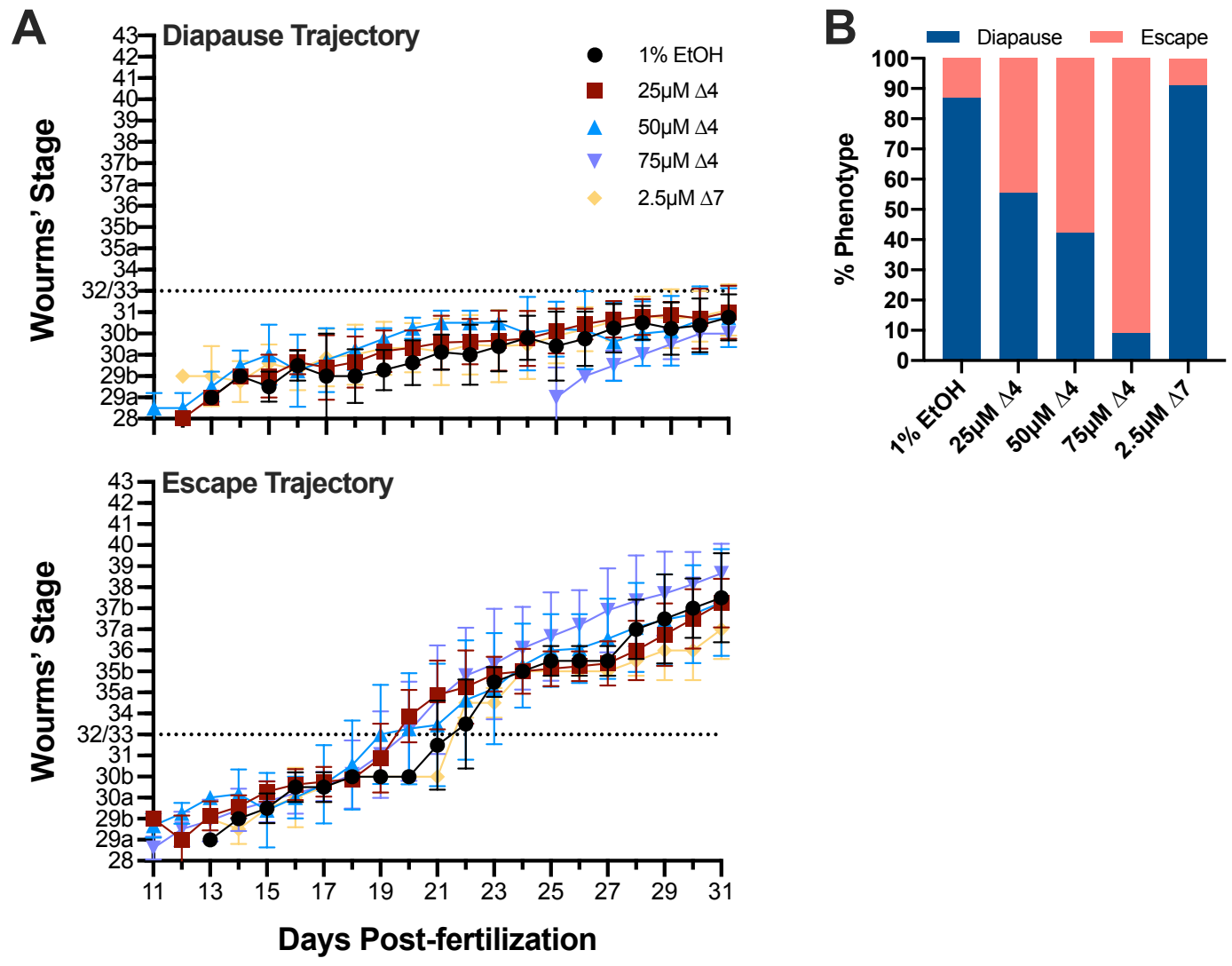

Figure 2.3. Effect of dafachronic acids on Austrofundulus limnaeus embryo development at $25^{\circ} \mathrm{C}$. (A) Developmental progression of embryos treated with $\Delta 4$ and $\Delta 7$ dafachronic acids. Treatments were split between embryos that either went into diapause or bypassed and followed the escape trajectory. This was interpreted as a result of the $\Delta 4$ dafachronic acid exposure as embryos incubated at $25^{\circ} \mathrm{C}$ are anticipated to enter diapause as the control group did. Similar growth rates indicate that higher concentrations of $\Delta 4$ dafachronic acid did not impact speed of development. Symbols are means \pm SD $(n=2-22$ per treatment when separated by trajectory). (B) Percent of embryos that either entered diapause or developed continuously as escape embryos for each treatment group at $31 \mathrm{dpf}$. Controls and embryos treated with $\Delta 7$-dafachronic acid mostly entered diapause $(86.67 \%$ and $90.91 \%$, respectively). The rate of bypassing diapause increased as the concentration of $\Delta 4$-dafachronic acid increased from 25 to $75 \mu \mathrm{mol} \mathrm{l}^{-1}$.

Table 2.3. Percent survival of Austrofundulus limnaeus embryos treated to $\Delta 4 \& \Delta 7$ dafachronic acids at $25^{\circ} \mathbf{C}$. Exposures began with 24 embryos, and number alive reported for each treatment group shows percent survival at final day of characterizations, 31 dpf. Percent phenotype reported in Fig. 2.3B is based on these final $n$ values. 


\begin{tabular}{|l|c|c|}
\hline \multicolumn{1}{|c|}{ Treatment } & Alive & Survival \\
\hline $1 \% \mathrm{EtOH}$ & 15 & $62.50 \%$ \\
\hline $25 \mu \mathrm{mol} ~^{-1} \Delta 4$-Dafachronic acid & 18 & $75.00 \%$ \\
\hline $50 \mu \mathrm{mol} \mathrm{l}^{-1} \Delta 4$-Dafachronic acid & 19 & $79.17 \%$ \\
\hline $75 \mu \mathrm{mol} \mathrm{l}^{-1} \Delta 4$-Dafachronic acid & 22 & $91.67 \%$ \\
\hline $2.5 \mu \mathrm{mol} \mathrm{l}{ }^{-1} \Delta 7$-Dafachronic acid & 22 & $91.67 \%$ \\
\hline
\end{tabular}

The potential role of other $N R$ in the regulation of diapause

The vitamin D receptor is a member of a closely related family of steroid nuclear receptors (Escriva et al., 2004; Evans and Mangelsdorf, 2014; Krasowski et al., 2011a; Reschly et al., 2007). To explore a possible role of these other receptors in trajectory determination we tested agonists and other drugs that are known to activate these nuclear receptors. Incubation in agonists for these other family members did not affect developmental trajectory in A. limnaeus (Table 2.4).

Table 2.4. Nuclear hormone receptor agonists and antagonists exposed to Austrofundulus limnaeus embryos had no effect on development observed. Table shows experimental set up for each exposure ( $\mathrm{n}=12$ each) as well as target nuclear receptor and the trajectory outcome percentage (Romney et al., 2018). DPF $=$ days postfertilization, $\% \mathrm{D} / \mathrm{R}=$ dispersion $/$ reaggregation, $\% \mathrm{DII}=$ diapause II trajectory, $\% \mathrm{ESC}=$ escape trajectory.

\begin{tabular}{|c|c|c|c|c|c|c|c|c|}
\hline$\frac{\text { Nuclear }}{\text { Receptor }}$ & Compound & Concentration & $\underline{\text { DPF }}$ & ${ }^{\circ} \mathbf{C}$ & $\%$ & \%DII & \%ESC & \%Dead \\
\hline \multirow{3}{*}{$\begin{array}{l}\text { Pregnane X/ } \\
\text { Vitamin D } \\
\end{array}$} & Lithocholic acid & $1 \mathrm{nmol} \mathrm{l}^{-1}$ & 4 & 25 & 18 & 64 & 18 & \\
\hline & & $10 \mathrm{nmol} \mathrm{l}^{-1}$ & 4 & 25 & & 75 & 17 & 8 \\
\hline & & $100 \mathrm{nmol} \mathrm{l}^{-1}$ & 4 & 25 & & 82 & 9 & 9 \\
\hline \multirow[t]{5}{*}{ Pregnane $\mathrm{X}$} & Rifampicin & $1 \mathrm{pmol} \mathrm{l}^{-1}$ & 1 & 20 & & 57 & & 43 \\
\hline & & $100 \mathrm{pmol}^{-1}$ & 1 & 20 & 50 & & & 50 \\
\hline & & $1 \mathrm{pmol} \mathrm{l}^{-1}$ & 1 & 25 & & 70 & & 30 \\
\hline & & $100 \mathrm{pmol} \mathrm{l}^{-1}$ & 2 & 25 & & 88 & & 12 \\
\hline & & $1 \mathrm{nmol}^{-1}$ & 1 & 25 & & 8 & & 92 \\
\hline \multirow[t]{2}{*}{ Pregnane $X$} & $\begin{array}{l}\text { 5-pregnen-3ß-ol- } \\
20 \text {-one }\end{array}$ & $1 \mathrm{nmol} \mathrm{l}^{-1}$ & 1 & 25 & 9 & 18 & & 73 \\
\hline & & $10 \mathrm{nmol} \mathrm{l}^{-1}$ & 1 & 25 & & 33 & & 67 \\
\hline
\end{tabular}




\begin{tabular}{|l|l|l|l|l|l|l|l|l|}
\hline & & $100 \mathrm{nmol} \mathrm{l}^{-1}$ & 1 & 25 & & 33 & & 67 \\
\hline Farnesoid X & \multirow{2}{*}{ GW4064 } & $1 \mathrm{nmol} \mathrm{l}^{-1}$ & 1 & 20 & 20 & 60 & 20 \\
\cline { 3 - 9 } & & $100 \mathrm{nmol} \mathrm{l}^{-1}$ & 1 & 20 & & 67 & 33 \\
\hline & & $1 \mathrm{nmol} \mathrm{l}^{-1}$ & 1 & 25 & 14 & 72 & & 14 \\
\hline & & $100 \mathrm{nmol} \mathrm{l}^{-1}$ & 1 & 25 & & 44 & & 56 \\
\hline & & $10 \mu \mathrm{mol} \mathrm{l}^{-1}$ & 2 & 25 & & 75 & 25 \\
\hline \multirow{2}{*}{ Liver X } & \multirow{2}{*}{ GW3965 } & $1 \mu \mathrm{mol} \mathrm{l}^{-1}$ & 2 & 25 & 8 & 17 & 75 \\
\hline & & $1 \mu \mathrm{mol} \mathrm{l}^{-1}$ & 1 & 25 & & 30 & 70 \\
\hline CYP450 & \multirow{2}{*}{ Ketoconazole } & $75 \mu \mathrm{mol} \mathrm{l}^{-1}$ & 4 & 30 & & 25 & 50 & 25 \\
\hline & & $100 \mu \mathrm{mol} \mathrm{l}^{-1}$ & 4 & 30 & & 17 & 75 & 8 \\
\hline & & $125 \mu \mathrm{mol} \mathrm{l}^{-1}$ & 4 & 30 & & 25 & 75 & \\
\hline & & & & & & & & \\
\hline
\end{tabular}

The potential role of the $m$ TOR pathway in regulating diapause

The mTOR pathway has been shown to regulate developmental arrest in mammalian embryos resulting in delayed implantation (Bulut-Karslioglu et al., 2016). However, inhibition of mTOR had no effect on developmental trajectory in embryos of A. limnaeus (Table 2.5).

Table 2.5. mTOR inhibitors exposed to Austrofundulus limnaeus embryos had no apparent effect on development. Table shows experimental set up for each exposure $(n=12$ each) as well as target nuclear receptor and the trajectory outcome percentage (Romney et al., 2018). DPF = days post-fertilization, \% $\mathrm{D} / \mathrm{R}=$ dispersion / reaggregation, $\% \mathrm{DII}=$ diapause II trajectory, \%ESC = escape trajectory.

\begin{tabular}{|c|c|c|c|c|c|c|c|c|}
\hline $\begin{array}{l}\text { Nuclear } \\
\text { Receptor }\end{array}$ & Compound & Concentration & $\underline{\text { DPF }}$ & $\stackrel{\circ}{{ }^{\circ} \mathrm{C}}$ & $\% \mathrm{D} / \mathrm{R}$ & \%DII & \%ESC & \%Dead \\
\hline \multirow{3}{*}{ mTOR } & Rapamycin & $500 \mathrm{nmol} \mathrm{l}^{-1}$ & 4 & 30 & & & 100 & \\
\hline & & $10 \mu \mathrm{mol} \mathrm{l}^{-1}$ & 4 & 30 & & & 100 & \\
\hline & & $100 \mu \mathrm{mol} \mathrm{l}^{-1}$ & 4 & 30 & & & 100 & \\
\hline \multirow[t]{6}{*}{ mTOR } & Torin1 & $1 \mu \mathrm{mol} \mathrm{1} 1^{-1}$ & 4 & 30 & & & 100 & \\
\hline & & $5 \mu \mathrm{mol} \mathrm{l}^{-1}$ & 4 & 30 & & & 67 & 33 \\
\hline & & $10 \mu \mathrm{mol} \mathrm{l}^{-1}$ & 4 & 30 & 67 & & & 33 \\
\hline & & $5 \mu \mathrm{mol} \mathrm{l}^{-1}$ & 4 & 25 & 20 & 80 & & \\
\hline & & $8 \mu \mathrm{mol} \mathrm{l}^{-1}$ & 4 & 25 & 67 & 25 & & 8 \\
\hline & & $10 \mu \mathrm{mol} \mathrm{l}^{-1}$ & 4 & 25 & 83 & & & 17 \\
\hline
\end{tabular}




\section{Discussion}

Blocking Vitamin $D_{3}$ synthesis induces diapause II in A. limnaeus

Gene expression and pharmacological studies suggest that the vitamin $\mathrm{D}_{3}$ signaling pathway plays a critical role in regulating early development of $A$. limnaeus embryos (Romney et al., 2018). Here, I show that blocking of vitamin $\mathrm{D}_{3}$ synthesis using dafadine $\mathrm{A}$, a potent inhibitor of CYP27A1 (vitamin $\mathrm{D}_{3}$ 25-hydroxylase), induces diapause II under conditions that should favor active development $\left(30^{\circ} \mathrm{C}\right)$. Interestingly, not all embryos responded in the same manner. When treated with 20 and $25 \mu \mathrm{mol} \mathrm{l}^{-1}$ of dafadine A, 70.59\% and $75.00 \%$ of embryos entered diapause, respectively. The remaining embryos did not enter diapause II as is expected for embryos incubated at $30^{\circ} \mathrm{C}$. However, they were not able to develop beyond Wourms' stage $35 \mathrm{~b}$, just prior to the onset of organogenesis (Podrabsky et al., 2017). These data suggest an incomplete blocking of vitamin $\mathrm{D}_{3}$ synthesis. However, increasing dafadine A exposures to $30 \mu \mathrm{mol}$ $1^{-1}$ caused death, and thus it was not possible to determine if these results are due to incomplete blockage of vitamin $\mathrm{D}_{3}$ synthesis or some other functional aspect of the signaling pathway. Entrance into diapause II induced by exposure to dafadine A can be rescued by co-incubation with $100 \mathrm{pmol}^{-1} 1,25(\mathrm{OH})_{2} \mathrm{VitD}_{3}$, suggesting that vitamin $\mathrm{D}_{3}$ signaling is indeed regulating entrance into diapause. However, while $100 \%$ of the embryos did escape the diapause trajectory, survival was low, and surviving embryos stalled in development slightly after organogenesis around Wourms' stage $37 \mathrm{~b}$ (Podrabsky et al., 2017). These data suggest a role for vitamin $\mathrm{D}_{3}$ signaling in the entrance into diapause II and a more general role in the support of active post-DII development since blocking vitamin $\mathrm{D}_{3}$ synthesis prevented the development associated 
with organogenesis. This pathway's relevance to internal organ formation in A. limnaeus suggests a broader role for vitamin $\mathrm{D}_{3}$ signaling in vertebrate development beyond the regulation of diapause in annual killifishes.

Blocking vitamin $D_{3}$ synthesis induces a diapause-like arrest in zebrafish

Blocking vitamin $\mathrm{D}_{3}$ synthesis in $D$. rerio embryos with dafadine $\mathrm{A}$ induces arrest of development at roughly the same developmental stage as diapause II in A. limnaeus. Since the two species use different staging systems, common developmental features were used to compare. When incubated with $25-35 \mu \mathrm{mol}^{-1}$ of dafadine A, zebrafish embryos closely matched the developmental features of a diapause II killifish embryo. Further, In addition, higher concentrations of dafadine A appeared to result in a reduction in metabolic rate as evidenced by reduced heart rate which is known to correlate with metabolic rate in fish embryos. The death of embryos exposed to a combination of dafadine $\mathrm{A}$ and $1,25(\mathrm{OH})_{2} \mathrm{VitD}_{3}$ is an interesting result that defies explanation at this time. However, removal of the inhibitor at $2 \mathrm{dpf}$, when embryos were in the diapause-like state, led to an apparent recovery as defined by the ability to complete embryonic development. These data strongly suggest a conserved role of vitamin $\mathrm{D}_{3}$ signaling in teleost development. However, it is interesting why the zebrafish embryos were able to reach full development after inhibition and why the combination of dafadine A and $1,25(\mathrm{OH})_{2} \mathrm{VitD}_{3}$ caused death. One possible explanation is that zebrafish utilize the VDRa isoform during most of development (Lin et al., 2012), while $A$. limnaeus appears to express mostly the VDRb isoform. Evidence for teleost-specific whole genome duplications have been known for some time and there are suspected 
divergent roles for the two VDR isoforms that are found in most teleost fish genomes (Glasauer and Neuhauss, 2014; Kollitz et al., 2014). It has been shown that the two share a similar ligand specificity and that the difference may lie in protein interaction with the specific NR and slew of coactivators (Kollitz et al., 2014). Thus, differences in isoform expression in the two species during embryonic development could explain some of the functional differences between the two species that are highlighted in this study through differences in their interaction with other protein partners.

Dafachronic acids promote active development in A. limnaeus embryos

Dafachronic acids are signaling molecules in C. elegans that bind to the DAF-12 nuclear receptor, the homolog of the VDR in fishes (Escriva et al., 2004). Presence of dafachronic acids in the nematode prevents developmental arrest in the dauer larval stage (developmental arrest similar to diapause in A. limnaeus) and promotes active development and reproduction (Antebi et al., 2000). DAF-9 synthesizes $\Delta 4-\& \Delta 7-$ dafachronic acids from 7-dehydrocholesterol (7-DHC), the same starting material for the vitamin $\mathrm{D}_{3}$ pathway (Bikle, 2011; Mahanti et al., 2014). Incredibly, A. limnaeus embryos exposed to $\Delta 4$-dafachronic acid were induced to actively develop along the escape pathway under conditions that should promote entrance into diapause $\left(25^{\circ} \mathrm{C}\right)$. These molecules are not produced in vertebrates, and the fact that they can promote active development in A. limnaeus is astonishing. These data support a similarity of the molecular mechanisms that regulate metabolic dormancy in animals, and perhaps all metazoans. Both VDR and DAF-12 are thought to induce dormancy when unbound with 
ligand and active development when activated by their ligands through orchestration of a complex gene expression response (Mahanti et al., 2014; Romney et al., 2018).

VDR has a unique, specific effect on regulating dormancy in $\mathrm{A}$. limnaeus

Due to the relatedness of subfamily 1 nuclear hormone receptors (Escriva et al., 2004; Schuster, 2011; Thomson et al., 2009), it was hypothesized that other NR in addition to the VDR may be able to impact developmental trajectory through possible overlap in ligand specificity. However, a survey of the effects of a large number of agonists and antagonists for closely related NRs (PXR, FXR, LXR) did not affect entrance into diapause II. PXR is activated by pregnane and other steroid hormone precursors and is very closely related to VDR so three different chemicals were utilized to evaluate this possible avenue for molecular cross-talk (Escriva et al., 2004; Krasowski et al., 2011a; Reschly et al., 2007). FXR, a nuclear receptor activated by bile acids (Walters, 2000), is commonly compared to DAF-12 in C. elegans, and bile acids have been shown to impact dauer formation in C. elegans through the DAF pathway (Antebi, 2015; Gerisch et al., 2007). The LXR, activated by oxysterols (Archer et al., 2012; Escriva et al., 2004), is slightly more removed phylogenetically from VDR but is thought to be similar to FXR/DAF receptors active in dauer formation (Escriva et al., 2004; Mooijaart et al., 2005). The fact that none of the compounds tested caused a trajectory shift supports a unique role for vitamin $\mathrm{D}_{3}$ signaling the regulation of diapause in $A$. limnaeus.

The mTOR pathway does not regulate entrance into diapause II in A. limaneus 
Recently, the mTOR pathway has been shown to regulate developmental arrest associated with delayed implantation of mammalian embryos (Bulut-Karslioglu et al., 2016). Further, mTOR is suggested to have impacts on metabolism, lipid homeostasis, and heat shock protein function (Chou et al., 2012; Lamming and Sabatini, 2013; Potter et al., 2019; Saxton and Sabatini, 2017), all of which are relevant to the biology of diapause in A. limnaeus. However, mTOR inhibition with two different compounds showed no impact on entrance into diapause II. It is interesting to note, however, that embryos treated with high levels of mTOR inhibitors were unable to develop beyond the dispersed cell stage and thus future experiments should explore a role for mTOR in regulation of entrance into diapause I in A. limnaeus.

\section{Conclusion}

This study reports for the first time, that the vitamin $\mathrm{D}_{3}$ signaling pathway acts as a unique molecular mechanism of trajectory determination in embryos of the annual killifish, A. limnaeus, and allows for exploration of this pathway's involvement in trajectory determination in other species of annual killifishes. The specificity for VDR signaling in the regulation of diapause is supported by data showing that pharmacologically targeting other NRs did not impact early development or entrance into diapause. Further, this Chapter supports a role for the vitamin $\mathrm{D}_{3}$ signaling pathway's importance in normal embryonic development in non-diapausing species, especially those events associated with organogenesis. This suggests a key role for VDR signaling in teleost embryology more generally, and opens the idea that vitamin D synthesis and signaling play a role in the normal morphological development of teleost fishes. Finally, 
the ability of dafachronic acids to induce development in a vertebrate system suggests a common mechanism of regulating dormancy in animals. 


\title{
CHAPTER 3:
}

\section{Reigniting the furnace: The role of vitamin $D_{3}$ signaling, heat shock protein activity, and DNA methylation in the exit from diapause in an annual killifish}

\begin{abstract}
Embryonic diapause allows annual killifishes to persist in seasonal aquatic environments that are characterized by environmental extremes. Recently it was discovered that vitamin $\mathrm{D}_{3}$ signaling regulates entry into diapause II in embryos of Austrofundulus limnaeus, but mechanisms that control exit from diapause have not been explored. To explore the role of vitamin $\mathrm{D}_{3}$ signaling in exit from diapause, diapause II embryos were exposed to a variety of vitamin $\mathrm{D}_{3}$ metabolites. Further, the potential role of HSP70 and HSP90 heat shock proteins in exit from diapause was evaluated using pharmacological inhibitors. Here we show that hydroxylated forms of vitamin $\mathrm{D}_{3}$ can induce exit from diapause II in a dose-dependent manner. Inhibition of heat shock protein activity in isolation did not affect exit from diapause. However, significant interactions were observed between vitamin $\mathrm{D}_{3}$ signaling and HSP function. Exposure of diapause II embryos to $1 \alpha, 25$-dihydroxyvitamin $\mathrm{D}_{3}$ led to changes in the methylation status of hundreds of genes, many of which have been associated with regulation of dormancy in other species. These data support a significant role for active vitamin $\mathrm{D}_{3}$ signaling in promoting exit from diapause and an inhibitory role for HSP70. Changes in DNA methylation as a result of treatment with 1 $\alpha, 25$-dihydroxyvitamin $\mathrm{D}_{3}$ allowed for the
\end{abstract}


identification of a number of genes that likely play a role in regulation of metabolism and stress tolerance associated with diapause. 


\section{Introduction}

Many organisms undergo metabolic dormancy to survive unfavorable conditions. Entrance into dormancy has been compared to turning a furnace down to the "pilot light" - the minimal energy consumption needed to maintain function (Hochachka et al., 1997; Lutz and Nilsson, 2004). The ability to pause development, or undergo diapause, allows for the possibility of synchronizing completion of development with environmental conditions conducive to growth and reproduction in highly seasonal habitats. Diapause is also a common strategy to increase resistance to environmental stress and can be responsible for persistence of individuals or even populations through seasonal conditions that would otherwise be lethal (Denlinger, 2013; Furness, 2015). Entrance into and exit from diapause are regulated by environmental cues, such as temperature and photoperiod, that are thought to have predictive value for optimizing organismal fitness (Taylor and Spalding, 1988). How these cues are sensed and how the information is integrated into organismal responses is not known. Further, it is not clear if the same molecular events that cause entrance into diapause and "dial down" metabolism are also involved in reigniting the furnace upon exit from diapause. In this study we explore the role of vitamin $\mathrm{D}_{3}$ signaling and heat shock protein function in the regulation of exit from diapause in embryos of the annual killifish, Austrofundulus limnaeus.

Vitamin $\mathrm{D}_{3}$ synthesis and signaling have recently been shown to regulate entrance into diapause II in embryos of $A$. limnaeus (Romney et al., 2018). Even short periods of exposure to light and increased temperature $\left(30-33^{\circ} \mathrm{C}\right)$ are sufficient to induce embryos to develop without entering diapause II (escape trajectory) whereas darkness and low temperatures $\left(20-25^{\circ} \mathrm{C}\right)$ promote entrance into diapause II (Romney et al., 2018; 
Romney and Podrabsky, 2018). Vitamin $\mathrm{D}_{3}$ acts through the vitamin D receptor (VDR); a nuclear hormone receptor (NR) that is known to regulate gene expression and alter a variety of complex cellular phenotypes through its ability to partner and interact with other proteins including: other nuclear receptors, heat shock proteins, and epigenetic modifying proteins (Ameri et al., 2013; Chen et al., 2016b; Fetahu et al., 2014; GonzálezDuarte et al., 2015; Larriba et al., 2014; Marcinkowska and Gocek, 2010; Mark et al., 2016; Salehi-Tabar et al., 2012).

The molecular mechanisms that promote exit from diapause have received relatively little attention, despite a breadth of research detailing the number of environmental cues that can be used to "break" diapause under natural and laboratory conditions (Booth, 2002; Hodek, 1996; King and MacRae, 2012; Loomis et al., 1996; Polejaeva et al., 1997; Robbins et al., 2010; Tissenbaum et al., 2000; Van Der Linden et al., 1988; Yaginuma and Yamashita, 1986). In Caenorhabditis elegans, it appears that changes in the insulin-like signaling pathway are critical for exit from the diapause-like dauer dormancy (Gelmedin et al., 2011). In other systems, changes in expression of heat shock proteins that are associated with dormancy seem to be involved in sustaining dormancy and preventing exit from diapause (King and MacRae, 2012; Liang and Macrae, 1999; Podrabsky and Somero, 2007; Rinehart and Denlinger, 2000; Rinehart et al., 2000; Yocum et al., 1998).

The mechanisms that regulate exit from diapause in annual killifishes are currently unknown. In this paper we explore the potential role of vitamin $\mathrm{D}_{3}$ signaling in exit from diapause and resumption of active development in the annual killifish Austrofundulus limnaeus. We also explore the potential interaction between heat shock 
protein activity and vitamin $\mathrm{D}_{3}$ signaling during exit from diapause. Further because the VDR has known interactions with DNA modifying enzymes, including but not limited to DNA methyltransferases (Fetahu et al., 2014; Saccone et al., 2015; Zhang and Ho, 2011), we also explored changes in DNA methylation following treatment with $1 \alpha, 25$ dihydroxyvitamin $\mathrm{D}_{3}$ to identify potential targets of epigenetic regulation associated with the reactivation of development. We hypothesize that active vitamin $\mathrm{D}_{3}$ signaling will induce exit from diapause II in A. limnaeus embryos under laboratory conditions which perpetuate diapause.

\section{Methods}

Animal care and embryo collection

Adult annual killifish Austrofundulus limnaeus were housed in Portland State University's Aquatic Vertebrate facility according to previously established protocols (Podrabsky, 1999) and under the approval of the Institutional Animal Care and Use Committee (IACUC protocols \# 33 and \#64). Fish are descendants of a wild-caught sampling collected from near Quisiro, Venezuela in 1995 (Podrabsky et al., 1998). Fish were kept in 101 tanks with 21 tanks sharing a common sump and filtration system. Water (10-20\% of the system volume) was changed twice daily. Fish (42 mating pairs) were allowed to spawn twice weekly and embryos were collected immediately after spawning. Embryos were bathed in embryo medium that mimics the natural pond environment (10 mmol $\mathrm{l}^{-1} \mathrm{NaCl}, 2.15 \mathrm{mmol} \mathrm{l}^{-1} \mathrm{MgCl}_{2}, 0.8 \mathrm{mmol} \mathrm{l}^{-1} \mathrm{CaCl}_{2}, 0.14 \mathrm{mmol} \mathrm{l}^{-1}$ $\mathrm{KCl}, 1.3 \mathrm{mmol}^{-1} \mathrm{MgSO}_{4}$ ) with the addition of $0.0001 \%$ methylene blue at $25^{\circ} \mathrm{C}$ in darkness (Podrabsky, 1999; Podrabsky et al., 1998). At 4 days post-fertilization (dpf) 
embryos were treated with two washes of 5 min each in $0.03 \%$ sodium hypochlorite separated by a 5 min wash in embryo medium. This bleach treatment is highly effective for preventing microbial infections during prolonged incubations. Following bleaching the embryos were transferred to medium containing $10 \mathrm{mg} \mathrm{l}^{-1}$ gentamicin sulfate at $25^{\circ} \mathrm{C}$ in darkness until they had entered diapause II. Embryos typically enter diapause II when incubated at $25^{\circ} \mathrm{C}$ after $24 \mathrm{dpf}$. Embryo medium was changed daily.

\section{Pharmacological exposures}

To explore the potential role of vitamin $\mathrm{D}_{3}$ signaling in the exit of embryos from diapause II (DII), DII embryos were exposed to $100 \mathrm{nmol}^{-1}$ of vitamin $\mathrm{D}_{3}$ metabolites that represent multiple points in the biosynthetic pathway: 7-dehydrocholesterol (7-DHC; Sigma-Aldrich, St. Louis, Missouri), vitamin $\mathrm{D}_{3}$ (VitD ${ }_{3}$; Sigma-Aldrich), 25hydroxyvitamin $\mathrm{D}_{3}(25 \mathrm{OHVitD}$; Selleck Chemicals, Houston, TX), and 24,25dihydroxyvitamin $\mathrm{D}_{3}\left(24,25(\mathrm{OH})_{2} \mathrm{VitD}_{3}\right.$; ChemCruz, Santa Cruz, CA). Embryos were exposed to 10 and $100 \mathrm{nmol}^{-1} 1 \alpha, 25$-dihydroxyvitamin $\mathrm{D}_{3}\left(1,25(\mathrm{OH})_{2} \mathrm{VitD}_{3}\right.$; Selleck Chemicals or Cayman Chemicals, Ann Arbor, MI). Vitamin $\mathrm{D}_{3}$ synthesis was inhibited using dafadine A (Sigma-Aldrich). Dafadine A is an inhibitor of CYP27A1, the enzyme that catalyzes the 25 -hydroxylation of vitamin $\mathrm{D}_{3}$. To explore a potential role for heat shock proteins (HSPs) in the maintenance or diapause II, DII embryos were exposed to VER155008 (Selleck Chemicals) to inhibit HSP70 activity, and ganetespib (Selleck Chemicals) to inhibit HSP90 activity. Potential interactions between vitD ${ }_{3}$ signaling and HSP function were explored by simultaneous incubation in HSP inhibitors and $1,25(\mathrm{OH})_{2} \mathrm{VitD}_{3}$. 
Diapause II embryos (30-40 dpf) were individually placed into wells of a 96-well plate for developmental tracking of individuals ( $\mathrm{n}=12$ per group). Each well contained $120 \mu \mathrm{L}$ of experimental media, and media was replaced every 1-3 d. Stocks of pharmacological agents were prepared in 100\% dimethyl sulfoxide (DMSO) or 100\% ethanol (EtOH). For exposures to vitamin $\mathrm{D}_{3}$ metabolites, a final concentration of $1 \%$ DMSO or EtOH were used. For exposures with the HSP70 inhibitor VER155008, 2\% final DMSO was required due to the lower solubility of this chemical in DMSO and water. Similarly, for the HSP90 inhibitor ganetespib, 5\% DMSO was required to maintain solubility. Previous experiments indicate no observable effects of 5\% DMSO on embryo development or entrance into diapause II (Pri-Tal et al., 2011). Embryos were observed and their stage recorded every 1-3 d until the completion post-DII development $(10-33 \mathrm{~d})$ according to previously described staging for this species (Podrabsky et al., 2017).

To begin exposures, media was removed completely. Then embryos were rinsed once with fresh media followed by introduction of media containing the pharmacological compounds. Embryos were incubated at $25^{\circ} \mathrm{C}$ or $30^{\circ} \mathrm{C}$. The typical temperature in the laboratory for $A$. limnaeus is $25^{\circ} \mathrm{C}$. At this temperature embryos spontaneously exit diapause II over the span of several months. A temperature of $30^{\circ} \mathrm{C}$ during early development prevents entrance into DII (Podrabsky et al., 2010), and exposure to $30^{\circ} \mathrm{C}$ and constant light for $48 \mathrm{~h}$ is sufficient to induce exit from DII in most embryos (Meller et al., 2012). Care was taken to manipulate and view embryos only under minimal yellow light exposure to minimize unwanted vitamin $\mathrm{D}_{3}$ synthesis using a Leica inverted microscope at 40X magnification (DMIRB, Leica Microsystems, Wetzlar, Germany). 


\section{Heart rate}

Increased heart rate is one of the first indicators that embryos have resumed active development, and thus heart rates of individual embryos were monitored during the experiment (Podrabsky et al., 2010). Embryos were monitored in a temperaturecontrolled room set at $25^{\circ} \mathrm{C}$. Embryo temperature was confirmed during data collection using a beaded wire thermocouple probe. Embryos were viewed at $40 \mathrm{X}$ magnification with minimal yellow light. Contractions were counted using a hand-held tally counter for $30 \mathrm{~s}$. This number was recorded and multiplied by 2 to obtain beats per minute.

DNA Methylation in response to treatment with $1,25(\mathrm{OH})_{2} \mathrm{Vit}_{3}$

Diapause II embryos (40 dpf) were exposed to $10 \mathrm{nmol}^{-1} 1,25(\mathrm{OH})_{2} \mathrm{VitD}_{3}$ in embryo medium containing 1\% DMSO for 2.5 days while controls were incubated in embryo medium containing 1\% DMSO. Eight groups $(n=4$ for control, and $n=4$ for $1,25(\mathrm{OH})_{2} \mathrm{VitD}_{3}$ treatment) of 10-15 embryos per well were incubated in a 24 -well plate. Temperature was controlled at $25^{\circ} \mathrm{C}$ and embryos were kept in the dark except during observations which were done under dim yellow light in an otherwise dark room. After the 2.5 days of treatment with $10 \mathrm{nmol} \mathrm{l}^{-1} 1,25(\mathrm{OH})_{2} \mathrm{VitD}_{3}, 5$ embryos with the morphology of DII embryos and elevated heart rates were chosen from each replicate for DNA extraction and bisulfite sequencing to represent the earliest stages of exit from diapause. 5 embryos from each control replicate that were morphologically in DII and had low heart rates were sampled to represent embryos in diapause II. 


\section{DNA Extraction}

Embryos were treated with a $0.015 \%$ treatment of sodium hypochlorite (Clorox bleach) for $5 \mathrm{~min}$ and washed twice with sterile-filtered $(0.45 \mu \mathrm{m})$ embryo medium. DNA was extracted using a DNeasy DNA purification kit (Kit 69504, Qiagen, Germantown, MD, USA). Embryos were homogenized in $180 \mu \mathrm{l}$ of buffer ALT using a PTFE pellet pestle in a $1.5 \mathrm{ml}$ microcentrifuge tube. Proteinase $\mathrm{K}$ was added $\left(20 \mu \mathrm{lof}\right.$ a $20.2 \mathrm{mg} \mathrm{ml}^{-1}$ stock) and homogenates were digested at $56^{\circ} \mathrm{C}$ for $14 \mathrm{~h}$. RNase A was added and samples were gently mixed by inversion and incubated for $10 \mathrm{~min}$ at room temperature. DNA was then isolated according to the manufacturer's instructions by application to DNeasy silica spin columns. DNA was eluted in two $100 \mu \mathrm{l}$ washes of buffer AL (from the kit) that was prewarmed to $56^{\circ} \mathrm{C}$. Columns were incubated at $56^{\circ} \mathrm{C}$ for 4 min prior to collection of the eluate by centrifugation. DNA was precipitated by addition of 2.5 volumes of $95 \%$ ethanol and 0.1 volumes of $3 \mathrm{M}$ sodium acetate $(\mathrm{pH}=5.2)$ followed by $3 \mathrm{~h}$ of incubation at $-20^{\circ} \mathrm{C}$. The DNA pellet was washed twice with $75 \%$ ethanol, allowed to air dry and resuspended in $20 \mu \mathrm{l}$ of buffer AE. DNA quantity was determined using a Quant-iT PicoGreen dsDNA assay kit (P7589, Invitrogen, ThermoFisher, Waltham, MA, USA). DNA was stored at $4^{\circ} \mathrm{C}$.

\section{Reduced Representation Bisulfite Sequencing (RRBS)}

RRBS libraries for each of the experimental and control DNA samples were prepared using $150 \mathrm{ng}$ of DNA by the Knight Cardiovascular Institute Epigenetics Consortium at Oregon Health \& Science University. DNA samples were digested overnight with the MspI restriction enzyme and the digested DNA cleaned using AMPure 
XP magnetic beads according to the manufacturer's instructions. RRBS sequencing libraries were prepared using a NEXTflex Bisulfite-Seq kit (Perkin Elmer). Bisulfite conversion was performed using the EZ DNA Methylation-Gold Kit. PCR amplification with NEBNext Multiplex oligos was used to amplify and barcode each library. DNA was cleaned for sequencing using the AMPure system as described above. Libraries were sequenced at the University of Oregon Genomics and Cell Characterization Core Facility using a HiSeq 4000 with 100 bp single-end reads.

Analysis of Differentially Methylated Regions (DMR)

Sequence reads were trimmed using TrimGalore with a quality cutoff score of 20. Sequence quality before and after adapter trimming was evaluated using FastQC. Bismark was used to align reads to the Austrofundulus limnaeus reference genome version 1.0 and to identify sites of methylation. Differential methylation was determined using the methylKit $\mathrm{R}$ package. The genome was tiled into $1 \mathrm{~kb}$ nonoverlapping segments and $\mathrm{CpG}$ methylation rates were averaged over the $1 \mathrm{~kb}$ region. Only regions with at least 10X coverage were used for DMR analysis. Regions of significant changes in methylation were identified using a logistic regression model compared to the average methylation value of the region. P-values were converted to false discovery rate-adjusted P-values (q-values) using the SLIM method. Significance was defined at a q-value $<0.10$ and a percent difference in methylation of $10 \%$ or greater. DMRs were annotated based on overlap with genome annotation features - promoters, exons, introns, and intergenic regions. Promoters were defined as $3 \mathrm{~kb}$ upstream of the transcription start site. If the DMR did not overlap with an annotated structure it was designated as intergenic. 
Gene ontology of analysis

OrthoMCL (Li et al., 2003) was used to generate a list of orthologous proteins between the genome of $A$. limnaeus and the zebrafish, Danio rerio which was used as a teleost comparison tool since the D. rerio genome is heavily annotated (Sprague et al., 2006). Gene ontology terms (GO) associated with the zebrafish genome were then retrieved using gene2go and these terms were applied to orthologous proteins in the annotated genome of A. limnaeus. TopGo was used to test for enrichment of GO terms in the statistically significant DMRs. The total set of GO terms associated with $D$. rerio genes with orthologs in A. limnaeus was used as a background for the GO enrichment analysis. Significance was determined using the TopGO Fisher's exact test corrected for multiple comparisons $(\mathrm{P}<0.05)$.

\section{Statistical analysis and graphical representation of data}

Statistics and graphics were generated using GraphPad Prism 8 software (V8.4.2). Survival analyses assessed the probability of embryos exiting diapause II in response to treatment with pharmacological agents. For exposure to vitamin $\mathrm{D}_{3}$ metabolites, the $a$ priori assumption was that these chemicals would induce exit from diapause II, and thus a one-tailed P-value was used. For all other comparisons, a two-tailed P-value was used. Statistical significance was determined at $\mathrm{P}<0.05$ using Bonferroni's adjustment for multiple comparisons. Venn diagrams were created in BioVenn to indicate overlap in differential methylation of genomic elements (Hulsen et al., 2008). 


\section{Results}

Hydroxylated Vitamin $D_{3}$ metabolites induce exit from diapause II

Exposure of DII embryos to hydroxylated forms of $100 \mathrm{nmol} \mathrm{l}^{-1}$ vitamin $\mathrm{D}_{3}$ metabolites increases probability of exit from DII compared to controls (Fig 3.1A). Vitamin $\mathrm{D}_{3}$ analogues that are farther down the biosynthetic pathway towards $1,25(\mathrm{OH})_{2} \mathrm{VitD}_{3}$ increase in their potency, with $1,25(\mathrm{OH})_{2} \mathrm{VitD}_{3}$ being the most potent and resulting in $100 \%$ of the embryos exiting DII after only $2 \mathrm{~d}$ of exposure. Interestingly, 24,25(OH) $)_{2} \mathrm{VitD}_{3}$ is also able to induce exit from diapause with a similar potency as $25 \mathrm{OHVitD}$. The probability of exit from diapause when exposed to vitamin $\mathrm{D}_{3}$ metabolites is significantly higher than controls for all hydroxylated analogues of vitamin $\mathrm{D}_{3}$ (Fig 3.1B; Survival analysis, $\mathrm{P}<0.01$ for significance based on multiple comparisons; 7-DHC $\mathrm{P}=0.071, \mathrm{VitD}_{3} \mathrm{P}=0.046,25 \mathrm{OHVitD}_{3} \mathrm{P}<0.0001$, $\left.24,25(\mathrm{OH})_{2} \mathrm{VitD}_{3} \mathrm{P}<0.0001,1,25(\mathrm{OH})_{2} \mathrm{VitD}_{3} \mathrm{P}<0.0001\right)$. Exposure to $1,25(\mathrm{OH})_{2} \mathrm{VitD}_{3}$ causes an increase in heart rate within $24 \mathrm{~h}$ compared to embryos that remain in DII, indicating a relatively quick mode of action for initiation of developmental processes involved in breaking of diapause (Fig 3.1C). 

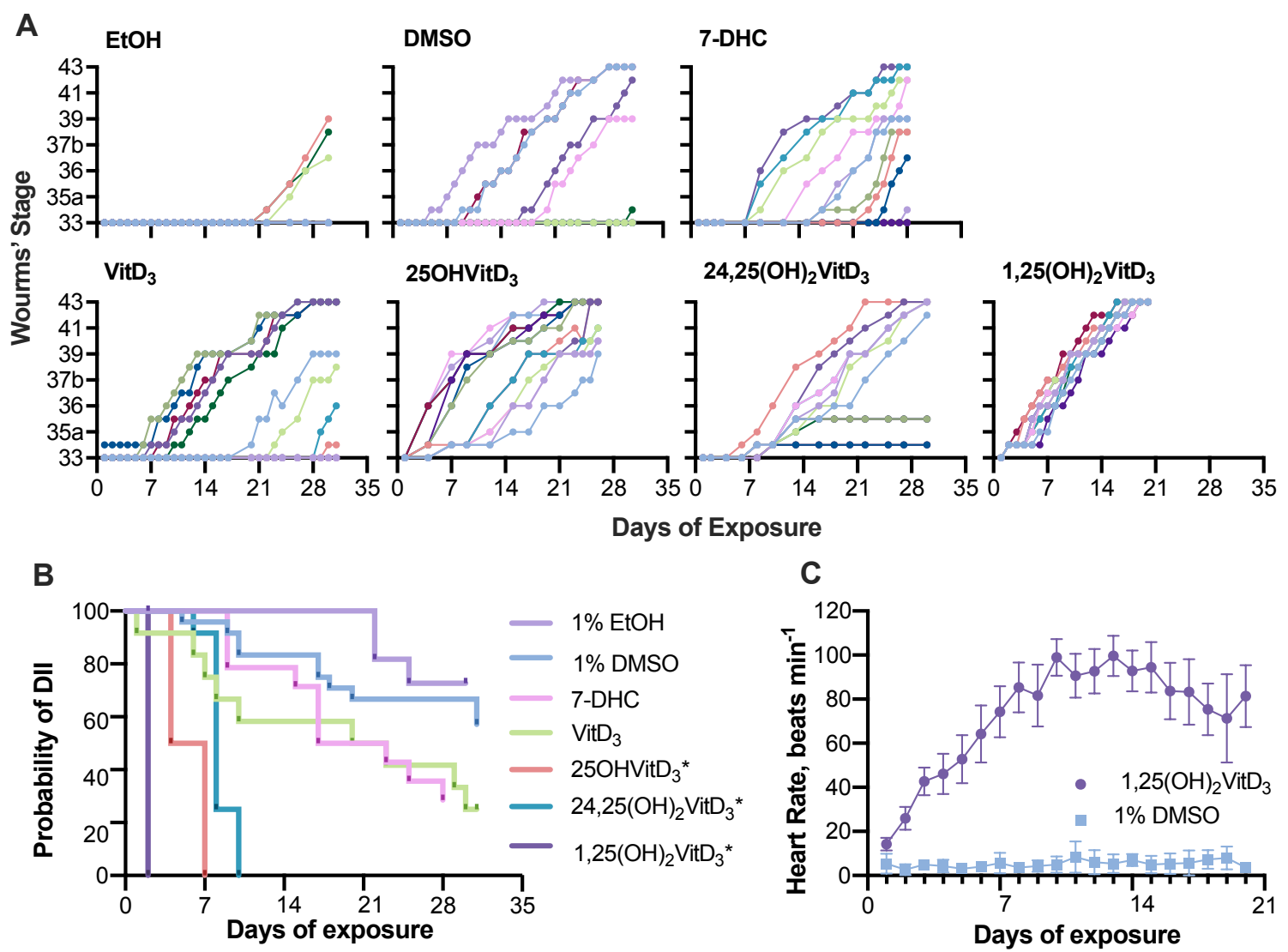

Figure 3.1. Effect of vitamin $D_{3}$ metabolites on exit from diapause and active development in Austrofundulus limnaeus embryos at $25^{\circ} \mathrm{C}$. (A) Line plots of the development of individual embryos (Wourms' Stage) over time during continuous incubation in $100 \mathrm{nmol} \mathrm{l}^{-1}$ of each vitamin $\mathrm{D}_{3}$ metabolite as indicated above each graph ( $n=12$ per group). Each embryo is represented by a different color. Developmental progression is expressed in Wourms' Stages. The most potent analogue is $1,25(\mathrm{OH})_{2} \mathrm{VitD}_{3}$. (B) The probability of exiting from diapause is significantly increased by exposure to the three hydroxylated forms of vitamin $\mathrm{D}_{3}-25 \mathrm{OHVitD}$, $24,25(\mathrm{OH})_{2} \mathrm{VitD}_{3}$ and $1,25(\mathrm{OH})_{2} \mathrm{VitD}_{3}$. Analogues marked with an asterisk exit diapause II significantly faster than controls (Survival analysis, $\mathrm{P}<0.0001 ; \mathrm{n}=12$ per treatment). See text for more details on statistical methods used. (C) Heart rate immediately increases upon exposure to $1,25(\mathrm{OH})_{2} \mathrm{VitD}_{3}$ compared to DII embryos in $1 \%$ DMSO. Symbols are means $\pm \mathrm{SD},\left(\mathrm{n}=12\right.$ for $1,25(\mathrm{OH})_{2} \mathrm{VitD}_{3}, \mathrm{n}=6$ for $\left.1 \% \mathrm{DMSO}\right)$. Heart rates for other treatments were not recorded.

To test for a minimal exposure to $1,25(\mathrm{OH})_{2} \mathrm{VitD}_{3}$ required to induce exit from diapause II at $25^{\circ} \mathrm{C}$, embryos were exposed to 10 and $100 \mathrm{nmol} \mathrm{l}^{-1} 1,25(\mathrm{OH})_{2} \mathrm{VitD}_{3}$ either 
continuously, or for $2,4,6,8,10$, or $12 \mathrm{~d}$ followed by transfer back to embryo medium. Individual embryos were tracked over time to obtain rates of exit from diapause. All embryos treated with $100 \mathrm{nmol}^{-1} 1,25(\mathrm{OH})_{2} \mathrm{VitD}_{3}$ for $2 \mathrm{~d}$ or more exited diapause and completed development at WS 43 (Fig 3.2A,B; $\mathrm{n}=12$ ). For the $10 \mathrm{nmol}^{-1}$ treatment, $100 \%$ of the embryos had exited DII as evidenced by increased heart rate, resumption of red blood cell circulation, and development of post-DII anterior structures after $4 \mathrm{~d}$ of exposure (Fig 3.2A). However, these embryos were not able to develop beyond WS 36 (Fig 3.2B).

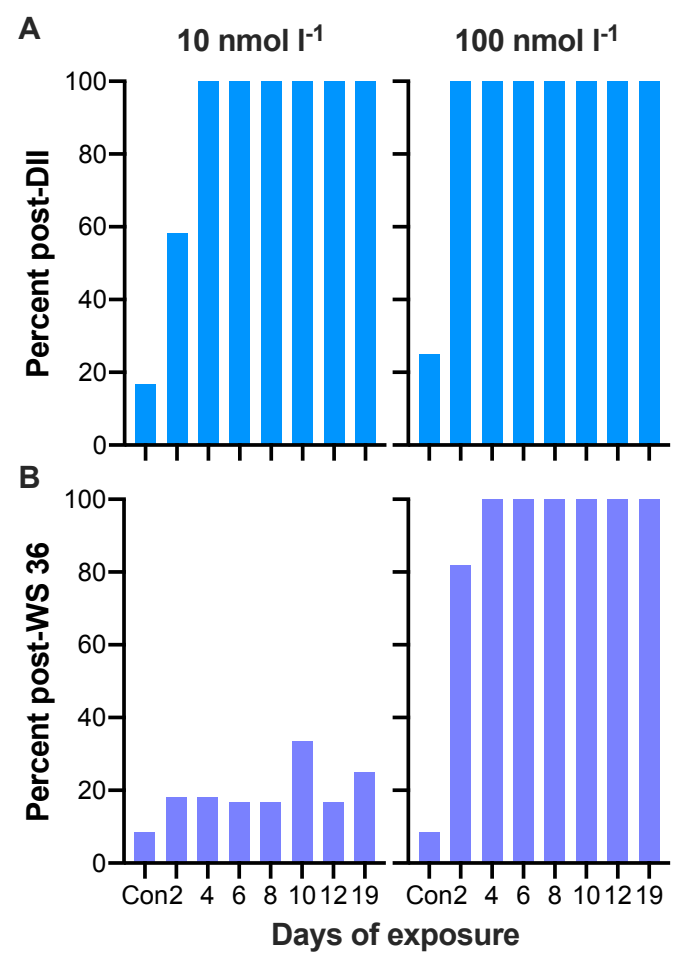

Figure 3.2. The effect of increasing durations of exposure to $10 \mathrm{nmol} \mathrm{l}^{-1}$ and 100 nmol $^{-1} 1,25(\mathrm{OH})_{2} \mathrm{VitD}_{3}$ on exit from diapause II and subsequent embryonic development at $25^{\circ} \mathbf{C}$. (A) 10 and $100 \mathrm{nmol}^{1-1}$ treatments lead to $100 \%$ of embryos exiting diapause after 4 and $2 \mathrm{~d}$, respectively. (B) However, embryos exposed to $10 \mathrm{nmol}$ $\mathrm{1}^{-1}$ were not able to develop past WS 36, while those exposed to $100 \mathrm{nmol}^{-1}$ were all able to develop continuously to completion of development at WS 43. 
Next, we evaluated if blocking vitamin $\mathrm{D}_{3}$ synthesis by inhibiting CYP27A1, the main enzyme responsible for the production of 25-OHVitD 3 (Luciani et al., 2011) could inhibit exit from diapause. Diapause II embryos exposed to $20 \mu \mathrm{mol} \mathrm{l^{-1 }}$ dafadine A in the presence of $100 \mathrm{nmol}^{-1} 7-\mathrm{DHC}$ at $25^{\circ} \mathrm{C}(\mathrm{n}=12$, each $)$ exited diapause at rates similar to that of controls and those treated with 7-DHC (Fig 3.3A,B). While the addition of dafadine A did not significantly alter the probability of embryos exiting DII, embryos were not able to develop beyond WS 36. Heart rates of individual embryos were recorded each day to characterize the relationship between heart rate and exit from diapause II. Most embryos exposed to 7-DHC exhibit an increase in heart rate several days before morphological development advances enough to recognize active development (Fig 3.3C, left 2 columns). Exposure to dafadine A tended to reduce heart rate and blunted the increase in heart rate that precedes exit from diapause II (Fig 3.3C, right 2 columns). 


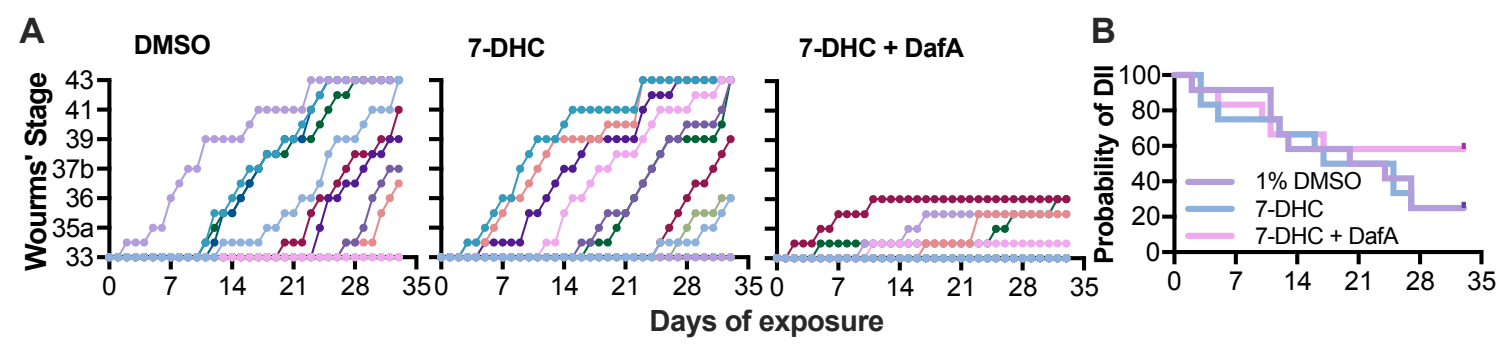

C
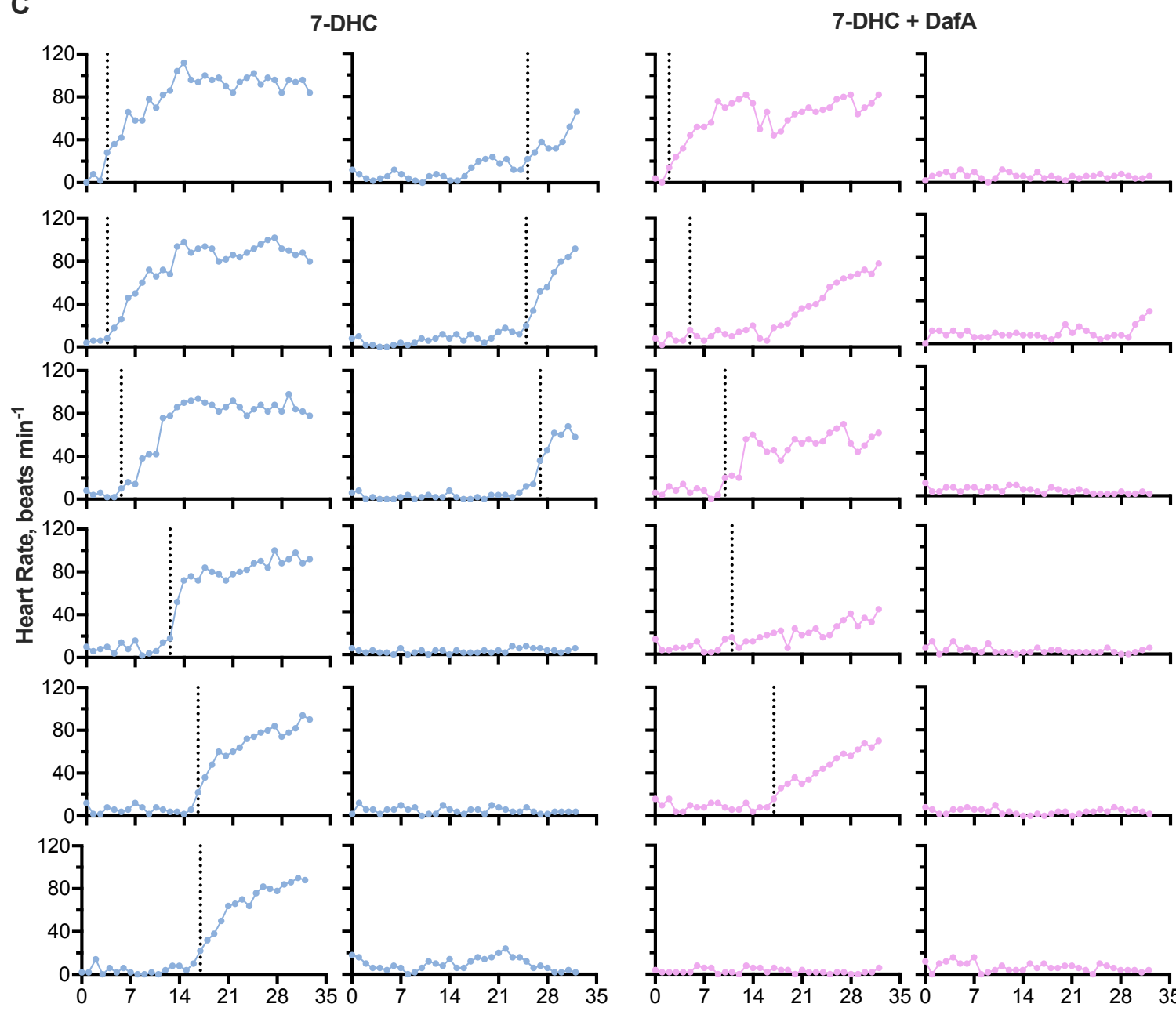

Days of exposure

Figure 3.3. Effect of continuous incubation in 7-dehydrocholesterol and dafadine $A$ on exit from diapause in Austrofundulus limnaeus embryos at $25^{\circ} \mathrm{C}$. (A) Line plots of individual embryos exiting diapause II in the presence of $100 \mathrm{nmol}^{-1} 7$-DHC or 100 nmol 1-1 7 -DHC $+20 \mu \mathrm{mol} \mathrm{l}^{-1}$ dafadine A (DafA) tracked over time ( $\mathrm{n}=12$ per group). Each embryo is represented by a different color. (B) The probability of exiting diapause II is not affected by exposure to 7-DHC or 7-DHC and DafA. However, those embryos that exit diapause do not progress past WS 36 (early organogenesis) in the presence of DafA. (C) An increase in heart rate precedes morphological developmental changes in embryos exiting DII at $25^{\circ} \mathrm{C}$. This response is muted in embryos treated with dafadine $\mathrm{A}$. 
Each panel is an individual embryo. Dashed vertical lines indicate the first day that the embryo was staged as post-diapause II, and individual embryo graphs are organized in chronological order for when the embryo first exited diapause II. Panels without dashed lines are embryos that remained in diapause II during the entire period of observation.

Inhibition of HSPs alters efficacy of $1,25(\mathrm{OH})_{2} \mathrm{VitD}_{3}$ in promoting exit from diapause II

Prior work showing that increased temperature and exposure to light can speed exit from diapause II (Meller et al., 2012) led us to test if inhibition of heat shock protein activity would alter exit from diapause in response to elevated temperatures $\left(30^{\circ} \mathrm{C}\right)$ or in the presence of $100 \mathrm{nmol}^{-1} 1,25(\mathrm{OH})_{2} \mathrm{VitD}_{3}$ at $25^{\circ} \mathrm{C}$. Inhibition of HSC/HSP70 with 150 $\mu \mathrm{mol} \mathrm{1^{-1 }}$ VER155008 or inhibition of HSP90 with $200 \mu \mathrm{mol}^{-1}$ ganetespib had no effect on exit from diapause II induced by transfer of embryos to $30^{\circ} \mathrm{C}$ (Fig 3.4), and in fact embryos developed normally in the presence of both inhibitors at $30^{\circ} \mathrm{C}$. At $25^{\circ} \mathrm{C}$, inhibition of heat shock proteins did not affect exit from diapause II (Fig 3.4A; survival analysis, $\mathrm{P}>0.99$ for VER155008, $\mathrm{P}=0.51$ for ganetespib). However, inhibition of $\mathrm{HSC} / \mathrm{HSP} 70$ in the presence of $100 \mathrm{nmol}^{-1} 1,25(\mathrm{OH})_{2} \mathrm{VitD}_{3}$ caused immediate exit from diapause II and accelerated the rate of development (Fig 3.4A,B; survival analysis, $\mathrm{P}<$ 0.001). However, these embryos developed abnormally. Conversely, inhibition of HSP90 in the presence of $1,25(\mathrm{OH})_{2} \mathrm{VitD}_{3}$ significantly reduced the probability that embryos would exit diapause II (Fig 3.4A,B; survival analysis, $\mathrm{P}<0.001$ ). While many of these embryos did eventually exit from diapause during the trial, they either developed very slowly, or failed to develop past the initial post-diapause II stage (WS 34). 


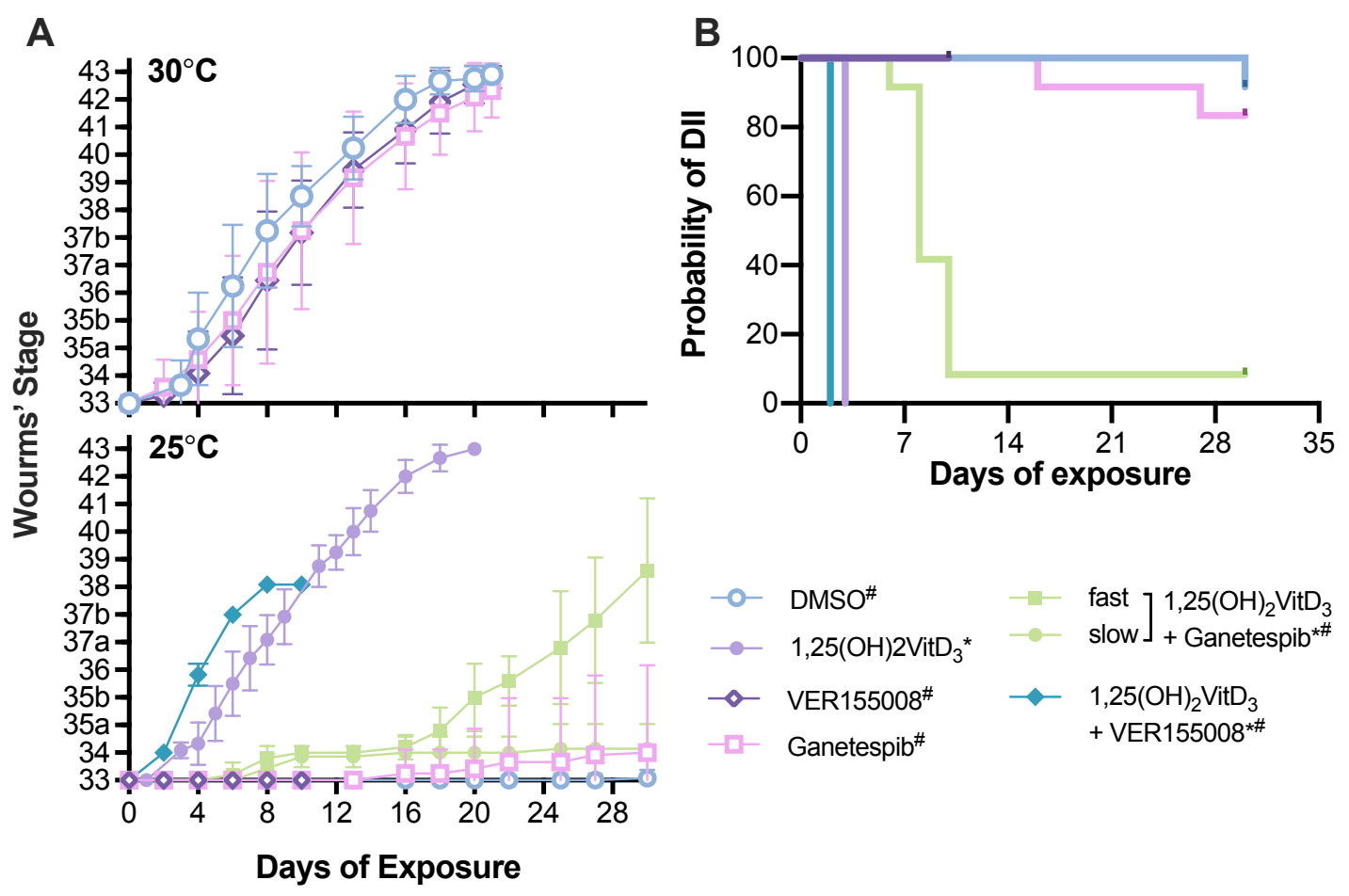

Figure 3.4. The effect of heat shock protein inhibition on exit from diapause II in embryos of Austrofundulus limnaeus. (A, Top) Inhibition of HSC/HSP70 activity with $150 \mu \mathrm{mol} \mathrm{l^{-1 }}$ VER155008 or HSP90 activity with $200 \mu \mathrm{mol} \mathrm{l}^{-1}$ ganetespib has no effect on the exit of embryos from diapause II induced by transfer from 25 to $30^{\circ} \mathrm{C}$. (A, Bottom) At $25^{\circ} \mathrm{C}$ inhibition of HSC/HSP70 in the presence of $100 \mathrm{nmol} \mathrm{l}^{-1}$ $1,25(\mathrm{OH})_{2} \mathrm{VitD}_{3}$ increased the rate of exit from diapause II induced by $1,25(\mathrm{OH})_{2} \mathrm{VitD}_{3}$ while inhibition of HSP90 blocks the ability of $1,25(\mathrm{OH})_{2} \mathrm{VitD}_{3}$ to induce exit from diapause II. Over time some embryos exposed to ganetespib do break diapause and resume development at a considerably slower rate than those exposed to $1,25(\mathrm{OH})_{2} \mathrm{VitD}_{3}$. Interestingly, embryos that break diapause II in the presence of HSP90 inhibitor either stop developing almost immediately (at WS 34, labeled slow) or slowly progress through development at variable rates (labeled fast). Exposure to either HSP inhibitor alone has no apparent effect on exit of embryos from diapause II at $25^{\circ} \mathrm{C}$. Symbols are means \pm $\mathrm{SD} ; \mathrm{n}=12$. (B) Survival analysis supports a significant effect of HSC/HSP70 inhibition and HSP90 inhibition on the ability of $1,25(\mathrm{OH})_{2} \mathrm{VitD}_{3}$ to induce exit from diapause II at $25^{\circ} \mathrm{C}$ (Survival analysis, $\mathrm{P}<0.001$, treatments with an asterisk are different from controls, those with a hashtag are different from the $1,25(\mathrm{OH})_{2} \mathrm{VitD}_{3}$ treatment).

DNA methylation is altered by treatment with $1,25(\mathrm{OH})_{2} \mathrm{VitD}_{3}$

The vitamin D receptor is known to interact with a number of chromatin modifying enzymes including DNA methyltransferases (Fetahu et al., 2014). To gain 
insight into possible changes in DNA methylation associated with exit from DII induced by $1,25(\mathrm{OH})_{2} \mathrm{VitD}_{3}$, embryos were exposed to $10 \mathrm{nmol} \mathrm{l}^{-1} 1,25(\mathrm{OH})_{2} \mathrm{VitD}_{3}$ for 2.5 days. This short incubation of low concentration $1,25(\mathrm{OH})_{2} \mathrm{VitD}_{3}$ was used to highlight those early changes in DNA methylation likely specific to exit from diapause rather than those associated with resumption of active embryonic development. Analysis of the RRBS sequencing data resulted in the identification of 258 DMRs, of which 51 were hypomethylated and 207 were hypermethylated in DII embryos exposed to $10 \mathrm{nmol} \mathrm{1}^{-1}$ $1,25(\mathrm{OH})_{2} \mathrm{VitD}_{3}(\mathrm{Fig} 3.5 \mathrm{~A})$. Introns are the genomic element with the highest representation in both hypo- and hypermethylated groups (Fig 3.5B). Many of the DMRs overlapped with more than one genomic element, and about $30 \%$ of the hypermethylated and $22 \%$ of the hypomethylated regions include a unique promotor annotation (Fig $3.5 \mathrm{~B}, \mathrm{C})$.

The DMRs with the largest change in methylation after treatment with $1,25(\mathrm{OH})_{2} \mathrm{VitD}_{3}$, reported as percent methylation difference, are presented in Figure 3.6. Hypomethylation refers to a decrease in methylation after treatment while hypermethylation refers to a responding increase in methylation. The largest increase in hypermethylation was observed to overlap with two genes involved in regulating endocytosis and endosome recycling, micall 1 a and rabep 1, respectively. Also included amongst the highest levels of hypermethylation are a gene for a nuclear envelope protein (lamin B1), and a DMR that contains both a chaperone for mitochondrial heat shock protein 70 (dnlz1) and a nucleoside metabolism enzyme (uck1). Also of interest in the top 20 hypermethylated regions are genes involved in regulation of translation and apoptosis (eif5A1-like) and regulation of zinc finger transcription factors (id2). The regions with 
the largest decrease in methylation contain a gene for a zinc importer (scl39a1) and an mRNA binding protein (cpeb3).
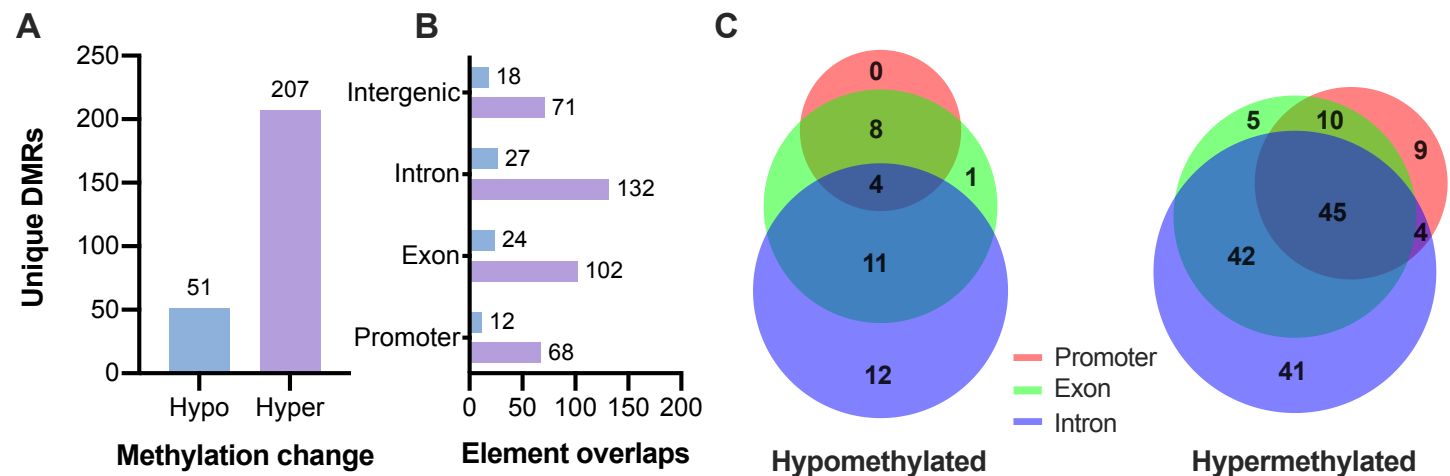

Figure 3.5. Summary of differentially methylated regions (DMRs) in diapause II embryos treated with $\left.10 \mathrm{nmol} \mathrm{l}^{-1} \mathbf{1 , 2 5 ( O H}\right)_{2} V_{\text {VitD }}$. (A) A total of 258 unique differentially methylated regions were identified. Most DMRs were hypermethylated in response to $1,25(\mathrm{OH})_{2} \mathrm{VitD}_{3}$. (B) The overlap of DMRs with annotated genomic elements indicates that most overlap with introns. (C) A significant number of the DMRs overlapped with multiple genomic elements. 


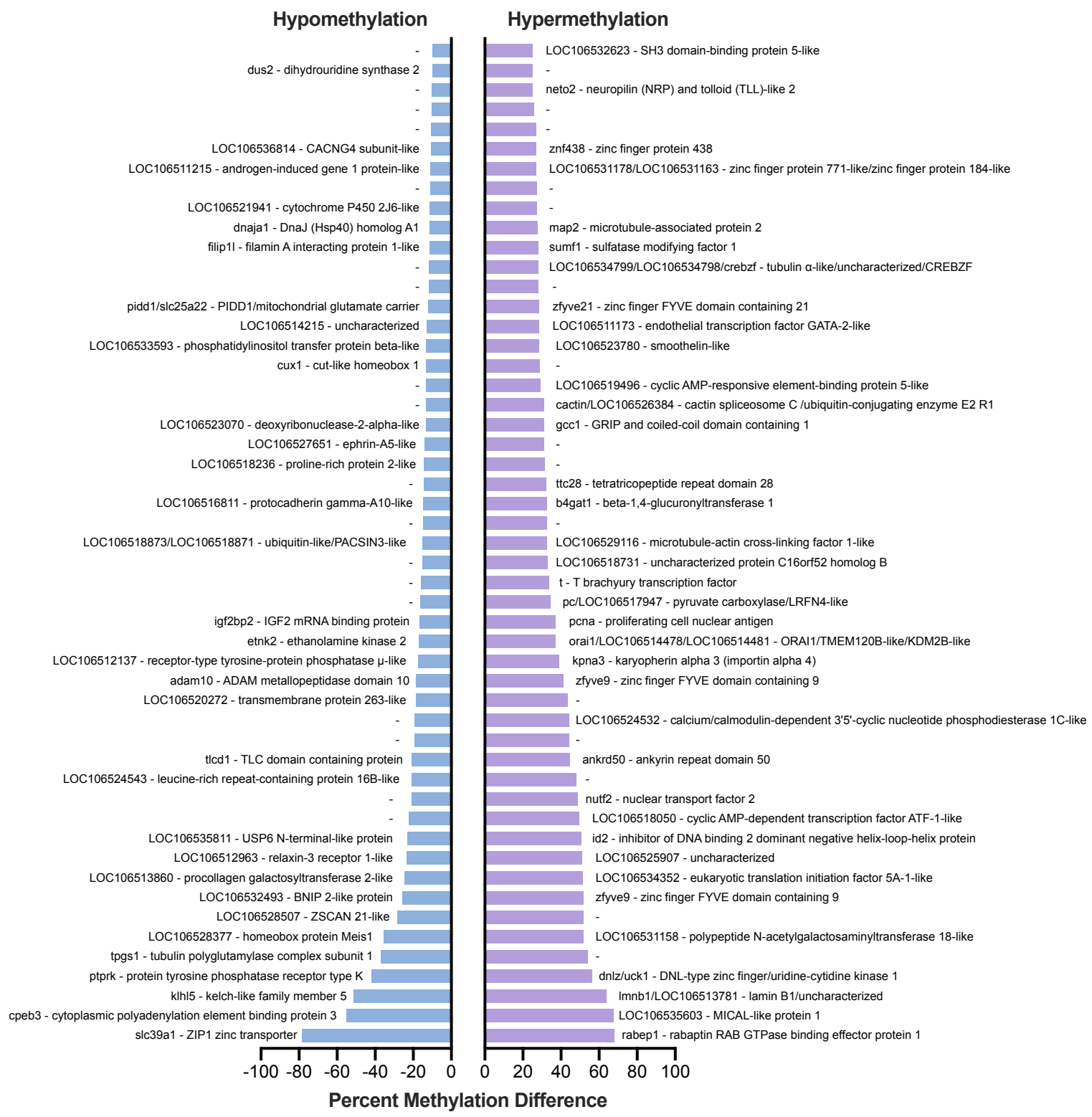

Figure 3.6. The top 51 hypo- and hypermethylated DMRs. Gene symbols or descriptions are provided for DMRs that overlapped with promoters, introns, or exons. DMRs that did not overlap with annotated regions of the genome are considered intergenic and are marked with a dash (-). For DMRs that overlap multiple genes, all genes are listed and separated by a forward slash (/).

\section{Gene Ontology of hypermethylated DMRs}


Gene ontology analysis using all genic elements (Fig 3.7) that overlapped with regions of hypermethylation reveals enrichment in 79 biological process GO terms including many with developmental roles, especially those associated with the nervous system (e.g. axon extension, glial cell development). There are also several terms involving immune cell function (e.g. peripheral $\mathrm{T}$ cell tolerance induction, positive regulation of neutrophil chemotaxis). These processes are associated with several aspects of cytoskeletal features, nerve axons, mitochondria, and the nucleus. Calcium binding is the most enriched molecular function, followed by binding to several cytoskeletal elements. Interestingly, most of the enriched GO terms of the hypermethylated regions for all genic elements indicated in Fig 3.7 are associated with only a handful of genes including: members of the protocadherin family (3), kinesin family members (2), and the Ephrin B4 receptor.

If the gene ontology analysis is limited to only those DMRs that overlap with promoters, a slightly different picture arises (Fig 3.8). The most significantly enriched GO terms are associated with regulation of insulin receptor signaling, endothelial cell proliferation, and glycogen metabolism. These processes are associated with several components of the nucleus, cytoskeleton, and mitochondrion. Their molecular functions are diverse. The enriched GO terms in hypermethylated promoters are associated mainly with the function of four genes: igf2, id2, pcna, and T-brachyury. 


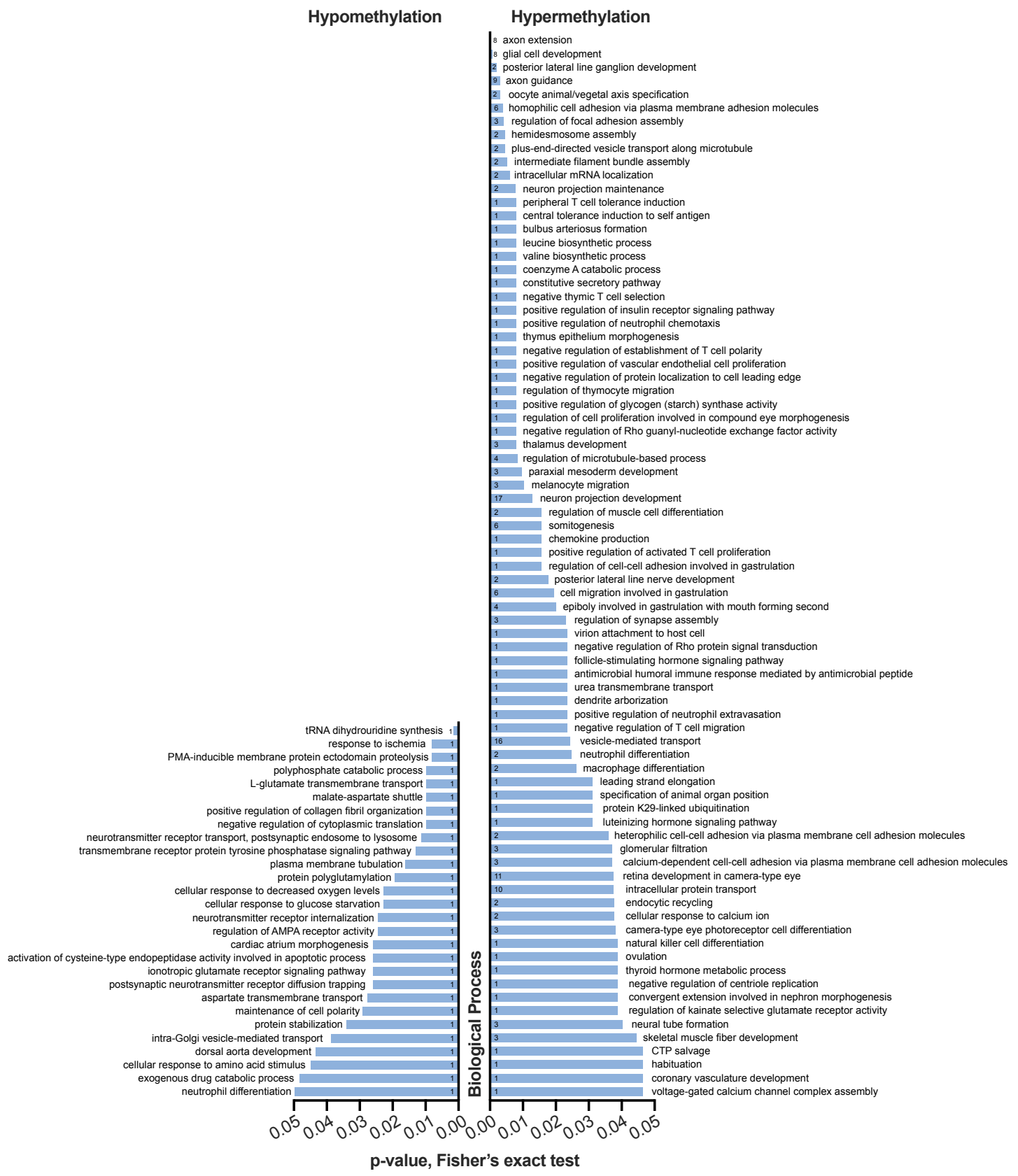




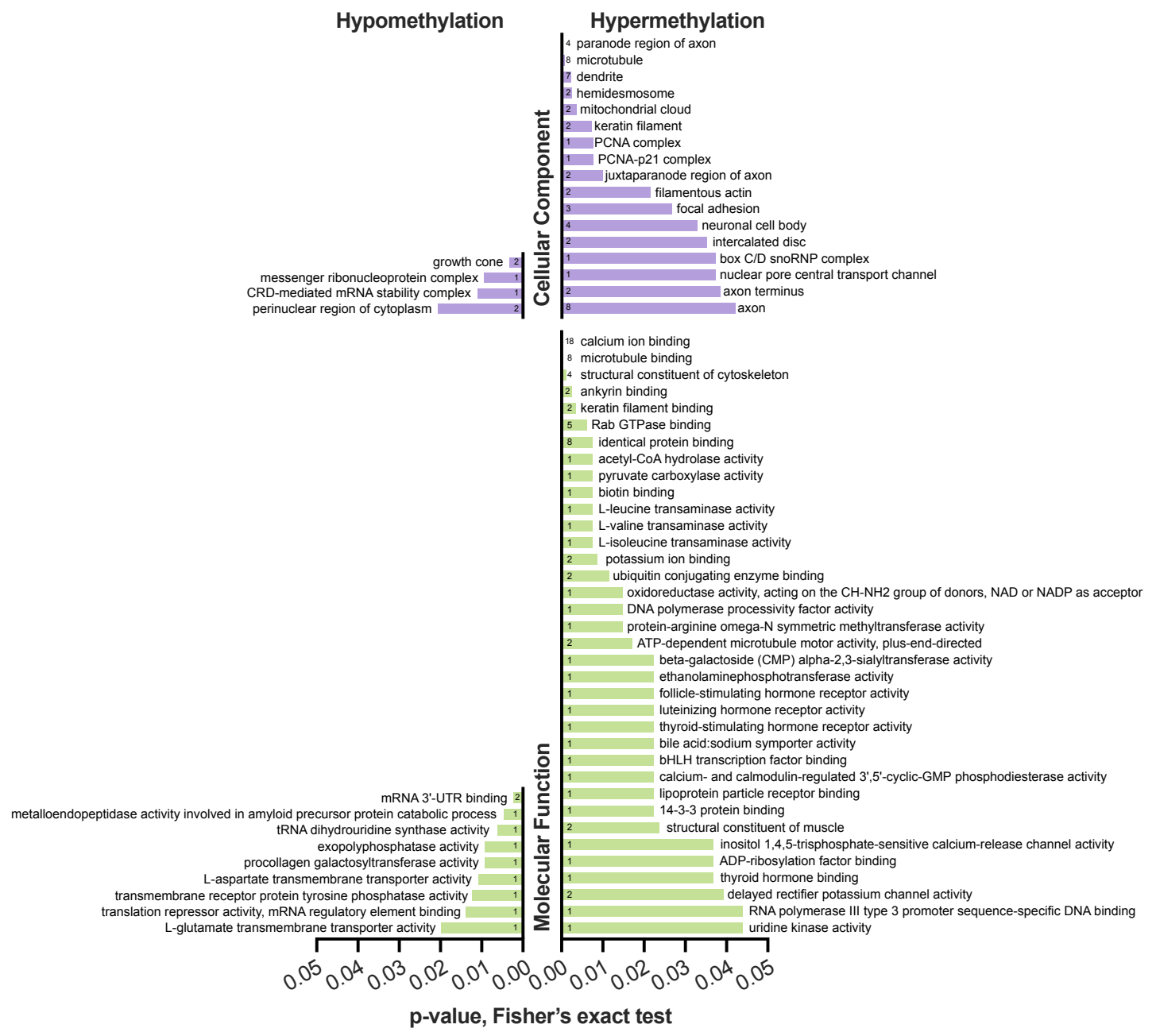

Figure 3.7. Gene ontology analysis of differentially methylated regions in response to $1,25(\mathrm{OH})_{2} \mathrm{VitD}_{3}$ that were associated with annotated genic elements in the genome of Austrofundulus limnaeus. GO term enrichment highlights a number of developmental and physiological processes that may be regulated by the vitamin D receptor upon exit from diapause II. Graphs of p-values for each GO term are separated by biological processes (blue), cellular components (purple) and molecular function (green). Numbers at the base of the bars indicate the number of genes represented in the DMR data that map to that specific GO term. 
Hypomethylation

response to ischemia polyphosphate catabolic process L-glutamate transmembrane transport
malate-aspartate shuttle negative regulation of cytoplasmic translation plasma membrane tubulation protein polyglutamylation cellular response to decreased oxygen levels cellular response to glucose starvation ionotropic glutamate receptor signaling pathway aspartate transmembrane transport cellular response to amino acid stimulus negative regulation of neuron apoptotic process regulation of endocytosis

\section{Hypermethylation}

1 positive regulation of insulin receptor signaling pathway

1 positive regulation of vascular endothelial cell proliferation

1 positive regulation of glycogen (starch) synthase activity

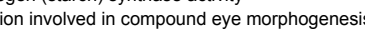

1 positive regulation of activated T cell proliferation

1 regulation of cell-cell adhesion involved in gastrulation

1 urea transmembrane transport

$1 \quad$ leading strand elongation

1 specification of animal organ position

$1 \quad$ thyroid hormone metabolic process

1 negative regulation of centriole replication

$1 \quad$ CTP salvage

ation complex assembly

RNA polymerase III prein
hepatocyte proliferation

1 regulation of cell aging

UMP salvage

$1 \quad$ positive regulation of ubiquitin-protein transferase activity

$\begin{array}{ll}1 & \text { cell projection morphogenesis }\end{array}$

translational initiation

translational initiation
store-operated calcium entry

1 store-operated calcium entry

anterior/posterior axis specification, embryo

notochord formation

regulation of photoreceptor cell differentiation

NLS-bearing protein import into nucleus

intra-S DNA damage checkpoint

1 determination of left/right asymmetry in diencephalon

1. oocyte animal/vegetal axis specification

bile acid and bile salt transport

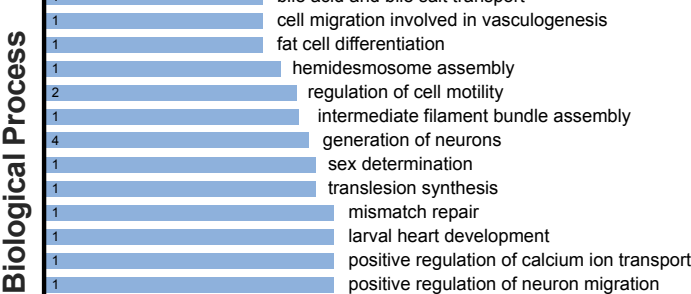

1 PCNA complex

PCNA-p21 complex

box C/D snoRNP complex

transcription factor TFIIIB complex

mRNA cap binding complex secretory granule membran

eukaryotic translation initiation factor $4 \mathrm{~F}$ complex

nuclear envelope

hemidesmosom
microtubule

messenger ribonucleoprotein complex growth cone dendritic spine 
Figure 3.8. Enriched Gene Ontology terms for DMRs that overlapped with annotated promoter regions in the Austrofundulus limnaeus genome.

Hypermethylated promoter region GO terms were dominated by igf 2 , id 2 , pcna, and $\mathrm{t}$ (brachyury) annotations. Hypomethylated promoter GO terms were almost exclusively associated with cpeb3, slc25a22, and bnipl. Graphs of p-values for each GO term are separated by biological processes (blue), cellular components (purple) and molecular function (green). Numbers at the base of the bars indicate the number of genes represented in the DMR data that map to that specific GO term.

\section{Gene ontology of hypomethylated regions}

There were 28 biological process GO terms associated with hypomethylation in response to $1,25(\mathrm{OH})_{2} \mathrm{VitD}_{3}(\mathrm{Fig} 3.7)$. Of note among these are tRNA modification, response to ischemia, polyphosphate metabolism, amino acid transport, response to decreased oxygen and glucose starvation, endocytosis, negative regulation of translation, and organization of the extracellular matrix. These processes are associated with neuronal growth cones, mRNA ribonuclear complexes, and the perinuclear cytoplasm. Enriched molecular function GO terms include mRNA 3-UTR binding, extracellular matrix modifying activities, and tRNA modification. Most of these GO terms are associated with the function of four gene: cpeb3 (6), cacng4 (4), meis1 (4), and slc39a1(3).

Hypomethylated promoter regions are associated with GO terms that are similar to those when all genic elements are included in the analysis (Fig 3.8). Importantly, almost all of these GO terms are associated with only 3 gene promoters: cpeb3, slc25a22, and a bnip1-like gene.

\section{Discussion}

Vitamin $D_{3}$ metabolites initiate and regulate exit from diapause II 
Exposure of diapause II embryos to hydroxylated forms of vitamin $\mathrm{D}_{3}$ promotes exit from DII. The first overt sign of exit from DII is a pronounced increase in heart rate followed closely by resumption of morphological development. Interestingly, a concentration of $10 \mathrm{nmol} \mathrm{l}^{-1}$ took longer to reach full effect (4 vs $2 \mathrm{~d}$ for $100 \mathrm{nmol} \mathrm{l}^{-1}$ ) and these embryos were not able to develop past early organogenesis (Podrabsky et al., 2017). This result parallels the phenotype of some embryos exposed to dafadine A to block vitamin $\mathrm{D}_{3}$ synthesis found in Ch 2 (Fig 2.1; Romney et al., 2018). In combination, these data suggest that a lower threshold concentration of $1,25(\mathrm{OH})_{2} \mathrm{VitD}_{3}$ is required to initiate exit from diapause, while a higher concentration may be needed to sustain active growth and development. This idea of higher metabolite levels perpetuating growth is consistent with the results of a large-scale human study, where low levels of circulating $25(\mathrm{OH}) \mathrm{D}_{3}$ during the second trimester were associated with lower rates of fetal growth in the third trimester (Miliku et al., 2016). Low levels of vitamin $\mathrm{D}_{3}$ are also thought to impact early organogenesis in humans (Gluckman et al., 2008) consistent with our observations in $A$. limnaeus.

In contrast to the hydroxylated forms of vitamin $\mathrm{D}_{3}, 7$-DHC and vitamin $\mathrm{D}_{3}$ itself were not effective at speeding exit from diapause at the concentrations used in this study. We had hypothesized that these forms of vitamin $\mathrm{D}_{3}$ would also induce exit from diapause. There does appear to be a pattern of increasing effect as the products along the biosynthetic pathway approach the $1,25(\mathrm{OH})_{2} \mathrm{VitD}_{3}$. It is possible that the hydroxylase enzymes needed for production of $1,25(\mathrm{OH})_{2} \mathrm{VitD}_{3}$ are not highly expressed or active during diapause II, or that the levels of precursors used in these experiments were not high enough to produce effective concentrations of $1,25(\mathrm{OH})_{2} \mathrm{VitD}_{3}$. Further 
experimentation with different levels of vitamin $\mathrm{D}_{3}$ precursors and characterization of hydroxylase enzyme expression and activity are needed to address this issue.

\section{Heat shock proteins impact exit of diapause}

Heat shock proteins (HSP) 70 and 90 have active roles in embryogenesis and are normally expressed during vertebrate development (Ahn et al., 2005; Ali et al., 1996; King and MacRae, 2015; Krone et al., 1997; Podrabsky and Somero, 2007; Teixeira and Polavarapu, 2005). In isolation, inhibition of HSP function does not appear to alter the rate at which embryos exit from DII. However, there is a significant interaction between heat shock protein function and the effect of $1,25(\mathrm{OH})_{2} \mathrm{VitD}_{3}$ on exit from DII. Inhibition of HSP70 in combination with $1,25(\mathrm{OH})_{2} \mathrm{VitD}_{3}$ leads to rapid exit from diapause and accelerated development rate, while inhibition of HSP90 attenuates the action of $1,25(\mathrm{OH})_{2} \mathrm{VitD}_{3}$. These opposing effects of HSP70 and HSP90 on exit from metabolic dormancy in embryos of A. limnaeus are consistent with the literature on HSPs and the VDR (Angelo et al., 2008; Craig et al., 1999; Marcinkowska and Gocek, 2010; Swamy et al., 1999). HSC/HSP70 has been shown to directly bind with the VDR (Craig et al., 1999; Swamy et al., 1999). HSP90 is thought however, not to interact with the VDR directly, but rather to regulate the DNA binding of VDR as well as the expression of vitamin D activated genes (Angelo et al., 2008; Craig et al., 1999; Marcinkowska and Gocek, 2010). Inhibition of HSP90 significantly delays the action of $1,25(\mathrm{OH})_{2} \mathrm{VitD}_{3}$ on exit of embryos from DII, which suggests a role for HSP90 in promoting exit from DII. In Caco2 cells treated with $1,25(\mathrm{OH})_{2} \mathrm{VitD}_{3}$, inhibition of $\mathrm{HSP} 90$ with geldanamycin led to a $69 \%$ decrease in the transcript levels for CYP24, the enzyme that inactivates 
$1,25(\mathrm{OH})_{2} \mathrm{VitD}_{3}$ (Angelo et al., 2008). Further, inhibition of HSP90 lead to lower levels of VDR binding to vitamin D response elements (VDRE), specific DNA sequences in promoter regions of vitamin D targeted genes (Angelo et al., 2008). In addition, depletion of HSP90 reduced vitamin D related gene expression. Interestingly, nuclear VDR levels were not affected by inhibition or reduction of HSP90 $\beta$ activity, which suggests a role in VDR-DNA binding (Angelo et al., 2008).

The most striking result from the experiments with inhibition of HSP70, was the almost immediate release from diapause and accelerated developmental rate observed in embryos treated with $\mathrm{HSP} 70$ inhibitor and $1,25(\mathrm{OH})_{2} \mathrm{VitD}_{3}$ compared to $1,25(\mathrm{OH})_{2} \mathrm{VitD}_{3}$ alone. These data strongly suggest a role for HSP70 in promoting DII. Further, it is interesting that a normally inducible form of HSP70 is constitutively expressed in DII embryos of A. limnaeus (Podrabsky and Somero, 2007). DnaK, a member of the HSP family similar to HSP70 has been shown to bind to VDR in the hinge region of the protein between the DNA and ligand binding domains when expressed in E. coli (Swamy et al., 1999). These authors speculate this may also occur in eukaryotic cells under natural conditions and that HSP70 may play a role in directing the VDR to the nucleus (Swamy et al., 1999). It is possible that HSP70 may be opposing VDR entry into the nucleus, and thus be preventing exit from DII. This hypothesis, would be consistent with elevated temperatures accelerating exit from DII, because the increased heat stress might cause HSP70 molecules to release the VDR in preference for proteins being denatured in response to heat stress. Further exploration of this possibility is of great interest and would allow for another mechanism for temperature to be integrated into the developmental program of annual killifishes. 
There are many parallels with respect to HSP expression and function between exit from diapause in A. limnaeus and the flesh fly Sarcophaga bullata pupae. In $S$. bullata, exit from diapause is thought to include the ecdysone signaling pathway, a NR in the same subfamily as the VDR (Rinehart and Denlinger, 2000; Thomson et al., 2009). Interestingly, hsp70 transcripts were down-regulated $7 \mathrm{~h}$ and hsp90 transcripts upregulated $12 \mathrm{~h}$ after exit from diapause induced by hexane in S. bullata (Rinehart and Denlinger, 2000; Rinehart et al., 2000; Yocum et al., 1998). Further, genes for the ecdysone receptor, EcR and USP, increased in expression 1 hour and 9 hours after exposure, respectively, potentially indicating that the EcR is activated very early in diapause breakage (Rinehart et al., 2001). These data suggest striking parallels between ecdysone signaling and vitamin $\mathrm{D}_{3}$ signaling with a similar role for HSPs in insects and killifish embryos during exit from metabolic dormancy.

\section{Epigenetic regulation of exit from diapause}

The role of DNA methylation in the regulation of gene expression is complex. Initially, methylation was thought to be associated with gene silencing, but it is now well appreciated that it plays a multifaceted role in the regulation of gene expression (Bogdanovic and Gómez-Skarmeta, 2013; Keller et al., 2016; Muers, 2013; Varriale, 2014). For example, methylation of the first exon or intron may be more predictive of gene silencing than the methylation status of the promoter (Anastasiadi et al., 2018; Angeloni and Bogdanovic, 2019; Keller et al., 2016; Schmitz et al., 2019; Zhang et al., 2019). Further, increased methylation of exons may be associated with regulation of alternative splicing rather than gene silencing (Shayevitch et al., 2018). Also, what 
applies to mammalian systems, does not always apply to other groups of organisms including teleosts (Fang et al., 2013; Potok et al., 2013; Schmitz et al., 2019). Thus, the following discussion of differential DNA methylation in A. limnaeus in response to low dose $1,25(\mathrm{OH})_{2} \mathrm{VitD}_{3}$ should be considered preliminary.

The importance of the epigenome in regulating gene expression and the resulting cellular and organismal phenotypes is an area of immense growth and interest. The VDR is known to interact with a number of epigenetic regulators that can alter DNA structure and function (Fetahu et al., 2014). Indeed, treatment with a low dose of $1,25(\mathrm{OH})_{2} \mathrm{VitD}_{3}$ led to significant changes in the methylation status of 258 DMRs in embryos induced to exit from diapause most of which were hypermethylated (Fig 3.5). These changes in methylation highlight some interesting molecular pathways which are described below and provide a first glimpse into the molecular processes that may play major roles in the reactivation of development following dormancy.

The majority of the most hypermethylated regions of DNA in response to $1,25(\mathrm{OH})_{2} \mathrm{VitD}_{3}$ exposure are 5 ' regions of genes that include regions of the promoter and the first exon and intron. Therefore, these regions are likely to lead to reduction in the expression of these genes during exit from diapause II (Anastasiadi et al., 2018; Angeloni and Bogdanovic, 2019; Keller et al., 2016). The two most hypermethylated regions include genes involved in endocytosis and endosome recycling. This may suggest the need for membrane restructuring, or perhaps the recycling of membrane transporters and extracellular receptors that are critical for maintaining diapause or diapause-associated phenotypes. For example, the importance of IGF signaling in regulating A. limnaeus diapause has been reported (Woll and Podrabsky, 2017) and altered shuttling of IGF 
receptors to the plasma membrane may be an area to explore further in light of these hypermethylation data.

Lamin B1, a gene that encodes for a protein that contributes to the nuclear lamina, was also hypermethylated. Lamin B1 protein supports nuclear envelope structure, but is also involved in the formation and regulation of facultative heterochromatin regions regulated by histone methylation variants as well as regulating gene expression and gene splicing (Camps et al., 2015). Previous work in A. limnaeus has shown regions of chromatin that stain for histone H3 that has been dimethylated at lysine 27 (H3k27me2) are associated with the inner surface of the nuclear envelope (Toni and Padilla, 2016). Interestingly, this histone modification is associated with the polycomb gene regulatory complex that is known to be associated with maintenance of diapause in the African annual killifish Nothobranchius furzeri (Hu et al., 2020). This connection suggests a potential role for lamin b1 proteins (or protein variants) in the regulation of chromatin structure and gene expression in exit from diapause in A. limnaeus.

Dnlz1, a gene which codes for a chaperone of a mitochondrial HSP70 protein (HSPA9), was hypermethylated in response to treatment with $1,25(\mathrm{OH})_{2} \mathrm{VitD}_{3}$. DNLZ interacts with HSPA9 and positively regulates its chaperone function, catalytic activity and solubility (Vu et al., 2012). Interestingly, DNLZ contains a zinc-binding subdomain (ZBS) which has proven vital for proper complex formation with the HSPA9 ATPase domain. Thus, the hypomethylation of a zinc importer in response to $1,25(\mathrm{OH})_{2} \mathrm{VitD}_{3}$ (see below) may suggest regulation of DNLZ1 in association with exit from diapause II. Given the fact that HSP70 inhibition accelerates exit from diapause II, this connection 
between zinc, HSP70 function and exit from diapause is intriguing and deserves future attention.

Another hypermethylated gene, id2, codes for a zinc finger transcription factor regulator that binds to and suppresses the activity of a wide range of transcription factors (Chen et al., 2012) and supports cell proliferation through inactivation of the retinoblastoma protein (Lasorella et al., 2000). Regulation of the cell cycle and cell differentiation is very likely to be key to exit from diapause II, and thus exploring the function of ID2 protein in embryos of A. limnaeus could represent a "global" mechanism for preventing transcription factor binding and inhibiting development associated with diapause.

Gene ontology analyses of hypermethylated regions in response to $1,25(\mathrm{OH})_{2} \mathrm{VitD}_{3}$ treated diapause embryos produced results logical for the breakage of diapause and onset of active development. These included biological processes associated with development of the nervous system, cell migration, and immune cell function. During the initial two stages post-diapause in A. limnaeus, Wourms' stage (WS 34 and 35a), the embryonic axis lengthens and the head enlarges as the brain folds increase (Podrabsky et al., 2017). These early phenotypic changes would most definitely require activation of brain development and cell migration. These GO terms are dominated by a small number of gene identities, including igf $2, \mathrm{id} 2$ and pena. Of special interest in this group is the gene for insulin-like growth factor 2 , as this signaling pathway is known to be critical for regulation of diapause in a variety of systems including A. limnaeus (Altintas et al., 2016; Sim and Denlinger, 2013; Snell-Rood and Moczek, 2012; Woll and Podrabsky, 2017). 
Far fewer areas of hypomethylation were identified in response to treatment with $1,25(\mathrm{OH})_{2} \mathrm{VitD}_{3}$. The regions that experienced the largest decrease in DNA methylation include elements of genes for a zinc transporter (slc39a1) and an mRNA binding protein (cpeb3). Both of these genes have functions that are of great interest with respect to diapause, especially cpeb3. CPEB3 can bind to mRNAs and regulate their stability and translation (Ford et al., 2019; Pavlopoulos et al., 2011). Through activation by neuralized1, cpeb3 in mammals has been shown to impact synaptic plasticity and longterm memory (Pavlopoulos et al., 2011). Thus, it is possible that cpeb3 is important in the regulation of synapse formation and development of the nervous system in post-DII embryos.

The GO terms associated with hypomethylated regions are dominated by the function of cpeb3, the amino acid transporter slc25a22, and bnip1. These terms are associated with potential stress-resistance pathways such a: response to decreased oxygen and glucose starvation, negative regulation of translation, and response to ischemia. If hypomethylation leads to gene activation, then it is possible that these genes are critical in regulating the extreme stress tolerance associated with diapause and this possibility is worth pursuing. Amino acid transport, polyphosphate metabolism and tRNA modification are also functions associated with hypomethylation. There is some evidence for tRNA accumulation in the nucleus during diapause onset in Artemia which could be relevant in A. limnaeus diapause (Chen et al., 2016a). Of these genes, the best described is $\operatorname{slc} 25 a 22$, a gene that encodes for a mitochondrial glutamate carrier. Glutamate is the most abundant amino acid in A. limnaeus diapause II embryos and is consumed when embryos are exposed to anoxia (Podrabsky et al., 1998; Podrabsky et al., 2007). Further, 
slc25a22 repression by miR-184 is a mechanism that regulates insulin secretion in human cells and may play a role in insulin signaling and distribution in A. limnaeus embryos during diapause (Morita et al., 2013; Woll and Podrabsky, 2017).

The importance of zinc in the function of genes from several of the differentially methylated regions is interesting and deserves future attention. Zinc is known to be critical in the function of many cellular processes, especially in regulation of gene expression through chromatin modification and transcription control (Falchuk, 1998). However, the role of zinc in normal cellular physiology has received relatively little attention compared to other metals and divalent cations. It is possible that limiting zinc levels within cells is a global mechanism for inhibiting key regulatory functions associated with cell growth and proliferation (Vallee and Falchuk, 1981). This possibility, and the specific role of zinc in the regulation of diapause is a topic that should be explored in future studies.

\section{Conclusion}

This study reports that the vitamin $\mathrm{D}_{3}$ signaling is important for promoting exit from diapause in A. limnaeus. Further, the heat shock proteins HSP70 and HSP90 appear to be involved in signaling the exit from diapause in a manner that is consistent with findings in insect diapause and that provide another mechanism for temperature to affect exit from diapause. Lastly, a number of candidate genes that appear to be differentially methylated in response to $1,25(\mathrm{OH})_{2} \mathrm{VitD}_{3}$ exposure have been identified that suggest epigenetic regulation of gene expression is key to the regulation of diapause in $A$.

\section{limnaeus.}




\section{CHAPTER 4:}

\section{Hormone cell signaling to regulate embryonic life history}

In this study, we primarily used a pharmacological approach to explore the potential role(s) of various signaling pathways for the incorporation of environmental signals into the developmental program of Austrofundulus limnaeus. The data presented in this thesis support a key primary role of vitamin $\mathrm{D}_{3}$ signaling in regulating entrance into and exit from diapause. This finding is integral to understanding this species' ability to alter life history programming through interpretation of environmental information. Further, the induced diapause-like state in Danio rerio embryos and ability of dafachronic acids alter development in A. limnaeus suggest that metazoans may employ similar mechanisms that rely on nuclear hormone receptors to regulate developmental dormancy.

Arguably, the most exciting outcome of this thesis is the finding that the vitamin $\mathrm{D}_{3}$ pathway can regulate developmental progression based on temperature and light information from the environment. This molecular mechanism of regulating diapause entry and exit has been unknown to researchers and speculated for some time (Hand et al., 2016). Increasing light and temperature are cues that likely relate to the drying of an ephemeral pond and are the proposed signals that annual killifishes use to enact a phenotypic trajectory decision during embryonic development (Furness et al., 2015a; Hull, 1986; Markofsky and Matias, 1977). This idea is consistent with findings presented in this thesis that the vitamin $\mathrm{D}_{3}$ pathway acts as a mechanism of connecting light and temperature cues to developmental phenotype. 
Nuclear hormone receptors and regulation of metazoan development.

Results from this thesis suggest a vital importance for vitamin $\mathrm{D}_{3}$ signaling in normal teleost development. Inhibition of vitamin $\mathrm{D}_{3}$ synthesis induces a diapause-like state in $D$. rerio embryos - a species that does not typically experience diapause. This suggests a role for vitamin $\mathrm{D}_{3}$ signaling in the regulation of developmental rate/progression and the existence of key developmental checkpoints in a variety of fish species. Further exploration of the vitamin $\mathrm{D}_{3}$ signaling pathway may lead to a better understanding of developmental rate and checkpoints in vertebrates. Future studies should attempt to induce a diapause-like state via pharmacological exposures in nonannual killifish as well as other vertebrate embryos that do not experience diapause. These studies will be crucial to test the extent of which vitamin $\mathrm{D}_{3}$ signaling is vital for normal vertebrate development.

The work in this thesis points to a possible connection between 7dehydrocholesterol (7-DHC) derived signaling molecules and the regulation of complex life histories in animals. This study, and work by others in C. elegans and Drosophila reveal parallel mechanisms for the regulation of development via nuclear hormone receptors and their respective 7-DHC-derived ligands (Antebi et al., 2000; Arbeitman and Hogness, 2000). If additional studies confirm these similarities, then it may be possible to trace the evolution of metabolic dormancy through these closely-related nuclear hormone receptors and their respective ligands. This idea deserves further exploration.

Epigenetics and vitamin $D_{3}$ signaling 
Data presented in this thesis suggests a link between vitamin $\mathrm{D}_{3}$ signaling and epigenetic regulation of gene expression associated with exit from diapause. This is consistent with the known interaction of the vitamin D receptor with a wide variety of proteins involved in epigenetic modification of histones and DNA (An et al., 2010; Fetahu et al., 2014; Marcinkowska and Gocek, 2010; Salehi-Tabar et al., 2012; Swamy et al., 1999). Thus, our study adds another dimension to the accumulating evidence that epigenetic processes regulate biological responses to environmental cues, such as parental-to-offspring communication about the developmental environment in which they are entering (Autran et al., 2011; Delaval and Feil, 2004; Flatscher et al., 2012; Flores et al., 2013; Perez and Lehner, 2019; Zhou et al., 2017).

While pharmacological exposures targeting the vitamin $\mathrm{D}_{3}$ and related pathways provide a conceptual framework for metabolic dormancy in this species, exploring epigenetic pathways may help to highlight specific molecular events that are put into place in response to vitamin $\mathrm{D}_{3}$ signaling. To explore the interface of the vitamin $\mathrm{D}_{3}$ pathway and epigenetic machinery in A. limnaeus diapause, we utilized reduced representation bisulfite sequencing (RRBS; Meissner et al., 2005). Using this approach, a number of genic regions were identified as differentially methylated in response to exogenous $1,25(\mathrm{OH})_{2} \mathrm{VitD}_{3}$ treatment. Included in this list are genes shown to have important roles in A. limnaeus diapause already, including insulin-like signaling, heat shock proteins, heterochromatin formation and maintenance, and glutamate metabolism (Podrabsky et al., 1998; Podrabsky et al., 2007; Podrabsky and Somero, 2007; Toni and Padilla, 2016; Woll and Podrabsky, 2017). One gene that appears to be highly differentially methylated in response to exposure to vitamin $\mathrm{D}_{3}$ is a major cytoplasmic 
zinc transporter. Zinc deficiency is known to reduce growth in humans, and given the ability of zinc to regulate gene expression as a cofactor for a variety of proteins such as zinc finger transcription factors and nucleases, this connection between vitamin $\mathrm{D}_{3}$ signaling and zinc transport deserves further attention (Chen et al., 2012; Falchuk, 1998; Prasad, 2013; Vallee and Falchuk, 1981).

Additional experimentation is needed to fully understand the importance of epigenetic alterations in DNA in response to vitamin $\mathrm{D}_{3}$ signaling. Foremost, endogenous vitamin $\mathrm{D}_{3}$ metabolites during normal development and in response to relevant stimuli (light and heat) should be identified and quantified, possibly using liquid chromatography-mass spectroscopy and 2D nuclear magnetic resonance spectroscopy. Using sampling intervals that parallel RNA transcript data already available in $A$. limnaeus would allow for correlation between metabolite, RNA expression levels, and alterations to the epigenetic landscape.

This thesis supports a major role for vitamin $\mathrm{D}_{3}$ synthesis and signaling for the control of developmental dormancy in A. limnaeus. The parallels identified in a variety of animals that use nuclear hormone receptors and 7-DHC-derived ligands to regulate developmental progression suggests that these studies may be broadly important for understanding how complex life histories are regulated in animals. While there are still many pieces to decipher regarding the specifics of how vitamin $\mathrm{D}_{3}$ signaling and supporting pathways impact embryonic development, the data in this thesis present compelling evidence that vitamin $\mathrm{D}_{3}$ signaling is key to regulating the complex life history of annual killifishes, and provides a mechanism for linking environment cues to developmental outcomes through epigenetic mechanisms. 


\section{References}

Ahn, S.-G., Kim, S.-A., Yoon, J.-H. and Vacratsis, P. (2005). Heat-shock cognate 70 is required for the activation of heat-shock factor 1 in mammalian cells. Biochemical Journal 392, 145-152.

Ali, A., Krone, P. H., Pearson, D. S. and Heikkila, J. J. (1996). Evaluation of stressinducible $h s p 90$ gene expression as a potential molecular biomarker in Xenopus laevis. Cell Stress \& Chaperones 1, 62-69.

Altintas, O., Park, S. and Lee, S.-J. V. (2016). The role of insulin/IGF-1 signaling in the longevity of model invertebrates, C. elegans and D. melanogaster. $B M B$ reports $\mathbf{4 9 , 8 1 .}$

Ameri, P., Giusti, A., Boschetti, M., Murialdo, G., Minuto, F. and Ferone, D. (2013). Interactions between vitamin D and IGF-I: from physiology to clinical practice. Clinical Endocrinology 79, 457-463.

An, B.-S., Tavera-Mendoza, L. E., Dimitrov, V., Wang, X., Calderon, M. R., Wang, H.-J. and White, J. H. (2010). Stimulation of Sirt1-regulated FoxO protein function by the ligand-bound vitamin D receptor. Molecular and Cellular Biology 30, 4890-4900.

Anastasiadi, D., Esteve-Codina, A. and Piferrer, F. (2018). Consistent inverse correlation between DNA methylation of the first intron and gene expression across tissues and species. Epigenetics \& chromatin 11, 37.

Androwski, R. J., Flatt, K. M. and Schroeder, N. E. (2017). Phenotypic plasticity and remodeling in the stress-induced Caenorhabditis elegans dauer. Wiley Interdisciplinary Reviews: Developmental Biology 6, e278.

Angelo, G., Lamon-Fava, S., Sonna, L. A., Lindauer, M. L. and Wood, R. J. (2008). Heat shock protein $90 \beta$ : a novel mediator of vitamin D action. Biochemical and Biophysical Research Communications 367, 578-583.

Angeloni, A. and Bogdanovic, O. (2019). Enhancer DNA methylation: implications for gene regulation. Essays in Biochemistry 63, 707-715.

Antebi, A. (2015). Nuclear receptor signal transduction in C. elegans. WormBook 1, 49.

Antebi, A., Yeh, W.-H., Tait, D., Hedgecock, E. M. and Riddle, D. L. (2000). Daf-12 encodes a nuclear receptor that regulates the dauer diapause and developmental age in C. elegans. Genes and Development 14, 1512-1527.

Aranda, A. and Pascual, A. (2001). Nuclear hormone receptors and gene expression. Physiological Reviews.

Arbeitman, M. N. and Hogness, D. S. (2000). Molecular chaperones activate the Drosophila ecdysone receptor, an RXR heterodimer. Cell 101, 67-77.

Archer, A., Kitambi, S. S., Hallgren, S. L., Pedrelli, M., Olsén, K. H., Mode, A. and Gustafsson, J.-A. (2012). The liver X-receptor (Lxr) governs lipid homeostasis in zebrafish during development.

Autran, D., Baroux, C., Raissig, M. T., Lenormand, T., Wittig, M., Grob, S., Steimer, A., Barann, M., Klostermeier, U. C., Leblanc, O. et al. (2011). Maternal epigenetic pathways control parental contributions to Arabidopsis early embryogenesis. Cell 145, 707-719. 
Badyaev, A. V. (2005). Stress-induced variation in evolution: from behavioural plasticity to genetic assimilation. Proceedings of the Royal Society B: Biological Sciences 272, 877-886.

Becker, B. (2014). Small Molecule Modulators of Dauer Formation and Longevity in Caenorhabditis elegans: Universität zu Köln.

Bikle, D. (2017). Vitamin D: production, metabolism, and mechanisms of action. In Endotext [Internet]: MDText. com, Inc.

Bikle, D. D. (2011). Vitamin D: an ancient hormone. Experimental Dermatology 20, 713.

Bikle, D. D. (2014). Vitamin D metabolism, mechanism of action, and clinical applications. Chemistry \& biology 21, 319-329.

Bizuayehu, T. T., Johansen, S. D., Puvanendran, V., Toften, H. and Babiak, I. (2015). Temperature during early development has long-term effects on microRNA expression in Atlantic cod. BMC Genomics 16.

Bogdanovic, O. and Gómez-Skarmeta, J. L. (2013). Embryonic DNA methylation: insights from the genomics era. Briefings in Functional Genomics.

Boland, R., Skliar, M., Curino, A. and Milanesi, L. (2003). Vitamin D compounds in plants. Plant Science 164, 357-369.

Booth, D. T. (2002). The Breaking of Diapause in Embryonic Broad-Shell River Turtles (Chelodina expansa). Journal of Herpetology 36, 304-307.

Bradford, M. J. and Roff, D. A. (1993). Bet Hedging and the Diapause Strategies of the Cricket Allonemobius Fasciatus. Ecology 74, 1129-1135.

Browse, J. and Xin, Z. (2001). Temperature sensing and cold acclimation. Current Opinion in Plant Biology 4, 241-246.

Bulut-Karslioglu, A., Biechele, S., Jin, H., Macrae, T. A., Hejna, M., Gertsenstein, M., Song, J. S. and Ramalho-Santos, M. (2016). Inhibition of mTOR induces a paused pluripotent state. Nature 540, 119.

Burgess, S. C. and Marshall, D. J. (2011). Temperature-induced maternal effects and environmental predictability. Journal of Experimental Biology 214, 2329-2336.

Campos, C., Valente, L. M. P., Conceição, L. E. C., Engrola, S., Sousa, V., Rocha, E. and Fernandes, J. M. O. (2013). Incubation temperature induces changes in muscle cellularity and gene expression in Senegalese sole (Solea senegalensis). Gene 516, 209-217.

Camps, J., Erdos, M. R. and Ried, T. (2015). The role of lamin B1 for the maintenance of nuclear structure and function. Nucleus 6, 8-14.

Chen, D.-F., Lin, C., Wang, H.-L., Zhang, L., Dai, L., Jia, S.-N., Zhou, R., Li, R., Yang, J.-S. and Yang, F. (2016a). An La-related protein controls cell cycle arrest by nuclear retrograde transport of tRNAs during diapause formation in Artemia. BMC Biology 14, 1-13.

Chen, S., Villalta, S. A. and Agrawal, D. K. (2016b). FOXO1 Mediates Vitamin D Deficiency-Induced Insulin Resistance in Skeletal Muscle. Journal of Bone and Mineral Research 31, 585-595.

Chen, X. S., Zhang, Y. H., Cai, Q. Y. and Yao, Z. X. (2012). ID2: A negative transcription factor regulating oligodendroglia differentiation. Journal of Neuroscience Research 90, 925-932. 
Chennault, T. and Podrabsky, J. E. (2010). Aerobic and anaerobic capacities differ in embryos of the annual killifish Austrofundulus limnaeus that develop on alternate developmental trajectories. Journal of Experimental Zoology Part A: Ecological Genetics and Physiology 313A, 587-596.

Chou, S.-D., Prince, T., Gong, J. and Calderwood, S. K. (2012). mTOR is essential for the proteotoxic stress response, HSF1 activation and heat shock protein synthesis. PLoS ONE 7, e39679.

Connelly, S. J., Walling, K., Wilbert, S. A., Catlin, D. M., Monaghan, C. E., Hlynchuk, S., Meehl, P. G., Resch, L. N., Carrera, J. V. and Bowles, S. M. (2015). UV-stressed Daphnia pulex increase fitness through uptake of Vitamin D3. PLoS ONE 10, e0131847.

Cossins, A., Fraser, J., Hughes, M. and Gracey, A. (2006). Post-genomic approaches to understanding the mechanisms of environmentally induced phenotypic plasticity. Journal of Experimental Biology 209, 2328-2336.

Craig, T. A., Lutz, W. H. and Kumar, R. (1999). Association of prokaryotic and eukaryotic chaperone proteins with the human $1 \alpha, 25$-dihydroxyvitamin D3 receptor. Biochemical and Biophysical Research Communications 260, 446-452.

Craig, T. A., Sommer, S., Sussman, C. R., Grande, J. P. and Kumar, R. (2008). Expression and regulation of the vitamin D receptor in the zebrafish, Danio rerio. Journal of Bone and Mineral Research 23, 1486-1496.

Delaval, K. and Feil, R. (2004). Epigenetic regulation of mammalian genomic imprinting. Current Opinion in Genetics \& Development 14, 188-195.

Denlinger, D. (2013). Hormonal Control of Diapause. Endocrinology II 8, 353.

Donaldson-Matasci, M. C., Bergstrom, C. T. and Lachmann, M. (2013). When unreliable cues are good enough. The American Naturalist 182, 313-327.

Duerr, J. M. and Podrabsky, J. E. (2010). Mitochondrial physiology of diapausing and developing embryos of the annual killifish Austrofundulus limnaeus: implications for extreme anoxia tolerance. Journal of Comparative Physiology B: Biochemical, Systemic, and Environmental Physiology 180, 991-1003.

Dufty, A. M., Clobert, J. and Moller, A. P. (2002). Hormones, developmental plasticity and adaptation. Trends in Ecology \& Evolution 17, 190-196.

Escriva, H., Bertrand, S. and Laudet, V. (2004). The evolution of the nuclear receptor superfamily. Essays in Biochemistry 40, 11-26.

Evans, R. M. and Mangelsdorf, D. J. (2014). Nuclear receptors, RXR, and the big bang. Cell 157, 255-266.

Falchuk, K. H. (1998). The molecular basis for the role of zinc in developmental biology. Molecular and Cellular Biochemistry 188, 41-48.

Fang, X., Corrales, J., Thornton, C., Scheffler, B. E. and Willett, K. L. (2013). Global and gene specific DNA methylation changes during zebrafish development. Comparative Biochemistry and Physiology Part B: Biochemistry and Molecular Biology 166, 99-108.

Fantinou, A. A., Tsitsipis, J. A. and Karandinos, M. G. (1998). Diapause termination in Sesamia nonagrioides (Lepidoptera: Noctuidae) under laboratory and field conditions. Environmental Entomology 27, 53-58. 
Feil, R. and Fraga, M. F. (2012). Epigenetics and the environment: emerging patterns and implications. Nature Reviews Genetics 13, 97-109.

Fetahu, I. S., Höbaus, J. and Kállay, E. (2014). Vitamin D and the epigenome. Frontiers in Physiology 5, 164.

Flatscher, R., Frajman, B., Schönswetter, P. and Paun, O. (2012). Environmental heterogeneity and phenotypic divergence: can heritable epigenetic variation aid speciation? Genetics research international 2012, 1-9.

Flores, K. B., Wolschin, F. and Amdam, G. V. (2013). The role of methylation of DNA in environmental adaptation. Integrative and Comparative Biology 53, 359-72.

Ford, L., Ling, E., Kandel, E. R. and Fioriti, L. (2019). CPEB3 inhibits translation of mRNA targets by localizing them to $\mathrm{P}$ bodies. Proceedings of the National Academy of Sciences 116, 18078-18087.

Fujikawa, S., Kuroda, K. and Ohtani, J. (1997). Seasonal changes in dehydration tolerance of xylem ray parenchyma cells of Stylax obassia twigs that survive freezing temperatures by deep supercooling. Protoplasma 197, 34-44.

Furness, A. I. (2015). The evolution of an annual life cycle in killifish: adaptation to ephemeral aquatic environments through embryonic diapause. Biological Reviews.

Furness, A. I., Lee, K. and Reznick, D. N. (2015a). Adaptation in a variable environment: Phenotypic plasticity and bet-hedging during egg diapause and hatching in an annual killifish. Evolution 69, 1461-1475.

Furness, A. I., Reznick, D. N., Springer, M. S. and Meredith, R. W. (2015b). Convergent evolution of alternative developmental trajectories associated with diapause in African and South American killifish. Proceedings of the Royal Society B: Biological Sciences 282, 20142189.

Gelmedin, V., Brodigan, T., Gao, X., Krause, M., Wang, Z. and Hawdon, J. M. (2011). Transgenic C. elegans dauer larvae expressing hookworm phospho null DAF-16/FoxO exit dauer. PLoS ONE 6, e25996.

Gerisch, B., Rottiers, V., Li, D., Motola, D. L., Cummins, C. L., Lehrach, H., Mangelsdorf, D. J. and Antebi, A. (2007). A bile acid-like steroid modulates Caenorhabditis elegans lifespan through nuclear receptor signaling. Proceedings of the National Academy of Sciences 104, 5014-5019.

Glasauer, S. M. K. and Neuhauss, S. C. F. (2014). Whole-genome duplication in teleost fishes and its evolutionary consequences. Molecular Genetics and Genomics 289, 1045-1060.

Gluckman, P. D., Hanson, M. A., Cooper, C. and Thornburg, K. L. (2008). Effect of in utero and early-life conditions on adult health and disease. New England Journal of Medicine 359, 61-73.

Goltzman, D., Hendy, G. N., Karaplis, A. C., Kremer, R. and Miao, D. (2018). Understanding Vitamin D From Mouse Knockout Models. In Vitamin D, pp. 613631: Elsevier.

González-Duarte, R. J., Cázares-Ordoñez, V., Díaz, L., Ortíz, V., Larrea, F. and Avila, E. (2015). The expression of RNA helicase DDX5 is transcriptionally upregulated by calcitriol through a vitamin D response element in the proximal promoter in SiHa cervical cells. Molecular and Cellular Biochemistry 410, 65-73. 
Han, Y., Chen, A., Umansky, K.-B., Oonk, K. A., Choi, W.-Y., Dickson, A. L., Ou, J., Cigliola, V., Yifa, O. and Cao, J. (2019). Vitamin D stimulates cardiomyocyte proliferation and controls organ size and regeneration in Zebrafish. Developmental Cell 48, 853-863. e5.

Hand, S. C., Denlinger, D. L., Podrabsky, J. E. and Roy, R. (2016). Mechanisms of animal diapause: recent developments from nematodes, crustaceans, insects, and fish. American Journal of Physiology - Regulatory, Integrative and Comparative Physiology 310, R1193-R1211.

Hand, S. C. and Podrabsky, J. E. (2000). Bioenergetics of diapause and quiescence in aquatic animals. Thermochimica Acta 349, 31-42.

Hochachka, P. W., Land, S. C. and Buck, L. T. (1997). Oxygen sensing and signal transduction in metabolic defense against hypoxia: lessons from vertebrate facultative anaerobes. Comparative Biochemistry and Physiology 118A, 23-29.

Hodek, I. (1996). Diapause development, diapause termination and the end of diapause. Eur. J. Entomol. 93, 475-487.

Holick, M. F. (2003). Evolution and function of vitamin D. In Vitamin D Analogs in Cancer Prevention and Therapy, pp. 3-28: Springer.

Hu, C.-K., Wang, W., Brind'Amour, J., Singh, P. P., Reeves, G. A., Lorincz, M. C., Alvarado, A. S. and Brunet, A. (2020). Vertebrate diapause preserves organisms long term through Polycomb complex members. Science 367, 870-874.

Hull, E. (1986). The role of light in controlling the onset and duration of embryonic diapause in Nothobranchius guentheri, pp. 1-152: New York University.

Hulsen, T., de Vlieg, J. and Alkema, W. (2008). BioVenn-a web application for the comparison and visualization of biological lists using area-proportional Venn diagrams. BMC Genomics 9, 1-6.

Ibáñez, C., Kozarewa, I., Johansson, M., Ögren, E., Rohde, A. and Eriksson, M. E. (2010). Circadian clock components regulate entry and affect exit of seasonal dormancy as well as winter hardiness in Populus trees. Plant Physiology 153, 1823-1833.

Jackson, S. M., Ericsson, J. and Edwards, P. A. (1997). Signaling molecules derived from the cholesterol biosynthetic pathway. In Cholesterol, pp. 1-21: Springer.

Johnston, I. A., Lee, H. T., Macqueen, D. J., Paranthaman, K., Kawashima, C., Anwar, A., Kinghorn, J. R. and Dalmay, T. (2009). Embryonic temperature affects muscle fibre recruitment in adult zebrafish: genome-wide changes in gene and microRNA expression associated with the transition from hyperplastic to hypertrophic growth phenotypes. Journal of Experimental Biology 212, 17811793.

Jonsson, B. and Jonsson, N. (2019). Phenotypic plasticity and epigenetics of fish: embryo temperature affects later-developing lift-history traits. Aquatic Biology 28, 21-32.

Kaplan, R. H. (1987). Developmental plasticity and maternal effects of reproductive characteristics in the frog, Bombina orientalis. Oecologia 71, 273-279.

Keller, T. E., Han, P. and Yi, S. V. (2016). Evolutionary transition of promoter and gene body DNA methylation across invertebrate-vertebrate boundary. Molecular Biology and Evolution 33, 1019-1028. 
Kimmel, C. B., Ballard, W. W., Kimmel, S. R., Ullmann, B. and Schilling, T. F. (1995). Stages of embryonic development of the zebrafish. Developmental Dynamics 203, 253-310.

King, A. M. and MacRae, T. H. (2012). The small heat shock protein p26 aids development of encysting Artemia embryos, prevents spontaneous diapause termination and protects against stress. PLOS ONE 7, e43723.

King, A. M. and MacRae, T. H. (2015). Insect Heat Shock Proteins During Stress and Diapause. Annual Review of Entomology 60, 59-75.

Kollitz, E. M., Hawkins, M. B., Whitfield, G. K. and Kullman, S. W. (2014). Functional diversification of vitamin D receptor paralogs in teleost fish after a whole genome duplication event. Endocrinology 155, 4641-4654.

Kollitz, E. M., Zhang, G., Hawkins, M. B., Whitfield, G. K., Reif, D. M. and Kullman, S. W. (2016). Evolutionary and functional diversification of the vitamin D receptor-lithocholic acid partnership. PLOS ONE 11, e0168278.

Krasowski, M. D., Ai, N., Hagey, L. R., Kollitz, E. M., Kullman, S. W., Reschly, E. J. and Ekins, S. (2011a). The evolution of farnesoid X, vitamin D, and pregnane X receptors: insights from the green-spotted pufferfish (Tetraodon nigriviridis) and other non-mammalian species. BMC Biochemistry 12, 5.

Krasowski, M. D., Ni, A., Hagey, L. R. and Ekins, S. (2011b). Evolution of promiscuous nuclear hormone receptors: LXR, FXR, VDR, PXR, and CAR. Molecular and Cellular Endocrinology 334, 39-48.

Krone, P. H., Lele, Z. and Sass, J. B. (1997). Heat shock genes and the heat shock response in zebrafish embryos. Biochemistry and Cell Biology 75, 487-497.

Kumar, M. B., Fujimoto, T., Potter, D. W., Deng, Q. and Palli, S. R. (2002). A single point mutation in ecdysone receptor leads to increased ligand specificity: Implications for gene switch applications. 99, 14710-14715.

Lamming, D. W. and Sabatini, D. M. (2013). A central role for mTOR in lipid homeostasis. Cell Metabolism 18, 465-469.

Larriba, M. J., González-Sancho, J. M., Bonilla, F. and Muñoz, A. (2014). Interaction of vitamin D with membrane-based signaling pathways. Frontiers in Physiology 5, 60 .

Lasorella, A., Noseda, M., Beyna, M. and Iavarone, A. (2000). Id2 is a retinoblastoma protein target and mediates signalling by Myc oncoproteins. Nature 407, 592-598.

Li, L., Stoeckert, C. J. and Roos, D. S. (2003). OrthoMCL: identification of ortholog groups for eukaryotic genomes. Genome Research 13, 2178-2189.

Li, Y. C., Bergwitz, C., Jüppner, H. and Demay, M. B. (1997). Cloning and characterization of the vitamin D receptor from Xenopus laevis. Endocrinology 138, 2347-2353.

Liang, P. and Macrae, T. H. (1999). The synthesis of a small heat shock/a-crystallin protein in Artemia and its relationship to stress tolerance during development. Developmental Biology 207, 445-456.

Lin, C.-H., Su, C.-H., Tseng, D.-Y., Ding, F.-C. and Hwang, P.-P. (2012). Action of vitamin D and the receptor, VDRa, in calcium handling in zebrafish (Danio rerio). PLoS ONE 7, e45650. 
Lock, E.-J., Ørnsrud, R., Aksnes, L., Spanings, F., Waagbø, R. and Flik, G. (2007). The vitamin D receptor and its ligand 1 $\alpha, 25$-dihydroxyvitamin D3 in Atlantic salmon (Salmo salar). Journal of Endocrinology 193, 459-471.

Lock, E. J., Waagbo, R., Wendelaar Bonga, S. and Flik, G. (2010). The significance of vitamin D for fish: a review. Aquaculture nutrition 16, 100-116.

Loomis, S. H., Hand, S. C. and Fell, P. E. (1996). Metabolism of gemmules from the freshwater sponge Eunapius fragilis during diapause and post-diapause states. Biological Bulletin 191, 385-392.

Luciani, G. M., Magomedova, L., Puckrin, R., Urbanus, M. L., Wallace, I. M., Giaever, G., Nislow, C., Cummins, C. L. and Roy, P. J. (2011). Dafadine inhibits DAF-9 to promote dauer formation and longevity of Caenorhabditis elegans. Nature Chemical Biology 7, 891.

Lutz, P. L. and Nilsson, G. E. (2004). Vertebrate brains at the pilot light. Respiratory Physiology and Neurobiology 141, 285-296.

Macrae, T. H. (2005). Diapause: diverse states of developmental and metabolic arrest. Journal of Biological Research 3, 3-14.

Mahanti, P., Bose, N., Bethke, A., Judkins, J. C., Wollam, J., Dumas, K. J., Zimmerman, A. M., Campbell, S. L., Hu, P. J. and Antebi, A. (2014). Comparative metabolomics reveals endogenous ligands of DAF-12, a nuclear hormone receptor, regulating $C$. elegans development and lifespan. Cell Metabolism 19, 73-83.

Marcinkowska, E. and Gocek, E. (2010). Heat shock protein 90 interacts with vitamin $\mathrm{D}$ receptor in human leukemia cells. The Journal of steroid biochemistry and molecular biology 121, 114-116.

Mark, K. A., Dumas, K. J., Bhaumik, D., Schilling, B., Davis, S., Oron, T. R., Sorensen, D. J., Lucanic, M., Brem, R. B. and Melov, S. (2016). Vitamin D promotes protein homeostasis and longevity via the stress response pathway genes skn-1, ire-1, and xbp-1. Cell reports 17, 1227-1237.

Markofsky, J. and Matias, J. R. (1977). Effects of light: dark cycles and temperature on embryonic diapause in the East African annual fish, Nothobranchius guentheri. Chronobiologia 4, 130-131.

Martinez-Lamparero, A., Casero, M. C., Ortiz-Caro, J. and Sastre, L. (1996). Transcriptional regulation during the activation and development of Artemia franciscana encysted embryos. International Journal of Developmental Biology Supplement I, 91S-92S.

Meissner, A., Gnirke, A., Bell, G. W., Ramsahoye, B., Lander, E. S. and Jaenisch, R. (2005). Reduced representation bisulfite sequencing for comparative highresolution DNA methylation analysis. Nucleic Acids Research 33, 10.

Meller, C. L., Meller, R., Simon, R. P., Culpepper, K. M. and Podrabsky, J. E. (2012). Cell cycle arrest associated with anoxia-induced quiescence, anoxic preconditioning, and embryonic diapause in embryos of the annual killifish Austrofundulus limnaeus. Journal of Comparative Physiology B 182, 909-920.

Messing, J. A., Heuberger, R. and Schisa, J. A. (2013). Effect of vitamin D3 on lifespan in Caenorhabditis elegans. Current aging science 6, 220-224. 
Miliku, K., Vinkhuyzen, A., Blanken, L. M., McGrath, J. J., Eyles, D. W., Burne, T. H., Hofman, A., Tiemeier, H., Steegers, E. A. and Gaillard, R. (2016). Maternal vitamin D concentrations during pregnancy, fetal growth patterns, and risks of adverse birth outcomes. The American journal of clinical nutrition $\mathbf{1 0 3 ,}$ 1514-1522.

Milner, N. P., Nali, M., Gibson, J. M. and Rees, H. H. (1986). Early stages of ecdysteroid biosynthesis: The role of 7-dehydrocholesterol. Insect biochemistry 16, 17-23.

Monteiro, A., Tong, X., Bear, A., Liew, S. F., Bhardwaj, S., Wasik, B. R., Dinwiddie, A., Bastianelli, C., Cheong, W. F. and Wenk, M. R. (2015). Differential expression of ecdysone receptor leads to variation in phenotypic plasticity across serial homologs. PLoS Genetics 11, e1005529.

Mooijaart, S., Brandt, B., Baldal, E., Pijpe, J., Kuningas, M., Beekman, M., Zwaan, B., Slagboom, P., Westendorp, R. and Van Heemst, D. (2005). C. elegans DAF-12, nuclear hormone receptors and human longevity and disease at old age. Ageing Research Reviews 4, 351-371.

Morita, S., Horii, T., Kimura, M. and Hatada, I. (2013). MiR-184 regulates insulin secretion through repression of Slc25a22. PeerJ 1, e162.

Motola, D. L., Cummins, C. L., Rottiers, V., Sharma, K. K., Li, T., Li, Y., SuinoPowell, K., Xu, H. E., Auchus, R. J. and Antebi, A. (2006). Identification of ligands for DAF-12 that govern dauer formation and reproduction in C. elegans. Cell 124, 1209-1223.

Muers, M. (2013). Gene expression: Disentangling DNA methylation. Nature Reviews Genetics 14, 519.

Mylenko, M., Boland, S., Penkov, S., Sampaio, J. L., Lombardot, B., Vorkel, D., Verbavatz, J.-M. and Kurzchalia, T. V. (2016). NAD+ is a food component that promotes exit from dauer diapause in Caenorhabditis elegans. PLoS ONE 11, e0167208.

Norman, A. W. (2006). Vitamin D receptor: new assignments for an already busy receptor. Endocrinology 147, 5542-5548.

Pavlopoulos, E., Trifilieff, P., Chevaleyre, V., Fioriti, L., Zairis, S., Pagano, A., Malleret, G. and Kandel, E. R. (2011). Neuralized1 activates CPEB3: a function for nonproteolytic ubiquitin in synaptic plasticity and memory storage. Cell 147, 1369-1383.

Perez, M. F. and Lehner, B. (2019). Intergenerational and transgenerational epigenetic inheritance in animals. Nature Cell Biology, 1.

Pludowski, P., Holick, M. F., Pilz, S., Wagner, C. L., Hollis, B. W., Grant, W. B., Shoenfeld, Y., Lerchbaum, E., Llewellyn, D. J. and Kienreich, K. (2013).

Vitamin D effects on musculoskeletal health, immunity, autoimmunity, cardiovascular disease, cancer, fertility, pregnancy, dementia and mortality - a review of recent evidence. Autoimmunity reviews 12, 976-989.

Podrabsky, J., Riggs, C., Romney, A., Woll, S., Wagner, J., Culpepper, K. and Cleaver, T. (2017). Embryonic development of the annual killifish Austrofundulus limnaeus: An emerging model for ecological and evolutionary 
developmental biology research and instruction. Developmental Dynamics 246, 779-801.

Podrabsky, J., Riggs, C. and Wagner, J. (2016a). Tolerance of Environmental Stress. In Annual Fishes. Life History Strategy, Diversity, and Evolution, eds. N. Berois G. García and R. De Sá), pp. 159-184. Boca Raton, FL USA: CRC Press, Taylor \& Francis.

Podrabsky, J., Romney, A. and Culpepper, K. (2016b). Alternative Developmental Pathways. In Annual Fishes. Life History Strategy, Diversity, and Evolution, eds. N. Berois G. García and R. De Sá), pp. 63-73. Boca Raton, FL USA: CRC Press, Taylor \& Francis.

Podrabsky, J. E. (1999). Husbandry of the annual killifish Austrofundulus limnaeus with special emphasis on the collection and rearing of embryos. Environmental Biology of Fishes 54, 421-431.

Podrabsky, J. E., Garrett, I. D. F. and Kohl, Z. F. (2010). Alternative developmental pathways associated with diapause regulated by temperature and maternal influences in embryos of the annual killifish Austrofundulus limnaeus. Journal of Experimental Biology 213, 3280-3288.

Podrabsky, J. E. and Hand, S. C. (1999). The bioenergetics of embryonic diapause in an annual killifish, Austrofundulus limnaeus. Journal of Experimental Biology 202, 2567-2580.

Podrabsky, J. E. and Hand, S. C. (2015). Physiological strategies during animal diapause: Lessons from brine shrimp and annual killifish. Journal of Experimental Biology 218, 1897-1906.

Podrabsky, J. E., Hrbek, T. and Hand, S. C. (1998). Physical and chemical characteristics of ephemeral pond habitats in the Maracaibo basin and Llanos region of Venezuela. Hydrobiologia 362, 67-78.

Podrabsky, J. E., Lopez, J. P., Fan, T. W. M., Higashi, R. and Somero, G. N. (2007). Extreme anoxia tolerance in embryos of the annual killifish Austrofundulus limnaeus: Insights from a metabolomics analysis. Journal of Experimental Biology 210, 2253-2266.

Podrabsky, J. E. and Somero, G. N. (2007). An inducible 70 kDa-class heat shock protein is constitutively expressed during early development and diapause in the annual killifish Austrofundulus limnaeus. Cell Stress \& Chaperones 12, 199-204.

Polejaeva, I. A., Reed, W. A., Bunch, T. D., Ellis, L. C. and White, K. L. (1997). Prolactin-induced termination of obligate diapause of mink (Mustela vison) blastocysts in vitro and subsequent establishment of embryonic stem-like cells. J.Reprod.Fert. 109, 229-236.

Pols, H., Birkenhäger, J., Foekens, J. and Van Leeuwen, J. (1990). Vitamin D: a modulator of cell proliferation and differentiation. Journal of Steroid Biochemistry and Molecular Biology 37, 873-876.

Potok, M. E., Nix, D. A., Parnell, T. J. and Cairns, B. R. (2013). Reprogramming the maternal zebrafish genome after fertilization to match the paternal methylation pattern. Cell 153, 759-772.

Potter, S., Sifers, J., Yocom, E., Blümich, S. L., Potter, R., Nadolski, J., Harrison, D. A. and Cooper, R. L. (2019). Effects of inhibiting mTOR with rapamycin on 
behavior, development, neuromuscular physiology and cardiac function in larval Drosophila. Biology Open $\mathbf{8}$.

Prasad, A. S. (2013). Zinc in growth and development and spectrum of human zinc deficiency. Journal of the American College of Nutrition 7, 8.

Pri-Tal, B. M., Blue, S., Pau, F. K. Y. and Podrabsky, J. E. (2011). Hormonal components of altered developmental pathways in the annual killifish, Austrofundulus limnaeus. General and Comparative Endocrinology 174, 166-174.

Qiu, Z., Tsoi, S. C. M. and MacRae, T. H. (2007). Gene expression in diapausedestined embryos of the crustacean, Artemia franciscana. Mechanisms of Development 124, 856-867.

Renfree, M. B. and Fenelon, J. C. (2017). The enigma of embryonic diapause. Development 144, 3199-3210.

Reschly, E. J., Bainy, A. C. D., Mattos, J. J., Hagey, L. R., Bahary, N., Mada, S. R., Ou, J., Venkataramanan, R. and Krasowski, M. D. (2007). Functional evolution of the vitamin D and pregnane X receptors. BMC Evolutionary Biology 7, 222.

Rinehart, J. P., Cikra-Ireland, R. A., Flannagan, R. D. and Denlinger, D. L. (2001). Expression of ecdysone receptor is unaffected by pupal diapause in the flesh fly, Sarcophaga crassipalpis, while its dimerization partner, USP, is downregulated. Journal of Insect Physiology 47, 915-921.

Rinehart, J. P. and Denlinger, D. L. (2000). Heat-shock protein 90 is down-regulated during pupal diapause in the flesh fly, Sarcophaga crassipalpis, but remains responsive to thermal stress. Insect molecular biology 9, 641-645.

Rinehart, J. P., Yocum, G. D. and Denlinger, D. L. (2000). Developmental upregulation of inducible hsp70 transcripts, but not the cognate form, during pupal diapause in the flesh fly, Sarcophaga crassipalpis. Insect Biochemistry and Molecular Biology 30, 515-521.

Robbins, H. M., Van Stappen, G., Sorgeloos, P., Sung, Y. Y., MacRae, T. H. and Bossier, P. (2010). Diapause termination and development of encysted Artemia embryos: roles for nitric oxide and hydrogen peroxide. Journal of Experimental Biology 213, 1464-1470.

Romney, A., Davis, E., Corona, M., Wagner, J. and Podrabsky, J. (2018). Temperature dependent vitamin D signaling regulates developmental trajectory associated with diapause in an annual killifish. Proceedings of the National Academy of Sciences of the United States of America 115, 12763-12768.

Romney, A. and Podrabsky, J. (2017). Transcriptomic analysis of maternally provisioned cues for phenotypic plasticity in the annual killifish, Austrofundulus limnaeus. EvoDevo 8, 6.

Romney, A. and Podrabsky, J. (2018). Small noncoding RNA profiles along alternative developmental trajectories in an annual killifish. Scientific Reports 8, 13364.

Saccone, D., Asani, F. and Bornman, L. (2015). Regulation of the vitamin D receptor gene by environment, genetics and epigenetics. Gene 561, 171-180.

Salehi-Tabar, R., Nguyen-Yamamoto, L., Tavera-Mendoza, L. E., Quail, T., Dimitrov, V., An, B.-S., Glass, L., Goltzman, D. and White, J. H. (2012). Vitamin D receptor as a master regulator of the c-MYC/MXD1 network. 
Proceedings of the National Academy of Sciences of the United States of America, 201210037.

Saxton, R. A. and Sabatini, D. M. (2017). mTOR signaling in growth, metabolism, and disease. Cell 168, 960-976.

Schmitz, R. J., Lewis, Z. A. and Goll, M. G. (2019). DNA methylation: shared and divergent features across eukaryotes. Trends in Genetics 35, 818-827.

Schuster, I. (2011). Cytochromes P450 are essential players in the vitamin D signaling system. Biochimica et Biophysica Acta (BBA)-Proteins and Proteomics 1814, 186-199.

Shayevitch, R., Askayo, D., Keydar, I. and Ast, G. (2018). The importance of DNA methylation of exons on alternative splicing. RNA 24, 1351-1362.

Sim, C. and Denlinger, D. (2013). Insulin signaling and the regulation of insect diapause. Frontiers in Physiology 4, 1-10.

Slominski, A. T., Kim, T.-K., Hobrath, J. V., Oak, A. S., Tang, E. K., Tieu, E. W., Li, W., Tuckey, R. C. and Jetten, A. M. (2017). Endogenously produced nonclassical vitamin D hydroxy-metabolites act as "biased" agonists on VDR and inverse agonists on ROR $\alpha$ and ROR $\gamma$. Journal of Steroid Biochemistry and Molecular Biology 173, 42-56.

Snell-Rood, E. C. and Moczek, A. P. (2012). Insulin signaling as a mechanism underlying developmental plasticity: the role of FOXO in a nutritional polyphenism. PLoS ONE 7, e34857.

Sonino, N. (1987). The use of ketoconazole as an inhibitor of steroid production. New England Journal of Medicine 317, 812-818.

Sprague, J., Bayraktaroglu, L., Clements, D., Conlin, T., Fashena, D., Frazer, K., Haendel, M., Howe, D., Mani, P., Ramachandran, S. et al. (2006). The Zebrafish Information Network: the zebrafish model organism database. Nucleic Acids Research 34, D581-D585.

Sunde, M., Turk, C. and DeLuca, H. (1978). The essentiality of vitamin D metabolites for embryonic chick development. Science 200, 1067-1069.

Swamy, N., Mohr, S. C., Xu, W. and Ray, R. (1999). Vitamin D receptor interacts with DnaK/heat shock protein 70: identification of DnaK interaction site on vitamin D receptor. Archives of Biochemistry and Biophysics 363, 219-226.

Taylor, F. and Spalding, J. B. (1988). Fitness functions for alternative developmental pathways in the timing of diapause induction. The American Naturalist 131, 678699.

Teixeira, L. A. F. and Polavarapu, S. (2005). Expression of Heat Shock Protein 70 After Heat Stress During Pupal Diapause in Rhagoletis mendax (Diptera: Tephritidae). Annals of the Entomological Society of America 98, 966-972.

Thomson, S. A., Baldwin, W. S., Wang, Y. H., Kwon, G. and LeBlanc, G. A. (2009). Annotation, phylogenetics, and expression of the nuclear receptors in Daphnia pulex. BMC Genomics 10, 500.

Thoreen, C. C., Kang, S. A., Chang, J. W., Liu, Q., Zhang, J., Gao, Y., Reichling, L. J., Sim, T., Sabatini, D. M. and Gray, N. S. (2020). Correction: An ATPcompetitive mammalian target of rapamycin inhibitor reveals rapamycin-resistant functions of mTORC1. Journal of Biological Chemistry 295, 2886-2886. 
Tissenbaum, H. A., Hawdon, J., Perregaux, M., Hotez, P., Guarente, L. and Ruvkun, G. (2000). A common muscarinic pathway for diapause recovery in the distantly related nematode species Caenorhabditis elegans and Ancylostoma caninum. Proceedings of the National Academy of Sciences of the United States of America 97, 460-465.

Toni, L. S. and Padilla, P. A. (2016). Developmentally arrested Austrofundulus limnaeus embryos have changes in post-translational modifications of histone $\mathrm{H} 3$. Journal of Experimental Biology 219, 544-552.

Valdivielso, J. M. (2009). The physiology of vitamin D receptor activation. In Peritoneal Dialysis-From Basic Concepts to Clinical Excellence, vol. 163, pp. 206-212: Karger Publishers.

Vallee, B. and Falchuk, K. (1981). Zinc and gene expression. Philosophical Transactions of the Royal Society of London. B, Biological Sciences 294, 185197.

Van Der Linden, A., Blust, R., Van Laere, A. J. and Decleir, W. (1988). Lightinduced release of Artemia dried embryos from diapause: analysis of metabolic status. Journal of Experimental Zoology 247, 131-138.

Varriale, A. (2014). DNA Methylation, Epigenetics, and Evolution in Vertebrates: Facts and Challenges. International Journal of Evolutionary Biology 2014.

Vu, M. T., Zhai, P., Lee, J., Guerra, C., Liu, S., Gustin, M. C. and Silberg, J. J. (2012). The DNLZ/HEP zinc-binding subdomain is critical for regulation of the mitochondrial chaperone HSPA9. Protein Science 21, 258-267.

Walters, J. R. F. (2000). Bile acids are physiological ligands for a nuclear receptor. Gut 46, 308-309.

Warkentin, K. M. (1995). Adaptive plasticity in hatching age: a response to predation risk trade-offs. Proceedings of the National Academy of Sciences of the United States of America 92, 3507-3510.

Westerfield, M. (1995). The zebrafish book: a guide for the laboratory use of zebrafish (Brachydanio rerio): M. Westerfield (Eugene, OR).

Woll, S. and Podrabsky, J. (2017). Insulin-like growth factor signaling regulates developmental trajectory associated with diapause in embryos of the annual killifish Austrofundulus limnaeus. Journal of Experimental Biology 220, 27772786.

Wourms, J. P. (1972a). The developmental biology of annual fishes I. Stages in the normal development of Austrofundulus myersi Dahl. Journal of Experimental Zoology 182, 143-168.

Wourms, J. P. (1972b). The developmental biology of annual fishes II. Naturally occurring dispersion and reaggregation of blastomeres during the development of annual fish eggs. Journal of Experimental Zoology 182, 169-200.

Wourms, J. P. (1972c). The developmental biology of annual fishes III. Pre-embryonic and embryonic diapause of variable duration in the eggs of annual fishes. Journal of Experimental Zoology 182, 389-414.

Yaginuma, T. and Yamashita, O. (1986). Malate-aspartate cycle as an effective hydrogen shuttle at the termination of diapause in the eggs of Bombyx mori. Insect Biochem. 16, 677-685. 
Yocum, G., Joplin, K. and Denlinger, D. (1998). Upregulation of a $23 \mathrm{kDa}$ small heat shock protein transcript during pupal diapause in the flesh fly, Sarcophaga crassipalpis. Insect Biochemistry and Molecular Biology 28, 677-682.

Yoshizawa, T., Handa, Y., Uematsu, Y., Takeda, S., Sekine, K., Yoshihara, Y., Kawakami, T., Arioka, K., Sato, H. and Uchiyama, Y. (1997). Mice lacking the vitamin D receptor exhibit impaired bone formation, uterine hypoplasia and growth retardation after weaning. Nature Genetics 16, 391-396.

Zhang, X. and Ho, S. M. (2011). Epigenetics meets endocrinology. Journal of Molecular Endocrinology 46, R11-R32.

Zhang, Y., Shen, W., Cao, M., Li, J., Zheng, B., Lou, Z., Qian, B. and Xue, L. (2019). Dynamic alterations in methylation of global DNA and growth-related genes in large yellow croaker (Larimichthys crocea) in response to starvation stress. Comparative Biochemistry and Physiology Part B: Biochemistry and Molecular Biology 227, 98-105.

Zhou, F. C., Resendiz, M. and Lo, C.-L. (2017). Chapter 31 - Environmental Influence of Epigenetics. In Handbook of Epigenetics (Second Edition), (ed. T. O. Tollefsbol), pp. 477-494: Academic Press. 